City University of New York (CUNY)

CUNY Academic Works

Student Theses

Queens College

Summer 9-1-2020

\title{
Top-Down Control on Eruptive Style at Masaya Volcano Inferred from Melt Composition
}

Lisa Hlinka

CUNY Queens College

\section{How does access to this work benefit you? Let us know!}

More information about this work at: https://academicworks.cuny.edu/qc_etds/3

Discover additional works at: https://academicworks.cuny.edu

This work is made publicly available by the City University of New York (CUNY).

Contact: AcademicWorks@cuny.edu 


\title{
Top-Down Control on Eruptive Style at Masaya Volcano Inferred from Melt Composition
}

\author{
Lisa Hlinka ${ }^{1}$
}

Submitted in partial fulfillment of the requirements for the degree of Master of Arts in Geological and Environmental Sciences in the Graduate Division of Queens College, the City University of New York

\section{August 2020}

\section{$\underline{\text { Reviewing Committee: }}$}

Dr. Marc-Antoine Longpré ${ }^{1}$

Dr. Allan Ludman ${ }^{1}$

Dr. Benjamin Black ${ }^{2}$

${ }^{1}$ School of Earth and Environmental Sciences, Queens College, City University of New York, Queens, NY 11367, USA

${ }^{2}$ School of Earth and Atmospheric Sciences, The City College of New York, City University of New York, New York, NY 10031, USA 


\section{TABLE OF CONTENTS}

\section{Preface}

Abstract

List of Figures

List of Supplementary Figures

List of Supplementary Tables

1. Introduction

2. Methodology

2.1. Sampling strategy and processing

2.2. Secondary ion mass spectrometry (SIMS)

2.3. Electron probe micro-analysis (EPMA)

2.4. Laser ablation inductively coupled plasma mass spectrometry (LA-ICP-MS)

2.5. Assessment of post-entrapment modification of melt inclusions

3. Results and Discussion

3.1. Major elements

3.2. Trace elements

3.3. Volatile content systematics

3.4. Evidence for pre-eruptive degassing at low pressure

3.5. Syn-eruptive degassing and comparison with gas data

3.6. Estimates of undegassed $\mathrm{H}_{2} \mathrm{O}$ contents

3.7. Temperature and viscosity estimates

3.8. A thin line between open-conduit and Plinian eruptions at Masaya?

4. Conclusions

5. Acknowledgements

6. References

\section{Appendix}

A1. Supplementary Materials

S1.1. Sample description \& preparation

S1.2. Secondary ion mass spectrometry (SIMS)

S1.3. Electron probe micro-analysis (EPMA)

S1.4. Laser ablation inductively coupled plasma mass spectrometry (LA-ICP-MS)

S1.5. Correction Methods

S1.6. Degassing Simulations

A2. Supplementary Figures

A3. Supplementary Tables 


\section{Preface}

This thesis titled, "Top-Down Control on Eruptive Style at Masaya Volcano Inferred from Melt Composition" is submitted in partial fulfillment of the requirements for the degree of Master of Arts in Geological and Environmental Sciences in the Graduate Division of the School of Earth and Environmental Sciences at Queens College, the City University of New York. The work henceforth is presented in the format of a journal article written for a peer-reviewed publication. Specifically, it follows the writing style and formatting of Earth and Planetary Science Letters (EPSL). Thus, some information relevant towards this thesis is provided in the Appendix sections: A1. Supplementary Materials, A2. Supplementary Figures, and A3. Supplementary Tables. 


\begin{abstract}
Highly explosive, Plinian-type eruptions of basaltic magma are enigmatic because basaltic melts have lower viscosities than more silicic melts which have traditionally been considered essential for such explosive eruption style. Masaya volcano, Nicaragua, is one of the few basaltic volcanoes to have generated a wide range of eruptive styles, from effusive lava lake activity to voluminous Plinian fall deposits. This volcano thus offers a unique case study to better constrain ideas on basaltic eruption style controls.

We analyze olivine-, plagioclase- and clinopyroxene-hosted melt inclusions as well as matrix glasses from lava lake (LL) ejecta and two Plinian tephra deposits - the 2.1 ka Masaya Triple Layer (MTL) and the 1.9 ka Ticuantepe Lapilli (TIL) - for volatiles $\left(\mathrm{CO}_{2}, \mathrm{H}_{2} \mathrm{O}, \mathrm{S}, \mathrm{Cl}, \mathrm{F}\right)$, major, and trace elements, to test whether pre-eruptive volatile contents and degassing history may be linked to eruptive style. All samples display a relatively narrow and largely overlapping basaltic-basaltic andesitic compositional range (50-54 wt.\% $\mathrm{SiO}_{2}, 3-6$ wt.\% $\mathrm{MgO}$ ). However, lava lake and Plinian samples show systematic differences in pre-eruptive volatile contents, forming distinct groups with mean $\mathrm{H}_{2} \mathrm{O}$ contents of $0.6 \mathrm{wt} . \%$ in LL, $1.1 \mathrm{wt} . \%$ in MTL, and 1.9 wt. $\%$ in TIL. Together, these groups generate broad positive correlations between $\mathrm{S}, \mathrm{Cl}$ and $\mathrm{H}_{2} \mathrm{O}$ concentrations, with maximum values reaching 920 ppm, $1300 \mathrm{ppm}$ and $2.3 \mathrm{wt} . \%$, respectively, which are low compared to typical Central American arc magmas. Overall, calculated $\mathrm{P}_{\text {sat }}$ are low, mainly $<100 \mathrm{MPa}$, and temperature estimates, $1020-1170^{\circ} \mathrm{C}$, suggest melt viscosities of $10^{2}-10^{3} \mathrm{~Pa} \cdot \mathrm{s}$. These observations, coupled with evidence for $\mathrm{Cl}$ exsolution during secondboiling, demonstrate that regardless of eruption style, all Masaya magmas undergo variable, but extensive, pre-eruptive degassing in a shallow $(<4 \mathrm{~km})$ reservoir.

Pre-eruptive volatile contents are not the culprit for explosivity at Masaya. Our results instead suggest a top-down control on eruptive style, whereby temporary sealing of the conduit may instigate a transition to explosive behavior. When the seal eventually breaks from degassing-induced pressurization, rapid magma ascent could yield high degrees of undercooling, triggering rapid microlite growth, increasing viscosity and explosive potential. There may thus be a thin line between open-conduit conditions and Plinian eruptions at Masaya.
\end{abstract}




\section{List of Figures}

Fig. 1. Locality map of Masaya Caldera, Nicaragua and sampling locations.

Fig 2. Photomicrographs of representative Masaya melt inclusions. (a) bubble-free melt inclusion from a lava lake sample, (b) bubble-bearing melt inclusion from a Plinian sample.

Fig. 3. Fe, $\mathrm{Mg}$, and $\mathrm{Al}$ element intensity maps of olivine- and plagioclase-hosted melt inclusions to assess post-entrapment modification.

Fig. 4. Major element compositions for melt inclusions and matrix glasses. (a) TAS diagram, (b) $\mathrm{SiO}_{2}$ vs. $\mathrm{MgO}$, (c) $\mathrm{Al}_{2} \mathrm{O}_{3}$ vs. $\mathrm{MgO}$, (d) $\mathrm{FeO}^{*}$ vs. $\mathrm{MgO}$, (e) $\mathrm{CaO}$ vs. $\mathrm{MgO}$, (f) $\mathrm{K}_{2} \mathrm{O}$ vs. $\mathrm{MgO}$, (g) $\mathrm{Zr}$ vs $\mathrm{MgO}$.

Fig. 5. $\mathrm{Zr}$ as an index of magma differentiation. (a) $\mathrm{Y}$ vs. $\mathrm{Zr}$, (b) $\mathrm{Ce} / \mathrm{Y}$ vs. $\mathrm{Zr}$, (c) $\mathrm{Ba} / \mathrm{La}$ vs. $\mathrm{Zr}$.

Fig. 6. Chondrite-normalized rare earth element diagram for average melt inclusions and matrix glasses by eruption.

Fig. 7. Volatile content systematics for melt inclusions and matrix glasses. (a) $\mathrm{CO}_{2}$ vs. $\mathrm{H}_{2} \mathrm{O}$, (b) S vs. $\mathrm{H}_{2} \mathrm{O}$, (c) F vs. $\mathrm{H}_{2} \mathrm{O}$, (d) $\mathrm{Cl}$ vs. $\mathrm{H}_{2} \mathrm{O}$.

Fig. 8. Evidence for pre-eruptive degassing: Masaya melt inclusions compared to Central American data. (a) $\mathrm{H}_{2} \mathrm{O} / \mathrm{Ce}$ vs. $\mathrm{Zr}$, (b) $\mathrm{H}_{2} \mathrm{O} / \mathrm{Ce}$ vs. $\mathrm{Ba} / \mathrm{La}$, (c) $\mathrm{S} / \mathrm{Dy}$ vs. $\mathrm{Zr}$, (d) $\mathrm{F} / \mathrm{Nd}$ vs. $\mathrm{Zr}$, (e) $\mathrm{Cl} / \mathrm{K}$ vs $\mathrm{Zr}$.

Fig. 9. (a) Histogram of derived melt inclusion depths, (b) published depth estimates of Masaya reservoir, (c-e) volatile saturation pressure (MPa) vs. volatile concentration from melt inclusions and glasses.

Fig. 10. Molar volatile ratios in Masaya gases compared to melts. (a) $\mathrm{CO}_{2} / \mathrm{SO}_{2}$ or $\mathrm{CO}_{2} / \mathrm{S}$, (b) $\mathrm{H}_{2} \mathrm{O} / \mathrm{SO}_{2}$ or $\mathrm{H}_{2} \mathrm{O} / \mathrm{S}$, (c) $\mathrm{SO}_{2} / \mathrm{HCl}$ or $\mathrm{S} / \mathrm{Cl}$, (d) $\mathrm{HCl} / \mathrm{HF}$ or $\mathrm{Cl} / \mathrm{F}$, respectively.

Fig. 11. Pre-eruptive magma temperature estimates for lava lake and Plinian samples acquired using a series of mineral-melt geothermometers (Putirka, 2008; Waters \& Lange, 2015)

Fig. 12. BSE images of matrix glass chips from lava lake and Plinian samples, illustrating microlite crystal fraction of approximately $5 \mathrm{vol} \%$ for LL, $15 \mathrm{vol} \%$ for MTL, and $48 \mathrm{vol} \%$ for TIL.

Fig. 13. Schematic diagram of potential storage and ascent conditions within Masaya. 


\section{List of Supplementary Figures}

Fig. S1. SIMS analysis standard calibration curves for volatiles.

Fig. S2. SIMS in-run analyses of glass standard and background.

Fig. S3. Normalized major element composition, not yet corrected for PEC, of melt inclusions and matrix glasses compared to previously published data. (a) TAS diagram, (b) $\mathrm{SiO}_{2} \mathrm{vs}$. $\mathrm{MgO}$, (c) $\mathrm{Al}_{2} \mathrm{O}_{3}$ vs. $\mathrm{MgO}$, (d) $\mathrm{FeO}^{*}$ vs. $\mathrm{MgO}$, (e) $\mathrm{CaO}$ vs. $\mathrm{MgO}$, (f) $\mathrm{K}_{2} \mathrm{O}$ vs. $\mathrm{MgO}$, (g) $\mathrm{Zr}$ vs. $\mathrm{MgO}$.

Fig. S4. Normalized major element composition, not yet corrected for PEC, of melt inclusions and matrix glasses compared to previously published data. (a) $\mathrm{FeO}$ vs. $\mathrm{SiO}_{2}$, (b) $\mathrm{MgO}$ vs $\mathrm{SiO}_{2}$, (c) $\mathrm{Al}_{2} \mathrm{O}_{3}$ vs. $\mathrm{SiO}_{2}$.

Fig. S5. Rhodes diagram test for mineral-melt equilibrium in olivine-hosted melt inclusions. (ab) melt Mg\# uncorrected for PEC, (c) melt Mg\# is corrected for PEC.

Fig. S6. (a) $\mathrm{H}_{2} \mathrm{O}$ vs. $\mathrm{K}_{2} \mathrm{O}$ variation in melt inclusions. (b) $\mathrm{H}_{2} \mathrm{O}$ vs. melt inclusion size. (c) $\mathrm{H}_{2} \mathrm{O}$ vs Fo\% in olivine-hosted melt inclusions. (d) $\mathrm{H}_{2} \mathrm{O}$ vs $\mathrm{An} \%$ in plagioclase-hosted melt inclusions.

Fig. S7. S/Cl degassing trends calculated with SolEx (Witham et al., 2011). 


\section{List of Supplementary Tables}

Table S1. Major- and minor-element composition of melt inclusions and glasses obtained by EPMA.

Table S2. Volatile contents of melt inclusions and glasses obtained by SIMS.

Table S3. Trace-element composition of melt inclusions and glasses obtained by LA-ICP-MS.

Table S4. Major- and minor-element composition of Masaya host minerals obtained by EPMA.

Table S5. Data on in-run standards for SIMS analysis used in this study.

Table S6. Data on in-run standards for EPMA analysis used in this study. 


\section{Introduction}

In rare cases, basaltic magmas have generated highly explosive, Plinian-type eruptions. High magma viscosity linked to high silica content has traditionally been considered essential for explosive eruption style; however, the existence of basaltic tephra deposits of Plinian character calls this assumption into question (e.g., Williams, 1983). Other factors have been linked to eruptive style and intensity including: (1) magma composition, particularly high initial volatile contents which promote rapid ascent and explosivity (e.g., Roggensack et al., 1997; Sides et al., 2014); (2) magma ascent rate-rapid ascent-driven decompression causes volatiles (especially $\mathrm{CO}_{2}$ and $\mathrm{H}_{2} \mathrm{O}$ ) to exsolve from the melt and form bubbles, providing a driving force for eruption (e.g., Lloyd at al., 2014; Barth et al., 2019); (3) Shallow gas flux moderated by convective overturning may allow a system to maintain a steady-state without eruption (e.g., Stix, 2007); alternately, massive quantities of gas loss during quiescent degassing may depressurize shallow storage, triggering magma ascent from depth (e.g., Girona et al., 2015); and (4) Microlite growth - rapid crystallization during ascent can increase effective melt viscosity, affecting the rheology, permeability, and efficiency of outgassing, therefore, increasing explosive potential (e.g., Houghton \& Gonnermann, 2008; Arzilli et al., 2019).

Masaya volcano, Nicaragua, is a basaltic arc volcano that has displayed a unique combination of compositional homogeneity over $>30 \mathrm{ka}$, coupled with a wide range of eruptive styles from effusive lava lake activity to voluminous Plinian fall deposits, surge-deposits, and ignimbrites (Williams, 1983; Walker et al., 1993; Pérez et al., 2008; Zurek et al., 2019; Pérez et al., 2020). Thus, it represents an ideal natural laboratory to test ideas on eruptive style controls.

Masaya volcano has a broad, $6 \times 11 \mathrm{~km}$, vent-filled caldera that formed through multiple Plinian basaltic eruptions during the last 2-30 ka, located just $25 \mathrm{~km}$ southeast of Managua, the capital city (Fig. 1; Pérez et al., 2008; Pérez et al., 2020). Masaya volcano is inferred to be underlain by a shallow, enormous $>10 \mathrm{~km}^{3}$ open-system basaltic magma reservoir (Martin et al. 2010; Walker et al., 1993, Williams-Jones et al., 2003). Masaya's historic behavior is characterized by a persistently active open-conduit system that has been quiescently degassing for over 150 years, with little or no erupted material, and is known for hosting a dynamic lava lake that reemerged in December 2015 (Aiuppa et al., 2018; Martin et al., 2010; Walker et al., 1993). During the last $6 \mathrm{ka}$, however, Masaya has generated three highly explosive basaltic eruptions producing widespread pyroclastic deposits - the $\sim 6$ ka San Antonio Tephra, the $\sim 2.1$ ka Masaya Triple Layer, and the $\sim 1.9$ ka Masaya Tuff with associated Ticuantepe Lapilli Plinian fall deposit (Pérez \& Freundt, 2006; Pérez et al., 2009; Pérez et al., 2020).

The nature of Masaya's magmatic system is striking, remaining compositionally homogeneous, yet transitioning between effusive and explosive behavior. Persistent degassing without eruption at open-conduit basaltic systems such as Masaya, has been credited to vigorous convection and periodic influx of more primitive undegassed magma, producing steady-state conditions (de Moor et al., 2013; Palma et al., 2011; Shinohara, 2008; Stix, 2007). Masaya's magmatic flux is estimated to be $\sim 0.19 \mathrm{~km}^{3} \mathrm{yr}^{-1}$, suggesting that up to $47 \mathrm{~km}^{3}$ of magma may have degassed since the last effusive eruption in 1772, almost 250 years ago (Zurek et al., 2019). To explain Masaya's enigmatic Plinian events, experimental studies suggest rapid syn-eruptive microlite crystallization due to large degrees of undercooling could induce rheological changes and basaltic magma fragmentation (Bamber et al., 2020; Arzilli et al., 2019).

In this paper, major, trace, and volatile $\left(\mathrm{CO}_{2}, \mathrm{H}_{2} \mathrm{O}, \mathrm{S}, \mathrm{Cl}, \mathrm{F}\right)$ element data are reported for matrix glasses and melt inclusions hosted in olivine, plagioclase, and clinopyroxene crystals 
from lava lake (LL) ejecta and two Plinian deposits - the 2.1 ka Masaya Triple Layer (MTL) and the $1.9 \mathrm{ka}$ Ticuantepe Lapilli (TIL) — to test whether pre-eruptive volatile contents and degassing history may be linked to eruptive style at Masaya. Melt inclusions - parcels of melt trapped during crystal growth - offer the only direct method of evaluating a magma's pre-eruptive volatile content, which would otherwise be lost to degassing during ascent-driven decompression. Assuming that any post-entrapment modification of the melt inclusions compositions can be assessed, inclusions can provide unique insight into degassing history and magma storage conditions (Métrich \& Wallace, 2008). While we find clear differences in the volatile content systematics of lava lake and Plinian samples, pre-eruptive concentrations were generally low overall, indicating that all Masaya magmas undergo extensive degassing at shallow depths $(<4 \mathrm{~km})$ before final ascent and eruption. Our results indicate that magma composition and anomalously high initial volatile content can be eliminated as the primary control for eruptive style at Masaya. Instead, we propose that eruptive style is modulated in a top-down fashion, whereby temporary sealing of the system may be sufficient to transition to explosive behavior.

\section{Methodology}

\subsection{Sampling strategy and processing}

With assistance from the Instituto Nicaragüense de Estudios Territoriales (INETER), lava lake ejecta samples, representing open-conduit conditions and consisting of wind-blown Pele's hairs and scoria lapilli, were collected in 2016, 2017, and 2018 along the rim of the active Santiago crater. As representative products of Masaya's Plinian eruptions, we selected samples of the MTL and TIL lapilli fall deposits collected by Pérez et al. $(2006,2009)$ that bear sufficient amounts of phenocrysts larger than $250 \mu \mathrm{m}$. MTL lapilli contain $<5 \mathrm{vol} \%$ of olivine, plagioclase, and clinopyroxene phenocrysts in a vesicular sidermelane groundmass, TIL lapilli contain $\sim 5 \%$ phenocrysts in a vesicular microlite-rich tachylitic groundmass (Pérez \& Freundt, 2006). Sample locality and corresponding eruptive units are given in Fig. 1.

Phenocrysts of olivine, plagioclase, and clinopyroxene were handpicked or extracted through heavy liquid separation from crushed and sieved lapilli for each eruption. After cleaning in a sonic bath, the phenocrysts were mounted in epoxy and polished. Plagioclase is the most abundant phenocryst phase, followed by olivine, then clinopyroxene (cf. Walker et al., 1993). We targeted glassy, rounded to elliptical plagioclase- and olivine-hosted melt inclusions generally 25-150 $\mu \mathrm{m}$ in diameter, lacking evidence of leakage (Fig. 2). All selected melt inclusions are randomly distributed within the host crystals. When possible, we favored bubblefree inclusions to avoid the possible effect of $\mathrm{CO}_{2}$ loss to the vapor (e.g., Moore et al., 2015). While all LL and $36 \%$ of MTL inclusions selected are bubble-free, all TIL and 64\% of MTL inclusions contained at least one vapor bubble. Most bubble-bearing melt inclusions contain a single bubble $<1-20 \mu \mathrm{m}$ in diameter, with bubble size appearing to scale up with melt inclusion size. Four olivine-hosted and two clinopyroxene-hosted melt inclusions contain a daughter crystal or sulfide bleb. Further sample description details are provided in the Supplementary Materials. 


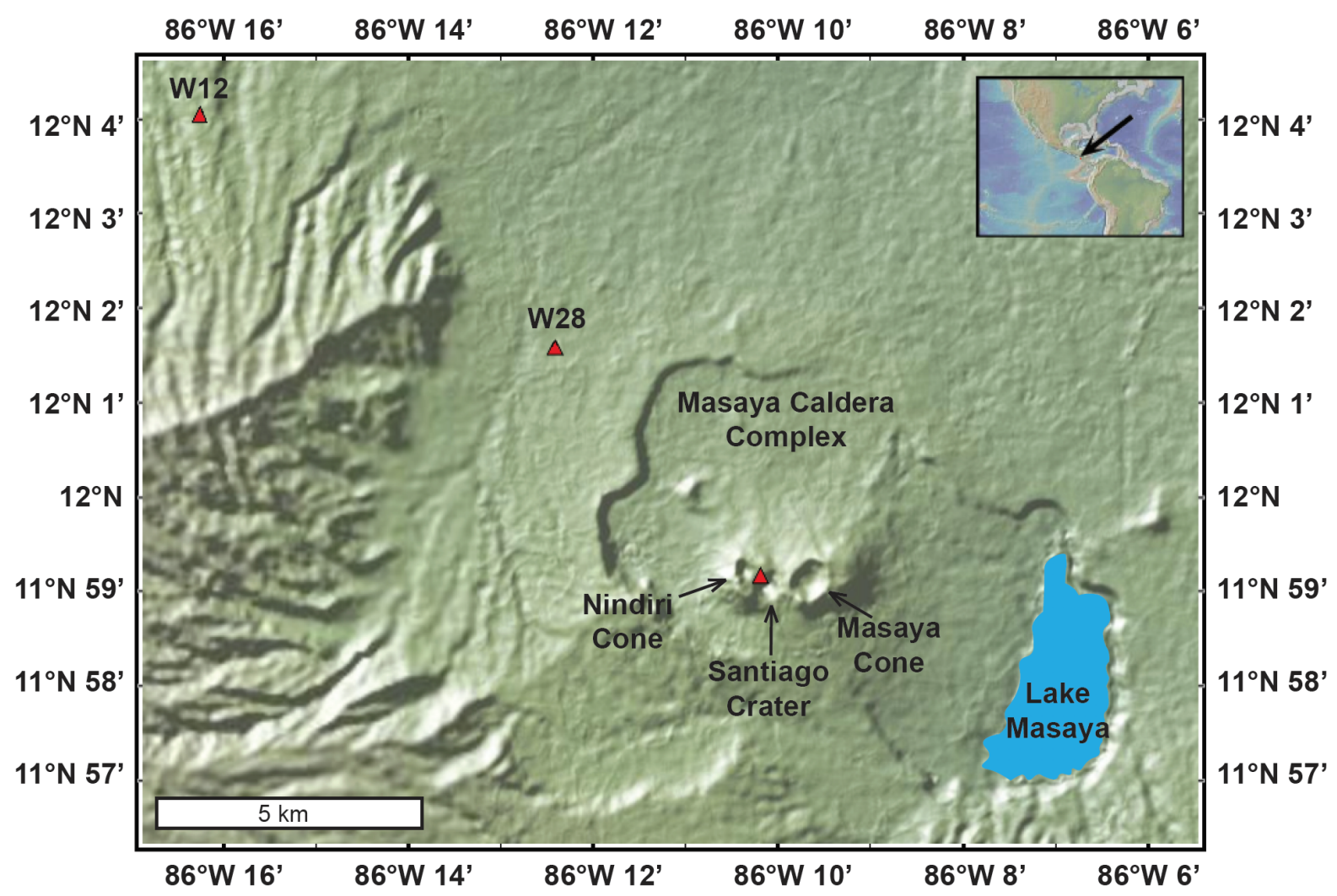

Fig. 1. Sample location map created with GeoMapApp. TIL sample W28A8a2 collected from E1 layer at outcrop W28 located at $12^{\circ} 1^{\prime} 35.12^{\prime \prime N}, 86^{\circ} 12^{\prime} 24.45^{\prime \prime W}$ (cf. Pérez \& Freundt, 2006). MTL sample W12E3 collected from C3 layer and sample W12E14 collected from C10 layer at outcrop W12 located at $12^{\circ} 4^{\prime} 3.22^{\prime \prime} \mathrm{N}, 86^{\circ} 16^{\prime} 15.12^{\prime \prime} \mathrm{W}$ (cf. Pérez \& Freundt, 2006; Pérez et al., 2009). LL lapilli and Pele's hair samples collected by Martha Ibarra Carcache on the western part of the Santiago crater, as well as near the crater lookout 2. Sample location is designated by red triangle symbol.
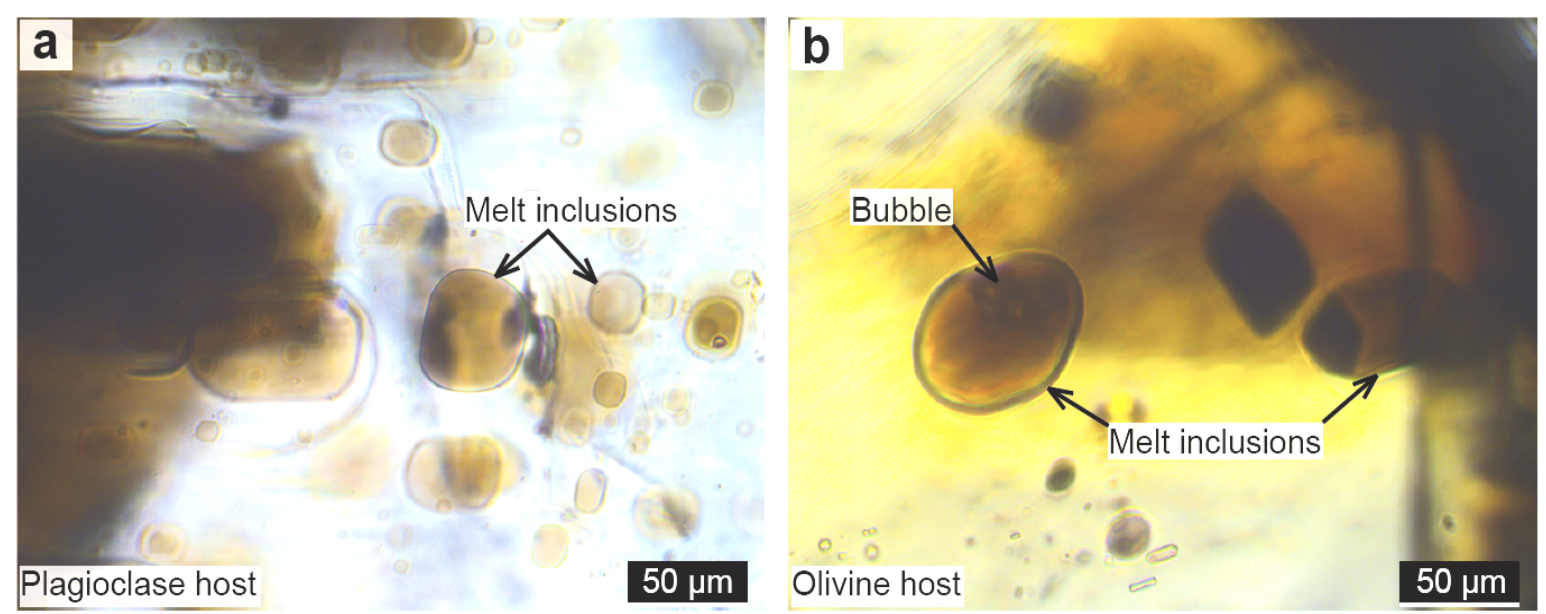

Fig. 2. Photomicrographs of Masaya samples showing representative melt inclusions. (a) Bubble-free plagioclase-hosted melt inclusions from a lava lake sample. (b) Bubble-bearing olivine-hosted melt inclusions from a MTL Plinian sample. 


\subsection{Secondary ion mass spectrometry (SIMS)}

Secondary ion mass spectrometry analyses were conducted on a Cameca IMS 1280 instrument at Woods Hole Oceanographic Institution to measure volatile $\left(\mathrm{CO}_{2}, \mathrm{H}_{2} \mathrm{O}, \mathrm{S}, \mathrm{F}\right.$ and $\left.\mathrm{Cl}\right)$ concentrations in a total of 48 melt inclusions (23 from LL, 14 from MTL, and 11 from TIL) and 18 matrix glass or Pele's hair chips (12 from LL, 3 from MTL, and 3 from TIL). Sample preparation protocols and analytical procedures are based on Hauri et al. (2002); see also Longpré et al. (2017) and the Supplementary Materials for details. Calibration curves for ${ }^{12} \mathrm{C} /{ }^{30} \mathrm{Si},{ }^{16} \mathrm{O}{ }^{1} \mathrm{H} /{ }^{30} \mathrm{Si},{ }^{19} \mathrm{~F} /{ }^{30} \mathrm{Si},{ }^{32} \mathrm{~S} /{ }^{30} \mathrm{Si}$ and ${ }^{35} \mathrm{Cl} /{ }^{30} \mathrm{Si}$ versus the respective volatile component were established using eight basaltic to basaltic andesite glass standards (Fig. S1). The standard error on the slope of the calibration curves is $1.8 \%$ or better for all volatiles. Repeated analysis $(n=8)$ of standard ALV519-4-1, a MORB glass, throughout our analytical session yielded $162 \pm 4 \mathrm{ppm}$ $\mathrm{CO}_{2}, 0.15 \pm 0.01$ wt. $\% \mathrm{H}_{2} \mathrm{O}, 105 \pm 2$ ppm F, $862 \pm 14$ ppm S, and $43 \pm 1$ ppm Cl (Fig. S2); this agrees well with values obtained by Colman et al. (2015). Spot analyses of host mineral adjacent to melt inclusions yielded $<3$ ppm $\mathrm{CO}_{2},<0.003$ wt. $\% \mathrm{H}_{2} \mathrm{O},<1 \mathrm{ppm} \mathrm{F},<1 \mathrm{ppm} \mathrm{S}$, and $<1 \mathrm{ppm} \mathrm{Cl}$, demonstrating low analytical backgrounds. Additional data quality is presented in the Supplementary Materials.

\subsection{Electron probe micro-analysis (EPMA)}

After SIMS work, major element compositions of melt inclusions, matrix glasses, and host minerals were obtained using a Cameca SX-100 electron microprobe at the American Museum of Natural History. Elements analyzed include $\mathrm{Na}, \mathrm{Al}, \mathrm{Mg}, \mathrm{Si}, \mathrm{K}, \mathrm{P}, \mathrm{Ca}, \mathrm{Ti}, \mathrm{Mn}$, and Fe. Analyses were conducted using an acceleration voltage of $15 \mathrm{kV}$, beam current of $10 \mathrm{nA}$, and beam diameters of $5 \mu \mathrm{m}, 10 \mu \mathrm{m}$, or $15 \mu \mathrm{m}$, depending on the size of available glass patches. Repeated analyses of our in-house standard P1326-2, a Juan de Fuca Ridge basaltic glass, demonstrate accuracy better than $2.4 \%$ relative for major elements over $1 \mathrm{wt} \%$ concentration. We also acquired X-ray intensity maps of twelve melt inclusions selected to reflect the full compositional range of our samples. Further details on the setup of X-ray maps and data quality are provided in the Supplementary Materials; additional in-run glass and mineral standards are reported in Table S6.

\subsection{Laser ablation inductively coupled plasma mass spectrometry (LA-ICP-MS)}

As a final analytical step, trace element concentrations in melt inclusions and matrix glasses were acquired by laser ablation inductively coupled plasma mass spectrometry at the Lamont-Doherty Earth Observatory of Columbia University, with a New Wave UP193-FX laser ablation system paired with a Thermo VG PQ ExCell mass spectrometer. Analytical conditions consist of $8-\mathrm{Hz}$ repetition rate and a fluency of $\sim 9.8 \mathrm{~J} / \mathrm{cm}^{2}$ on the sample surface. Calibration curves were established using the well-known BIR-1, BHVO-2, and BCR-2 basaltic glass standards. Melt inclusions were analyzed at various spot sizes $(40 \mu \mathrm{m}, 25 \mu \mathrm{m}$ and $10 \mu \mathrm{m})$ depending on the diameter of the inclusion, and matrix glasses were analyzed with $50 \mu \mathrm{m}$ and $75 \mu \mathrm{m}$ diameter spots. Repeated in-run analyses of the three calibration standards and two secondary glass standards, P1326-2 and ALV519-4-1, indicate that our measurements lie within $4 \%$ standard error for most trace elements; details in the Supplementary Materials. 


\subsection{Assessment of post-entrapment modification of melt inclusions}

Potential post-entrapment modification of our melt inclusions was assessed via a threefold approach: (1) compositions of melt inclusion were compared to matrix glass and published bulk rock values to flag any anomalous composition with respect to Masaya's liquid line of descent (Fig. S4); (2) following EPMA point analysis, we acquired elemental X-ray maps for 12 selected melt inclusions to test for homogeneity within each melt inclusion and across the melt inclusion-host mineral interface (Fig. 3); and (3) for olivine-hosted melt inclusions showing evidence of post-entrapment modification in (1) and/or (2), we performed a correction using Petrolog3 (Danyushevsy \& Plechov, 2011), assuming an oxygen fugacity of $1.7 \log$ units above
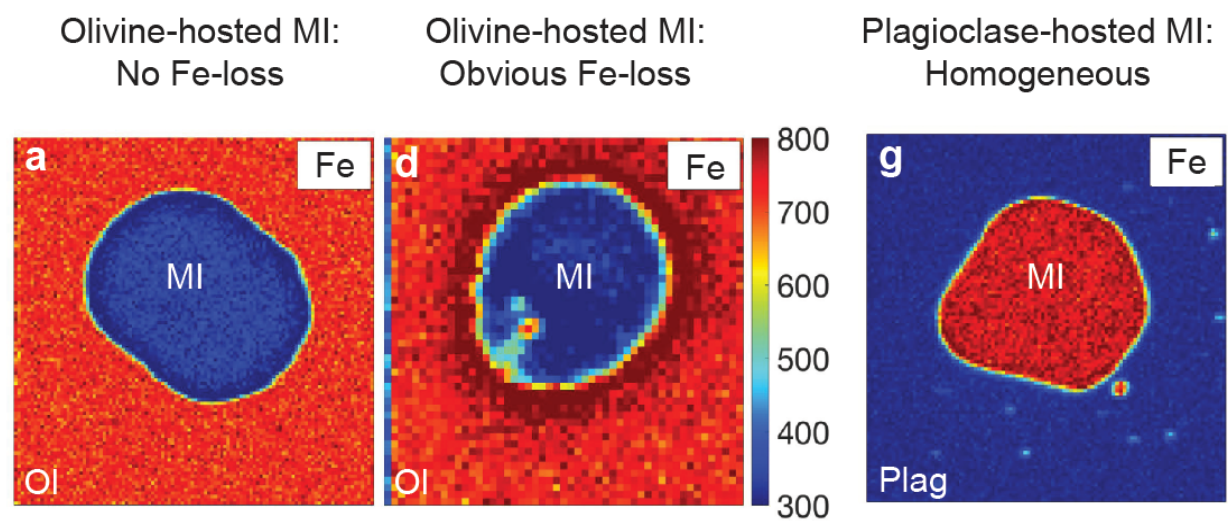
Plagioclase-hosted MI:
Minor compositional modification
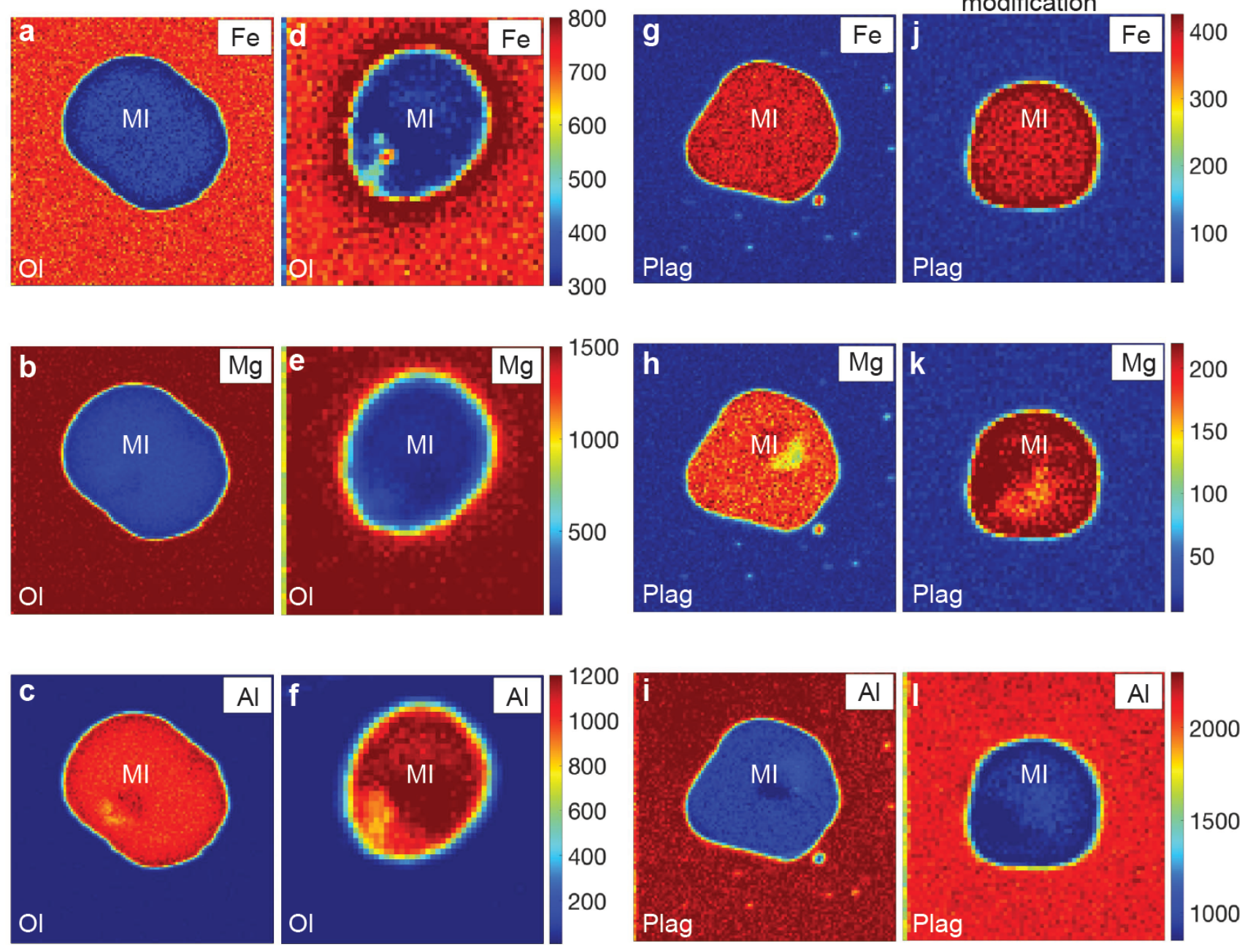

Fig. 3. Elemental maps of olivine- and plagioclase-hosted melt inclusions used to assess postentrapment modification. Olivine maps indicate no Fe-loss (a-c) compared to obvious Fe-loss (d-f). Plagioclase maps indicate homogenous (g-i) vs. minor compositional modification (j-1). Color bar represents relative element concentrations, units are arbitrary intensity units. Map constructed with EPMA data and XMapTools 2.5.2 (Lanari et al. 2014; 2019). All element intensity maps were rastered using a $1 \mu \mathrm{m}$ step size. From left to right, panel width is $110 \mu \mathrm{m}$ (a-c), $51 \mu \mathrm{m}(\mathrm{d}-\mathrm{f}), 101 \mu \mathrm{m}$ (g-i), and $65 \mu \mathrm{m}(\mathrm{j}-1)$. A SIMS pit is present within each melt inclusion. 
the fayalite-magnetite-quartz (FMQ) buffer (de Moor et al., 2013), host Fo\% content adjacent to melt inclusions, and initial melt $\mathrm{FeO}_{\mathrm{t}}$ estimated from a $\mathrm{SiO}_{2}-\mathrm{FeO}_{\mathrm{t}}$ linear regression of the liquid line of descent. Most olivine-hosted inclusions required $<5 \%$ correction. However, two small inclusions from the TIL samples show evidence of extensive post-entrapment modification requiring up to $23 \%$ correction; these inclusions are excluded from further discussion but are reported in Table S1. Plagioclase-hosted melt inclusions show little to no evidence of significant post-entrapment modification and thus were not corrected (Fig. 3; S6). For olivine-hosted melt inclusions, the text and figures present corrected data only, while both raw and corrected data are listed in full in the Supplements.

\section{Results and Discussion}

\subsection{Major elements}

Data reported in Fig. 4 reveal that our matrix glasses and melt inclusions hosted in olivine (Fo70-75), plagioclase $\left(\mathrm{An}_{66-90}\right)$, and clinopyroxene $\left(\mathrm{Mg \#}_{72-75}\right)$ phenocrysts display a relatively narrow basaltic-basaltic andesitic major element composition range, within 49.9-54.4 wt.\% $\mathrm{SiO}_{2}$, 3.8-5.8 wt.\% MgO, 13.1-17.1 wt. $\% \mathrm{Al}_{2} \mathrm{O}_{3}, 10.5-15.6$ wt.\% FeO*, 7.5-10.5 wt.\% CaO, and 0.9-1.7 wt. $\% \mathrm{~K}_{2} \mathrm{O}$. These results are very similar to bulk rock and glass measurements from earlier studies at Masaya (Fig. 4; Williams, 1983; Carr, 1984; Walker et al., 1993; Sadofsky et al., 2007; Costantini et al., 2010; Goepfert \& Gardner, 2010; Zurek et al., 2020; Pérez, personal communication). In detail, open-conduit LL and Plinian MTL compositions generally overlap, except for two MTL plagioclase-hosted melt inclusions that show anomalously high FeO* coupled to low $\mathrm{Al}_{2} \mathrm{O}_{3}$, which may reflect minor post-entrapment crystallization. In comparison, the Plinian TIL compositions display distinctly higher $\mathrm{Al}_{2} \mathrm{O}_{3}$ and appear slightly more primitive, though still fall within the range of published data (Fig. 4c).

Focusing on matrix glasses from lapilli and Pele's hairs, MTL and LL, which are both microlite-poor, show restricted and nearly identical compositions, whereas TIL, which is microlite-rich, records slightly lower $\mathrm{MgO}$ and $\mathrm{CaO}$ contents and higher $\mathrm{SiO}_{2}, \mathrm{Al}_{2} \mathrm{O}_{3}$, and $\mathrm{K}_{2} \mathrm{O}$ contents (Fig. 4). We attribute these differences and the comparatively higher variability in TIL matrix glass composition, at least in part, to the presence of abundant microlites.

Although $\mathrm{SiO}_{2}$ and $\mathrm{K}_{2} \mathrm{O}$ are negatively correlated with $\mathrm{MgO}$ for $\mathrm{LL}$ (and to a lesser extent MTL), major element concentrations generally show weak relationships with $\mathrm{MgO}$ at Masaya, both in our dataset and previously published data, limiting the use of major elements as differentiation indices.

Olivine host mineral cores and rims are similar and display a narrow compositional range (Fo70-75) for each eruption. This compositional homogeneity within the olivine crystals indicates there is no evidence for any late recharge event that otherwise would not be reflected in the melt inclusions (Fig. S6).

Our results are consistent with findings that have shown that Masaya lavas and tephras are relatively homogeneous in composition throughout the exposed stratigraphy, verifying that Masaya's magmatic system has maintained a compositionally buffered, steady state, for at least 30 ka (Walker et al., 1993; Zurek et al., 2019). Minor compositional variations are attributed to fractional crystallization of olivine, plagioclase and clinopyroxene in a large, shallow magma reservoir maintained by vigorous convection and periodic influx of less evolved basaltic magmas (Walker et al., 1993; Zurek et al., 2019). 

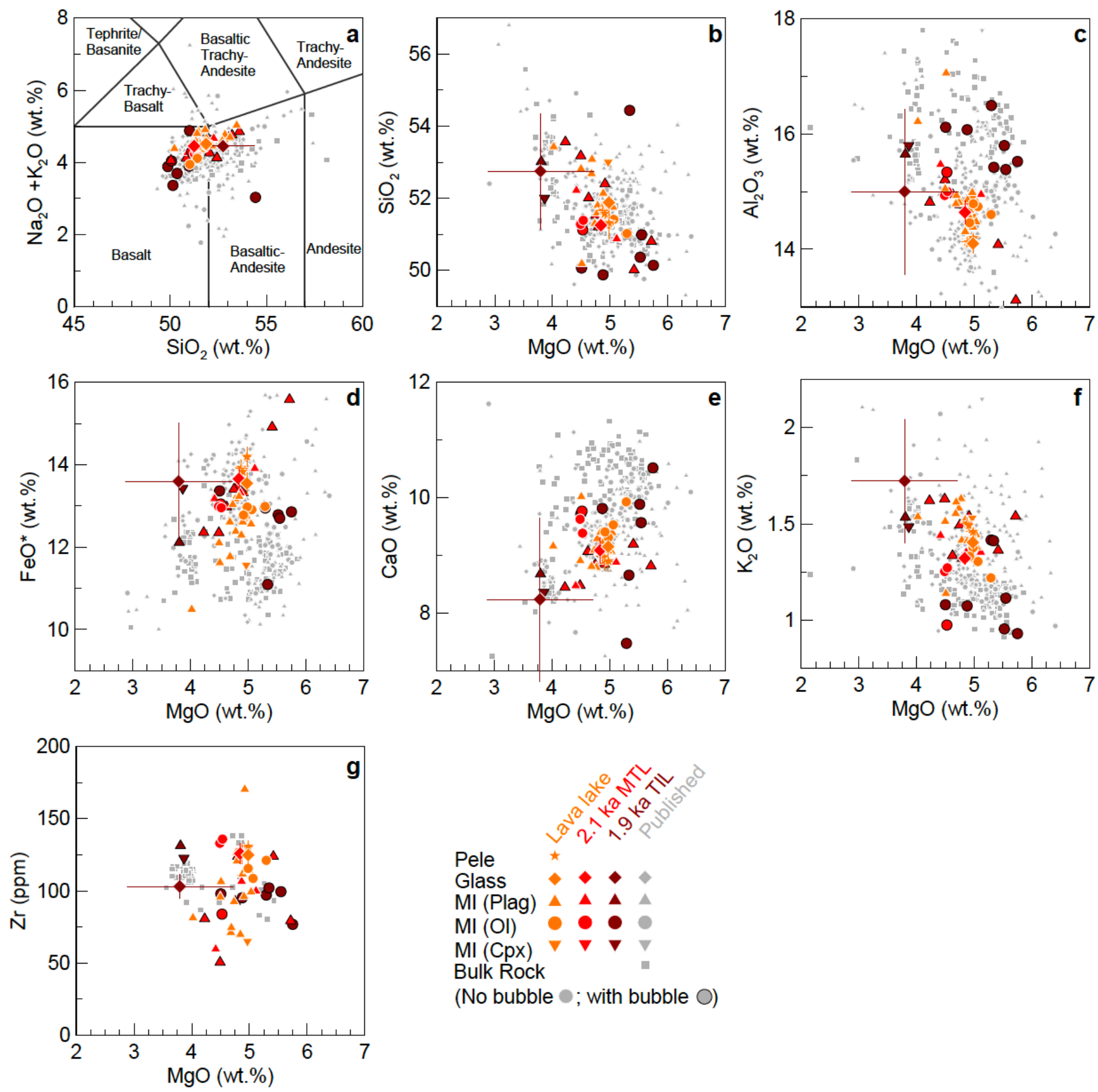

Fig. 4. Major element compositions for olivine-, plagioclase-, and clinopyroxene-hosted melt inclusions and matrix glasses for each eruption as compared to previously published bulk rock and glass data from Masaya (Williams, 1983; Carr, 1984; Walker et al., 1993; Sadofsky et al., 2007; Costantini et al., 2010; Goepfert \& Gardner, 2010; Zurek et al., 2019; Pérez, unpublished data). Olivine-hosted melt inclusion data are PEC corrected. (a) TAS diagram, (b) $\mathrm{SiO}_{2}$ vs. $\mathrm{MgO}$, (c) $\mathrm{Al}_{2} \mathrm{O}_{3}$ vs. $\mathrm{MgO}$, (d) $\mathrm{FeO}^{*}$ vs. $\mathrm{MgO}$, (e) $\mathrm{CaO}$ vs. $\mathrm{MgO}$, (f) $\mathrm{K}_{2} \mathrm{O}$ vs. $\mathrm{MgO}$, (g) $\mathrm{Zr}$ vs $\mathrm{MgO}$. Mean matrix glass and Pele's hair compositions are shown with $1 \sigma$ error bars (not shown when smaller than symbol size). 


\subsection{Trace elements}

In contrast to major elements displaying minor variability, several trace elements show relatively wide concentration ranges in our samples. High field strength zirconium, for example, varies by more than a factor of three, from 50 to $170 \mathrm{ppm}$, showing no correlation with $\mathrm{MgO}$ (Fig. 4g). Fig. 5 compares trace element characteristics of our samples in terms of $\mathrm{Y}$ concentration and $\mathrm{Ce} / \mathrm{Y}$ and $\mathrm{Ba} / \mathrm{La}$ ratios as a function of $\mathrm{Zr}$ concentration. A strong positive correlation between $\mathrm{Y}$ and $\mathrm{Zr}$ is observed, consistent with the melt inclusion entrapment after variable extents of crystallization have occurred. Notably, the matrix glass and olivine-hosted melt inclusions from the LL and MTL have higher Y and Zr than those of TIL, which may be slightly more primitive. Enriched primary melts with higher volatile concentrations may be predisposed to explosivity, and $\mathrm{Ce} / \mathrm{Y}$ should be an effective tracer of "enrichment" (Sides et al., 2014). The bulk of our Masaya glasses and inclusions record a relatively constant $\mathrm{Ce} / \mathrm{Y}$ ratio ( 0.6-1.1) over a wide range of $\operatorname{Zr}(50-170 \mathrm{ppm}$; Fig. 5b); this lack of correlation indicates that $\mathrm{Zr}$ concentration is not controlled by any major differences in source composition or the degree of melting, but rather is consistent with fractional crystallization producing any minor differentiation. Therefore, variations in primary magma composition do not seem to be the control of eruptive style at Masaya. In comparison to other Central American arc rocks, our Masaya glasses and melt inclusions record a relatively high yet narrow range of $\mathrm{Ba} / \mathrm{La}$ (mean 74 \pm 11 ), suggesting that contributions from subducting slab fluids do not vary considerably from eruption to eruption at Masaya, and therefore have no strong influence on eruptive style here. $\mathrm{Zr}$ and other incompatible trace elements, are therefore more sensitive indices of crystallization than major elements at Masaya.

Rare earth element data reported in Fig. 6 reveal similar patterns for each eruption and fall within the upper range of previously published whole rock (Bolge et al., 2009; Cooper et al., 2010; Moune et al., 2010; Patino et al., 2000; Chan et al., 1999) and melt inclusion (Sadofsky et al., 2007; Zurek et al., 2019) data for Masaya. Specifically, matrix glass from LL and MTL show nearly identical rare earth element concentrations, while the TIL matrix glass records slightly lower values. Matrix glass and melt inclusions from each eruption display nearly parallel
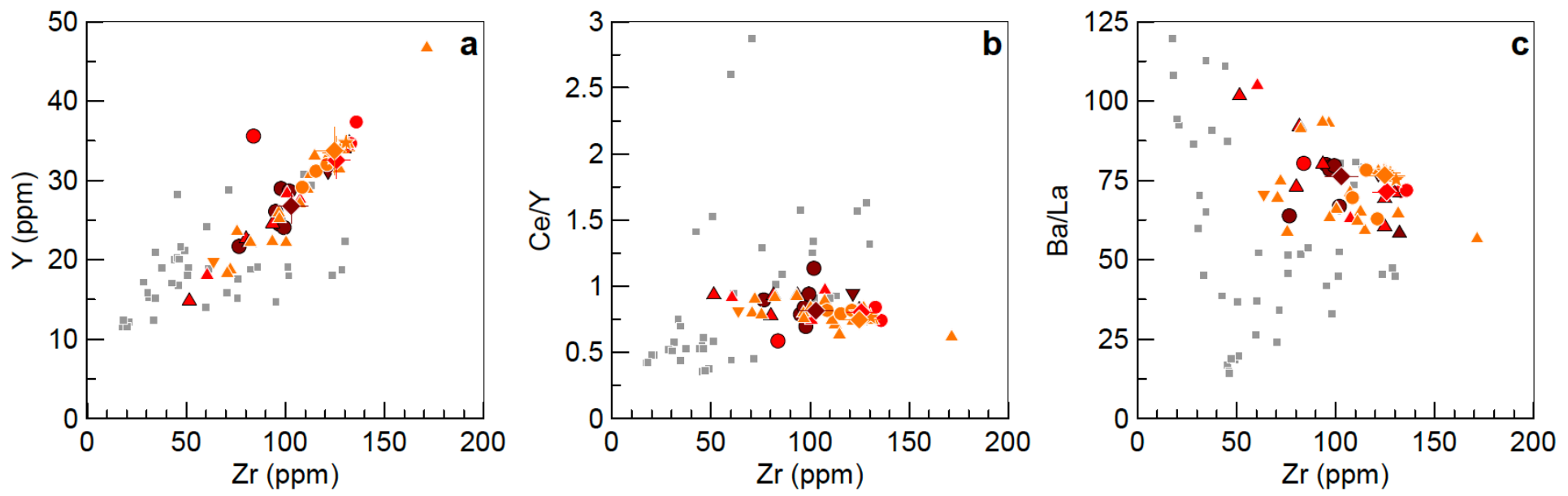

Fig. 5. $\mathrm{Zr}$ as an index of magma differentiation. (a) $\mathrm{Y}$ vs. $\mathrm{Zr}$, (b) $\mathrm{Ce} / \mathrm{Y}$ vs. $\mathrm{Zr}$ (c) $\mathrm{Ba} / \mathrm{La}$ vs. $\mathrm{Zr}$. Symbols as noted in Fig. 4. Mean matrix glass and Pele's hair compositions are shown with $1 \sigma$ error bars (not shown when smaller than symbol size). 


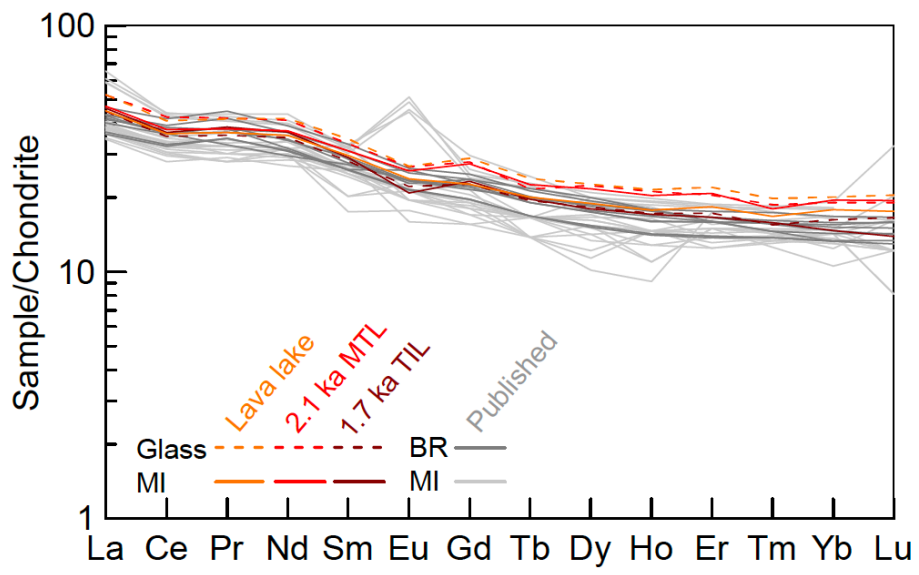

Fig. 6. Chondrite-normalized (Sun \& McDonough, 1995) rare earth element diagram for the average olivine-, plagioclase-, and clinopyroxene-hosted melt inclusions and matrix glasses. Plotted published data include bulk rocks (Bolge et al., 2009; Cooper et al., 2010; Moune et al., 2010; Patino et al., 2000; Chan et al, 1999) and melt inclusions (Sadofsky et al., 2007; Zurek et al., 2019). A few published melt inclusion data points show positive Eu anomalies, the origin of which is unclear.

signatures, consistent with a co-genetic link between the inclusions and carrier liquid. Additionally, we observe no significant europium anomaly for our samples, contrasting with the olivine-hosted melt inclusion data of Sadofsky et al. (2007) that display a marked positive anomaly, the origin of which is unclear. We detect only a subtle negative europium anomaly for our matrix glasses (mean $0.85 \pm 0.04$ for LL, $0.88 \pm 0.08$ for MTL, $0.88 \pm 0.02$ for TIL) and melt inclusions (mean $0.96 \pm 0.32$ for LL, $0.90 \pm 0.16$ for MTL, $0.87 \pm 0.05$ for TIL), indicating limited plagioclase fractionation.

\subsection{Volatile content systematics}

Marked differences between our samples begin to emerge in their volatile content systematics. Indeed, open-conduit LL and Plinian melt inclusions form distinct groups with mean $\mathrm{H}_{2} \mathrm{O}$ contents of $0.6 \pm 0.2 \mathrm{wt} . \%$ for LL, $1.1 \pm 0.2 \mathrm{wt} . \%$ for MTL, and $1.9 \pm 0.3 \mathrm{wt} . \%$ for TIL (Fig. 7). Within each group, there is little correlation between $\mathrm{H}_{2} \mathrm{O}$ and other volatiles; however, the whole dataset displays broad positive correlations between $\mathrm{S}, \mathrm{Cl}$ (and to a lesser extent $\mathrm{F}$ ) and $\mathrm{H}_{2} \mathrm{O}$, e.g., mean melt inclusion sulfur concentrations increase from $130 \pm 50 \mathrm{ppm}$ for LL, $420 \pm 240 \mathrm{ppm}$ for MTL, to $680 \pm 180 \mathrm{ppm}$ for TIL (Fig. 7). In contrast, $\mathrm{CO}_{2}$ concentrations are uniform across samples and, aside from five outliers, do not exceed $400 \mathrm{ppm}$. Compared to melt inclusions, the matrix glasses for each eruption are almost completely degassed in $\mathrm{H}_{2} \mathrm{O}, \mathrm{CO}_{2}$, and $\mathrm{S}$, except for TIL glass patches which retained on average $144 \pm 166 \mathrm{ppm} \mathrm{CO}_{2}$ (Fig. 7). It remains unclear whether this remnant $\mathrm{CO}_{2}$ is an artifact of carbon contamination during analysis or a genuine record of $\mathrm{CO}_{2}$ supersaturation. On the other hand, fluorine and chlorine concentrations remain significant in matrix glasses and generally sit at the low end of the melt inclusion range (Fig. $7 \mathrm{c}, \mathrm{d})$.

These results reveal significantly higher volatile contents in melt inclusions from Plinian fall deposits than from lava lake ejecta, however, even our highest measured concentrations are strikingly low with respect to typical maxima for mafic Central American arc magmas, which are commonly characterized by pre-eruptive $\mathrm{H}_{2} \mathrm{O}$ contents $>4$ wt.\% (Fig. 7) (e.g., Sadofsky et al., 2007; Roggensack et al., 1997; Plank et al., 2013). This agrees with previously published work at 
Masaya, which reported modest maximum $\mathrm{H}_{2} \mathrm{O}$ and $\mathrm{S}$ contents of 2.7 wt.\% and 590 ppm, respectively (Bamber et al., 2020; Sadofsky et al., 2007; Zurek et al., 2019; Goepfert and Gardner, 2010). These results strongly indicate that anomalously high pre-eruptive volatile contents cannot be invoked as a primary control on eruptive style at Masaya.

\subsection{Evidence for pre-eruptive degassing at low pressure}

Why are volatile contents so low at Masaya? We argue that these low volatile contents reflect extensive amounts of pre-eruptive low pressure degassing such that all Masaya melt inclusions record variably degassed melts. This is strongly indicated by the positive correlations between $\mathrm{S}, \mathrm{Cl}$ and $\mathrm{H}_{2} \mathrm{O}$ in our dataset (Fig. 7), which are best explained as degassing trends. Moreover, negative correlations between ratios of volatile and lithophile elements of similar bulk partition coefficients, such as $\mathrm{H}_{2} \mathrm{O} / \mathrm{Ce}, \mathrm{S} / \mathrm{Dy}, \mathrm{Cl} / \mathrm{K}$ and $\mathrm{F} / \mathrm{Nd}$, and $\mathrm{Zr}$ concentrations arise for each
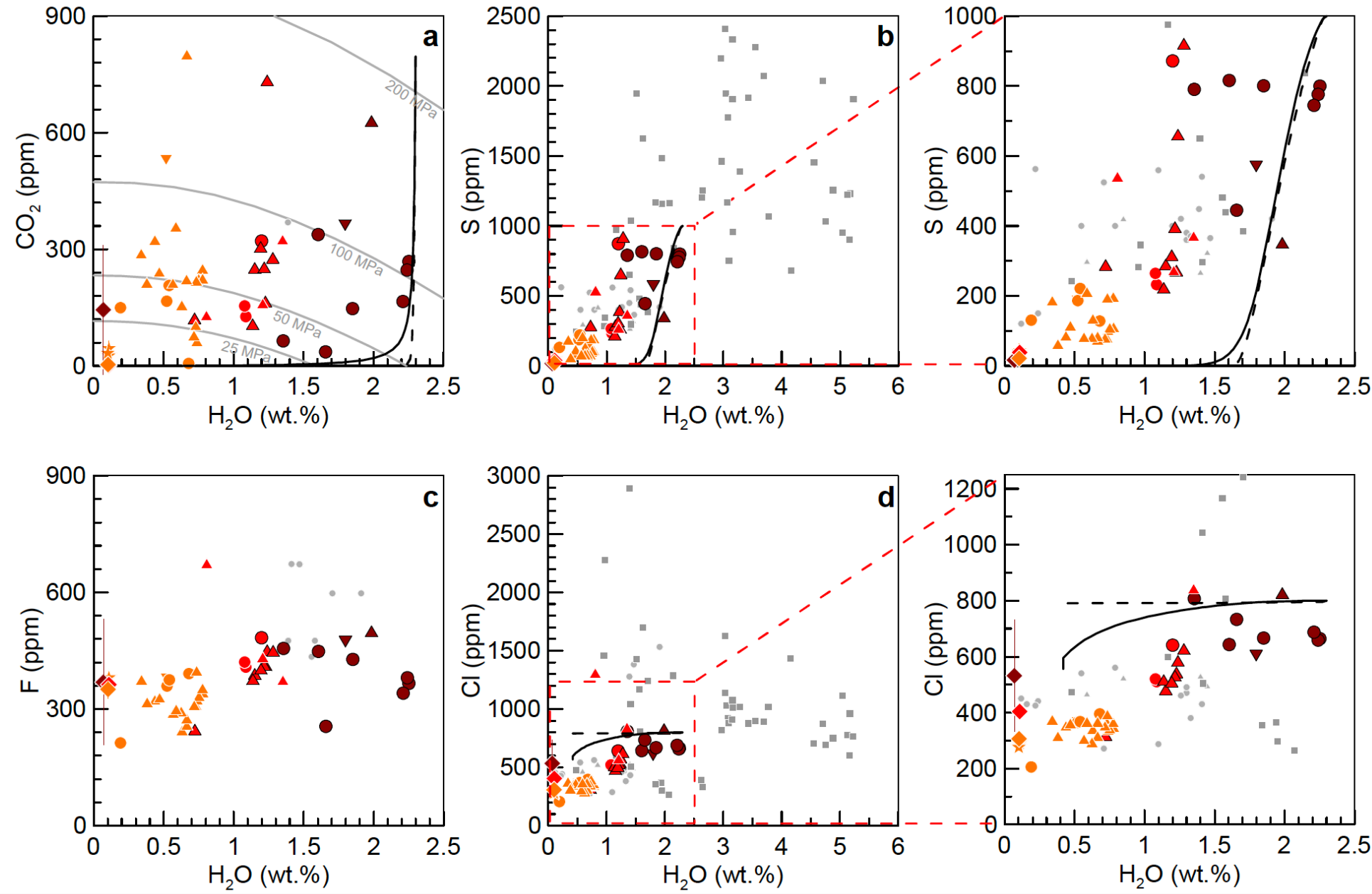

Fig. 7. Volatile content systematics for the olivine-, plagioclase-, and clinopyroxene-hosted melt inclusions, matrix glasses, and Pele's hairs. Symbols as in Fig. 4. (a) $\mathrm{CO}_{2}$ vs. $\mathrm{H}_{2} \mathrm{O}$ concentrations, with for 25, 50, 100 and $200 \mathrm{MPa}$ isobars calculated with SolEx (Witham et al., 2011) using the lava lake matrix glass composition and a temperature of $1115{ }^{\circ} \mathrm{C}$, (b) $\mathrm{S}$ vs. $\mathrm{H}_{2} \mathrm{O}$, with expanded inset, (c) $\mathrm{F}$ vs. $\mathrm{H}_{2} \mathrm{O}$, (d) $\mathrm{Cl}$ vs. $\mathrm{H}_{2} \mathrm{O}$, with expanded inset. For comparison, Sadofsky (2007) Central America data shown in dark gray and Masaya published glass data (Sadofsky et al., 2007; Wehrmann et al., 2011; Zurek et al., 2019) shown in light gray. Plots also show degassing models calculated with SolEx. Solid black line is closed system, dashed black line is open system. Mean matrix glass and Pele's hair compositions are shown with $1 \sigma$ error bars (not shown when smaller than symbol size). 
sample, corroborating melt inclusion entrapment during concomitant degassing and crystallization (Fig. 8). Post-entrapment $\mathrm{H}^{+}$diffusion can produce low $\mathrm{H}_{2} \mathrm{O}$ values in melt inclusion datasets due to re-equilibration of the trapped melt with the external melt through the host mineral (e.g., Portnyagin et al., 2008; Gaetani et al., 2012; Lloyd et al., 2012). However, the preservation of correlations between $\mathrm{H}_{2} \mathrm{O}$ and other volatiles, which should be destroyed by extensive post-entrapment diffusive water loss, rules out this process as a dominant control on sample-to-sample variability at Masaya (Fig. 7b). This is further supported by the lack of correlation between melt inclusion size and $\mathrm{H}_{2} \mathrm{O}$ content in our dataset (Fig. S6), because diffusive re-equilibration preferentially affects smaller inclusions (e.g., $<30 \mu \mathrm{m}$ ), and is expected to yield positive trends between these variables (e.g., Lloyd et al., 2012; Barth et al., 2019). In detail, however, some within-sample variability may be due to water loss. Particularly, it is likely that water loss is behind the relatively wide range of $\mathrm{H}_{2} \mathrm{O} / \mathrm{Ce}$ values at near constant $\mathrm{Zr}$ concentration ( $\sim 100 \mathrm{ppm})$ displayed by a few of the TIL inclusions (Fig. 8).

The low measured $\mathrm{CO}_{2}$ and $\mathrm{H}_{2} \mathrm{O}$ concentrations in our melt inclusions yield correspondingly low vapor saturation pressures $\left(\mathrm{P}_{\text {sat }}\right)$ calculated from the volatile solubility models of Newman \& Lowenstern (2002) and Iacono-Marziano et al. (2012). From the latter, we obtained a $\mathrm{P}_{\text {sat }}$ range of 8-147 $\mathrm{MPa}$, with only three melt inclusions giving values $>100 \mathrm{MPa}$. Comparing eruptions, we observe an increase in mean $\mathrm{P}_{\text {sat }}$ from $49 \pm 28 \mathrm{MPa}$ for LL, to $58 \pm 25$ $\mathrm{MPa}$ for MTL, and $84 \pm 32 \mathrm{MPa}$ for TIL. Given the evidence for pre-eruptive degassing discussed above, it seems safe to assume that $\mathrm{P}_{\text {sat }}$ values represent the magma storage pressures at which the melt inclusions were originally trapped or last re-equilibrated with the external melt (Fig. 7a). Low $\mathrm{CO}_{2}$ concentrations in melt inclusions are a common result of pre-eruptive degassing during ascent and crystallization; however, in some cases, bubble-bearing melt inclusions may only provide minimum $\mathrm{CO}_{2}$ estimates if a notable quantity of dissolved $\mathrm{CO}_{2}$ in the melt has exsolved into vapor bubbles (Roedder, 1984; Moore et al., 2014; Bucholz et al., 2013). Thus, melt inclusions must be carefully evaluated for effects of post-entrapment modification and vapor bubbles. Low and relatively homogeneous $\mathrm{CO}_{2}$ data are observed across all eruptions (Fig. 7a); all LL inclusions are bubble-free, and MTL bubble-free versus bubblebearing inclusions are in general agreement, implying volatile leakage is negligible here. All TIL inclusions contain bubbles, therefore we must take these $\mathrm{CO}_{2}$ concentrations as a minimum. With overall $\mathrm{P}_{\text {sat }}$ mainly below $100 \mathrm{MPa}$, corresponding to depths $<4 \mathrm{~km}$, it appears that even for Masaya's most explosive Plinian eruptions, the magma has been significantly degassed at shallow pressure before final ascent and eruption.

Strong evidence for substantial pre-eruptive $\mathrm{Cl}$ (and to a lesser extent $\mathrm{F}$ ) degassing may help place further constraints on magma reservoir depths at Masaya. Halogen partitioning between melt and fluid(s) is complex and responds variably to changes in pressure, temperature, melt and fluid composition (Webster et al., 2018). The relatively high solubility of $\mathrm{Cl}$ and $\mathrm{F}$ allow these phases to be retained by the melt during decompression-induced degassing (firstboiling) of ascending deep magma. Experimental studies demonstrate that for most shallow magmatic conditions, $\mathrm{Cl}$ partitions in favor of fluids over melts $\left(D_{C l}^{\text {fluid/melt }}>1\right)$, indicating $\mathrm{Cl}$ exsolution is more apparent during crystallization-induced degassing (second-boiling) at low pressures (Aiuppa et al., 2009; Spilliaert et al., 2006). For example, at Mount Etna, melt inclusion data indicate that chlorine and fluorine exsolution begins at pressures $\leq 100 \mathrm{MPa}$ and $\leq 10 \mathrm{MPa}$, respectively, only becoming important during shallow degassing (Spilliaert et al., 2006). This is consistent with the experiments of Lesne et al. (2011), designed to simulate decompression-driven closed-system degassing on Masaya compositions, showing that $\mathrm{Cl}$ 
largely remains dissolved in the melt at pressures $\geq 100 \mathrm{MPa}$, with modest $\mathrm{Cl}$ degassing only apparent for the low pressure runs at 25 and $50 \mathrm{MPa}$.

Comparing LL and Plinian data, we observe a general decrease in $\mathrm{Cl}$ concentration with decreasing $\mathrm{P}_{\text {sat }}$ (Fig. 9b). We model degassing paths with SolEx (Witham et al., 2011) to reproduce $\mathrm{H}_{2} \mathrm{O}-\mathrm{Cl}$ and $\mathrm{H}_{2} \mathrm{O}-\mathrm{S}$ trends (Fig. 7,9). Our models are calculated using average matrix glass melt composition and representative initial volatile contents of 800 ppm $\mathrm{CO}_{2}, 2.3$ wt.\% $\mathrm{H}_{2} \mathrm{O}, 1000 \mathrm{ppm} \mathrm{S}$, and $800 \mathrm{ppm} \mathrm{Cl}$. Model inputs include oxygen fugacity of FMQ +1.7 (de Moor et al., 2013), and pre-eruptive temperature estimates of $1115^{\circ} \mathrm{C}$ via mineral-liquid geothermometry (Putirka, 2008; Waters \& Lange, 2015), consistent with published estimates of $1097-1127^{\circ} \mathrm{C}$ based on olivine-liquid equilibria (de Moor et al., 2013). Using an open-system scenario, which is likely to be more realistic, $\mathrm{S}$ and $\mathrm{Cl}$ start degassing at $\leq 115 \mathrm{MPa}$ and $\leq 110$ $\mathrm{MPa}$, respectively. In a closed-system scenario, $\mathrm{S}$ similarly starts degassing at $\leq 115 \mathrm{MPa}$, though $\mathrm{Cl}$ starts degassing at $\leq 55 \mathrm{MPa}$ (Fig. 9b, S7). Therefore, evidence of $\mathrm{Cl}$ degassing in our melt inclusion dataset is consistent with low-pressure degassing $(<100 \mathrm{MPa})$ occurring for all Masaya magmas prior to eruption, and further suggests that $\mathrm{P}_{\text {sat }}$ values do not significantly suffer from $\mathrm{CO}_{2}$ loss to bubbles.
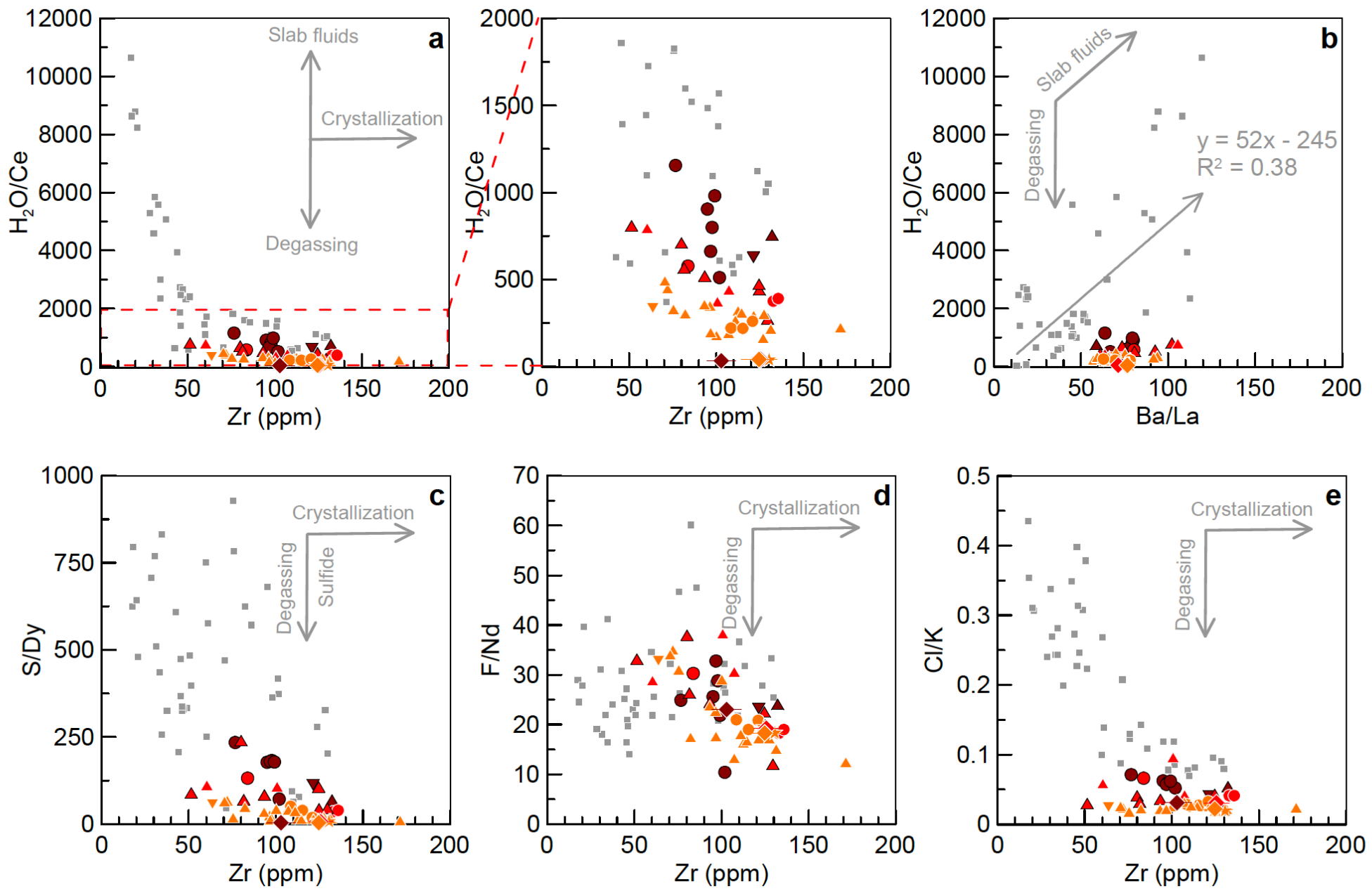

Fig. 8. Evidence for pre-eruptive degassing: Masaya melt inclusions from each eruption as compared to Sadofsky et al. (2007) Central American data. Symbols as noted in Fig. 4. (a) $\mathrm{H}_{2} \mathrm{O} / \mathrm{Ce}$ vs. $\mathrm{Zr}$ trends for each eruption; (b) $\mathrm{H}_{2} \mathrm{O} / \mathrm{Ce}$ vs. $\mathrm{Ba} / \mathrm{La}$ for each eruption. (c) $\mathrm{S} / \mathrm{Dy}$ vs. $\mathrm{Zr}$ (d) $\mathrm{F} / \mathrm{Nd}$ vs. $\mathrm{Zr}$ (e) $\mathrm{Cl} / \mathrm{K}$ vs $\mathrm{Zr}$. Mean matrix glass and Pele's hair compositions are shown with horizontal $1 \sigma$ error bars (not shown when smaller than symbol size). 

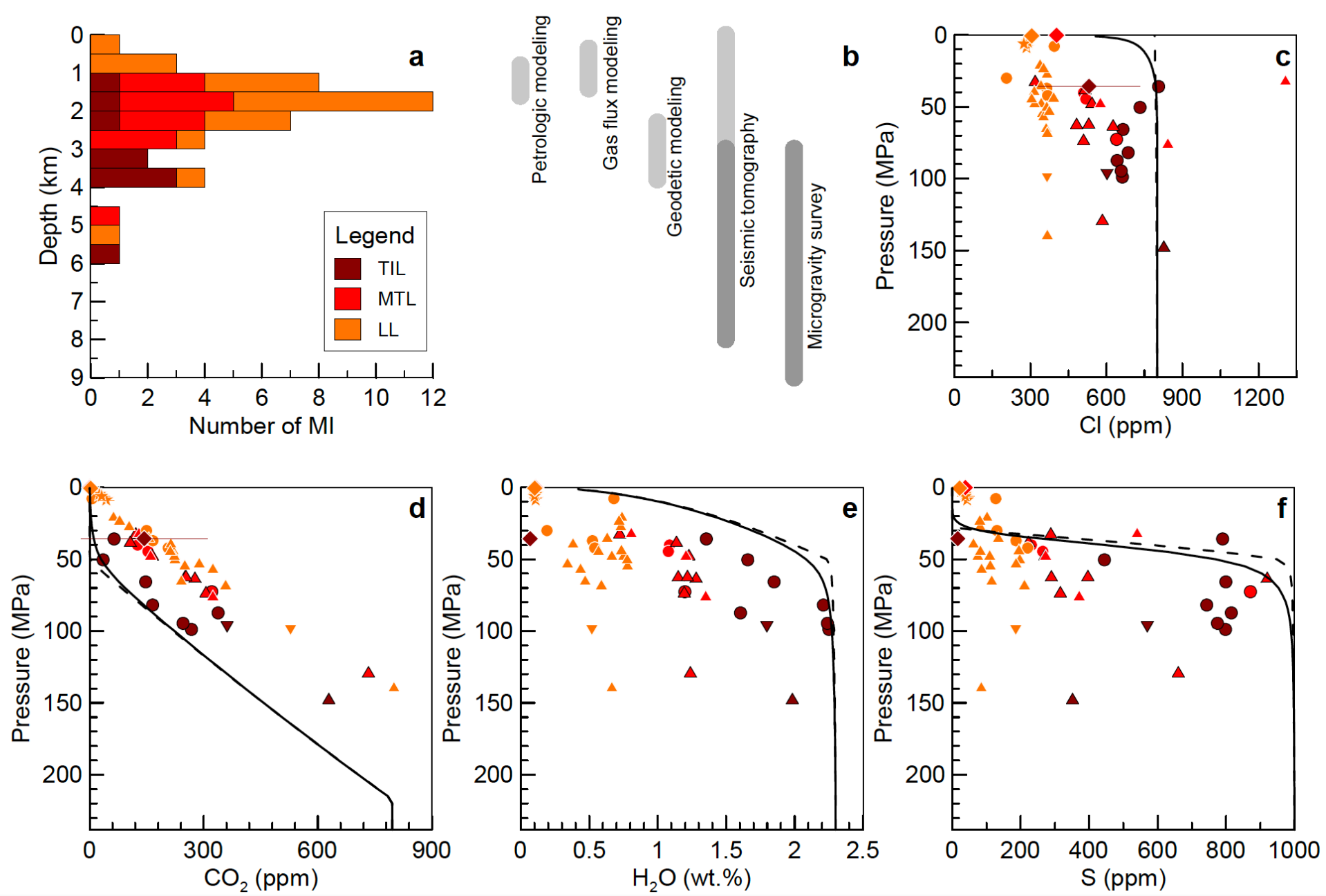

Fig 9. (a) Histogram of relative abundance of melt inclusions depths. Depths are calculated from volatile saturation pressures obtained from the model of Iacono-Marziano et al. (2012) and assuming a crustal density of $2700 \mathrm{~kg} / \mathrm{m}^{3}$. (b) Adjacent are published estimates on inferred depth of a shallow reservoir (light gray) and of a deeper sill body (dark gray) from Bamber et al. (2020), Aiuppa et al. (2018), Stephens et al. (2017), Obermann et al. (2019), and Metaxian et al. (1994), respectively. (c-e) volatile saturation pressure $(\mathrm{MPa})$ vs. volatile concentration from melt inclusions and glasses, including SolEx degassing curves (c) $\mathrm{MPa}$ vs. $\mathrm{Cl}$ (d) $\mathrm{MPa}$ vs. $\mathrm{CO}_{2}$ (e) $\mathrm{MPa}$ vs. $\mathrm{H}_{2} \mathrm{O}$ (f) $\mathrm{MPa}$ vs. S. Plots also show degassing models calculated with SolEx. Solid black line is closed system, dashed black line is open system. Mean matrix glass and Pele's hair compositions are shown with horizontal $1 \sigma$ error bars (not shown when smaller than symbol size).

\subsection{Syn-eruptive degassing and comparison with gas data}

Additional constraints on dynamics of magma degassing at Masaya may be obtained by a comparison of our in situ petrologic data and with the wealth of field-based gas measurements performed in the last two decades (e.g., Burton et al., 1999, Martin et al., 2010; Aiuppa et al., 2018). Particularly, we aim to compare observed volatile fluxes from persistent quiescent degassing conditions, with estimated syn-eruptive volatile yields obtained by the petrologic method (e.g., Devine et al., 1984). The petrologic method consists of calculating the difference in mean volatile content between melt inclusions and matrix glasses, then scaling to the reported erupted volume. Moreover, insights into the vapor-melt partitioning behavior of different volatile species may be derived from a comparison of volatile ratios in melts and gases. 
Strong syn-eruptive degassing of $\mathrm{H}_{2} \mathrm{O}, \mathrm{CO}_{2}$, and $\mathrm{S}$ is evident by their low concentrations in Masaya matrix glasses with respect to melt inclusions of the same samples (Fig. 7). Mean sulfur loss during eruption is valued at $385 \mathrm{ppm}$ for MTL $(423 \pm 235 \mathrm{ppm}$ in melt inclusions -38 $\pm 10 \mathrm{ppm}$ in matrix glass), and $661 \mathrm{ppm}$ for TIL (677 $\pm 176 \mathrm{ppm}$ in melt inclusions $-16 \pm 6 \mathrm{ppm}$ in matrix glass). From this, we estimate syn-eruptive sulfur yields of approximately $2.1 \mathrm{Mt} \mathrm{SO}_{2}$ from MTL and $3.6 \mathrm{Mt} \mathrm{SO}_{2}$ from TIL, assuming a $2 \mathrm{~km}^{3}$ dense rock equivalent magma volume and $2700 \mathrm{~kg} / \mathrm{m}^{3}$ density for each eruption (Pérez et al., 2020). These syn-eruptive sulfur yields for MTL and TIL are equivalent to $\sim 7$ and 11 years, respectively, of quiescent $\mathrm{SO}_{2}$ degassing at Masaya's present average of $867 \pm 364 \mathrm{t} \mathrm{d}^{-1}$ (Aiuppa et al., 2019). Syn-eruptive $\mathrm{CO}_{2}$ yields are 1.3 Mt from MTL and 0.6 Mt from TIL. Unsurprisingly, syn-eruptive degassing of $\mathrm{H}_{2} \mathrm{O}$ exhibits the greatest output of $56 \mathrm{Mt}$ from MTL and $98 \mathrm{Mt}$ from TIL. Meanwhile, the lowest $\mathrm{Cl}$ and F concentrations in matrix glass and melt inclusion are roughly equivalent, suggesting little syneruptive halogen degassing in our dataset. Chlorine and fluorine yields, respectively, are $1.1 \mathrm{Mt}$ and $0.3 \mathrm{Mt}$ from MTL, and 0.9 Mt and 0.2 Mt from TIL.

$\mathrm{CO}_{2}$ is the first volatile species to exsolve during magma ascent, due to its high vapormelt partitioning, followed by $\mathrm{H}_{2} \mathrm{O}, \mathrm{S}, \mathrm{Cl}$, then $\mathrm{F}$ (Werner et al., 2020). Therefore, variability in volatile emissions from open-vent degassing at active volcanoes is often correlated with flux in magma supply and eruptive activity (Aiuppa et al., 2017; Werner et al., 2020). The long-term stability of Masaya's shallow magmatic system is revealed by largely consistent $\mathrm{CO}_{2} / \mathrm{SO}_{2}$ gas molar ratios (2.3-2.7) over two decades of quiescent degassing (Burton et al., 1999; Martin et al., 2010; de Moor et al., 2017; Aiuppa et al., 2018; Aiuppa et al., 2019). Except, a short-term increase in $\mathrm{CO}_{2} / \mathrm{SO}_{2}$ signature was observed in the weeks preceding the 2015 lava lake formation, corresponding with an influx of deeply sourced gas bubbles prior to magma ascent (de Moor et al., 2017; Aiuppa et al., 2018). Fig. 10 compares gas volatile molar ratios with petrologic volatile molar ratios from our melt inclusions and matrix glasses, to gain insights into vapor-melt partitioning behavior at Masaya. The volatile ratio signatures from MTL and TIL melt inclusions are roughly equivalent, indicating Plinian magmas experienced similar partitioning behavior; whereas LL melt record markedly higher $\mathrm{H}_{2} \mathrm{O} / \mathrm{SO}_{2}$ and $\mathrm{CO}_{2} / \mathrm{SO}_{2}$, suggesting a deviation in magmatic processes (e.g., increased $\mathrm{S}$ exsolution). Interestingly, the LL melt $\mathrm{CO}_{2} / \mathrm{SO}_{2}$ is similar to the gas signature during periods of quiescence characterized by shallow degassing (Fig. 10a). Plinian melts retain slightly higher $\mathrm{S} / \mathrm{Cl}$ and $\mathrm{Cl} / \mathrm{F}$ signatures than $\mathrm{LL}$, suggesting Plinian magmas undergo relatively less partitioning of $\mathrm{S}, \mathrm{Cl}$, and $\mathrm{F}$ into the vapor phase (Fig. 10c,d). The gas $\mathrm{HCl} / \mathrm{HF}$ signature is notably higher than melt $\mathrm{Cl} / \mathrm{F}$, indicative of efficient shallow $\mathrm{Cl}$ degassing during periods of quiescence (Fig. 10d). Overall, the minor variation between LL and Plinian volatile ratios likely reflect the lower degassing pressure for LL melts.

\subsection{Estimates of undegassed $\mathrm{H}_{2} \mathrm{O}$ contents}

Our melt inclusions record pre-eruptive $\mathrm{H}_{2} \mathrm{O}$ contents up to 2.25 wt.\% for Masaya, which is low compared to the typical $\sim 4$ wt.\% for subduction zones (Plank et al., 2013). If all Masaya melt inclusions have experienced pre-eruptive degassing at shallow depths $<4 \mathrm{~km}$, then what were the original primitive undegassed $\mathrm{H}_{2} \mathrm{O}$ contents of Masaya magmas? In order to infer the initial undegassed magmatic water content, we apply three methods of calculation. First, we apply the Ca-in-olivine geohygrometer of Gavrilenko et al. (2016) to our olivine and melt inclusion compositions. This method is established on the premise that $\mathrm{H}_{2} \mathrm{O}$ and $\mathrm{MgO}$ content in 
the melt will affect the partitioning of calcium between olivine and melt $\left(\mathrm{D}_{\mathrm{CaO}}{ }^{\mathrm{O} / \mathrm{L}}\right)$. Using Equations 1 and 2 of Gavrilenko et al. (2016), we use the ratio of $\mathrm{CaO}_{\text {olivine }}(0.17-0.31 \mathrm{wt} . \%)$ to $\mathrm{CaO}_{\text {melt }}\left(8.7-11.8\right.$ wt.\%) to derive the partition coefficient $\mathrm{D}_{\mathrm{CaO}}{ }^{\mathrm{Ol} / \mathrm{L}}(0.02-0.03)$, and we use $\mathrm{MgO}_{\text {melt }}$ (4.5-9.8 wt.\%) to derive $\mathrm{D}_{\mathrm{CaO}}{ }^{\mathrm{Ol} / \mathrm{L}}(0.03-0.05)$, giving a $\Delta \mathrm{D}_{\mathrm{CaO}}{ }^{\mathrm{O} / \mathrm{L}}$ of $0.01-0.03$. $\mathrm{By}$ applying our derived partition coefficients to Equation 4 of Gavrilenko et al. (2016), we estimate an average $\mathrm{H}_{2} \mathrm{O}$ content of $4.2 \pm 1.3$ wt.\%.

As a secondary estimate, we exploit the $\mathrm{H}_{2} \mathrm{O} / \mathrm{Ce}$ vs. $\mathrm{Ba} / \mathrm{La}$ systematics of Central American arc magmas (Sadofsky et al., 2007) to reconstruct undegassed $\mathrm{H}_{2} \mathrm{O}$ contents at Masaya. $\mathrm{Ba} / \mathrm{La}$ is a convenient tracer of slab fluid contributions in arc magmas, such that higher $\mathrm{Ba} / \mathrm{La}$ ratios indicate higher fluid contributions. Therefore, high $\mathrm{Ba} / \mathrm{La}$ may be expected to be associated with magmas richer in $\mathrm{H}_{2} \mathrm{O}$ and thus having a higher $\mathrm{H}_{2} \mathrm{O} / \mathrm{Ce}$ ratio (Ruscitto et al.,
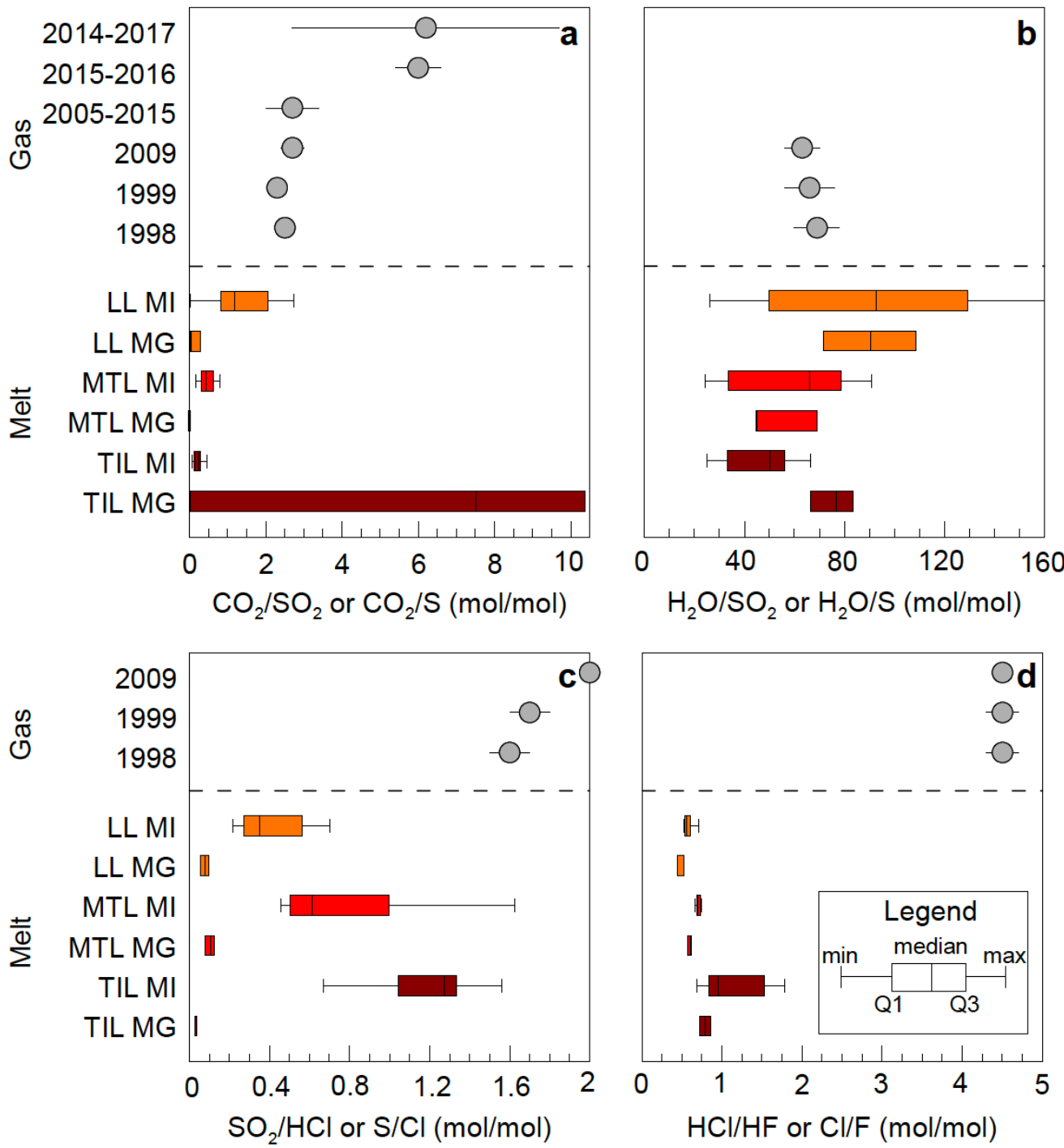

Fig 10. Molar volatile ratios in Masaya gases and melts (a) $\mathrm{CO}_{2} / \mathrm{SO}_{2}$ or $\mathrm{CO}_{2} / \mathrm{S}$, (b) $\mathrm{H}_{2} \mathrm{O} / \mathrm{SO}_{2}$ or $\mathrm{H}_{2} \mathrm{O} / \mathrm{S}$, (c) $\mathrm{SO}_{2} / \mathrm{HCl}$ or $\mathrm{S} / \mathrm{Cl}$, (d) $\mathrm{HCl} / \mathrm{HF}$ or $\mathrm{Cl} / \mathrm{F}$, respectively. From this study, box and whisker plots display melt inclusion and matrix glass molar volatile ratios by eruption, as compared to published timeaveraged gas molar volatile ratios from 1998 and 1999 (Burton, 1999), 2009 (Martin et al., 2010), 2005-2015 time averaged (Aiuppa et al., 2019), 2015-2016 (de Moor et al., 2017), 2014-2017 time averaged (Aiuppa et al., 2018). 
2012). For Central American arc volcanoes, there is a positive, albeit weak correlation $\left(\mathrm{R}^{2}=\right.$ 0.38 ) between $\mathrm{H}_{2} \mathrm{O} / \mathrm{Ce}$ and $\mathrm{Ba} / \mathrm{La}$ that is consistent with this expected relationship (Fig. $8 \mathrm{~b}$ ) (Sadofsky et al., 2007). Masaya melt inclusions, however, record much lower $\mathrm{H}_{2} \mathrm{O} / \mathrm{Ce}(511 \pm$ 354 ) for their $\mathrm{Ba} / \mathrm{La}$ ratios $(74 \pm 11)$ compared to the Central American trend. Even our highest $\mathrm{H}_{2} \mathrm{O} / \mathrm{Ce}$ ratios in TIL melt inclusions $(\sim 1,200)$ are quite low in comparison to other Central American arc magmas which display values up to 10,000. Projecting Masaya's melt inclusions onto the regression line in Fig. 8b yields estimated primary $\mathrm{H}_{2} \mathrm{O} / \mathrm{Ce}$ ratios of 3,600 \pm 600 . Given mean Ce concentrations of $23 \pm 5 \mathrm{ppm}$, this admittedly crude method yields high undegassed $\mathrm{H}_{2} \mathrm{O}$ contents of $8.3 \pm 2.8 \mathrm{wt} . \%$.

As a third estimate, we look to modern gas emissions surveys for Masaya (Martin et al., 2010; Burton et al., 1999) which have measured an $\mathrm{H}_{2} \mathrm{O}$ flux of $\sim 12,000 \mathrm{t} \mathrm{d}^{-1}$ and $\sim 34,600 \mathrm{t} \mathrm{d}^{-1}$, respectively, indicating massive degassing of $\mathrm{H}_{2} \mathrm{O}$ at Masaya. Though, Burton et al. (1999) note a portion of their observed water may come from a meteoric source. Assuming 100\% syneruptive degassing and $0.19 \mathrm{~km}^{3} \mathrm{yr}^{-1}$ magma flux (Zurek et al., 2019), we can extrapolate initial undegassed $\mathrm{H}_{2} \mathrm{O}$ estimates of 2.3 wt.\% and 6.6 wt.\% from these respective $\mathrm{H}_{2} \mathrm{O}$ flux measurements.

Though highly variable, these independent estimates overlap in a very narrow range (5.45.5 wt.\%) and all indicate undegassed water contents significantly exceeding our highest observed value. Pérez et al. (2020) concur that measured melt inclusion $\mathrm{H}_{2} \mathrm{O}$ contents significantly underestimate the original $\mathrm{H}_{2} \mathrm{O}$ contents in their respective melts at Masaya, estimating undegassed $\mathrm{H}_{2} \mathrm{O}$ contents of 5-6 wt.\% in the San Antonio Tephra melt.

\subsection{Temperature and viscosity estimates}

Additional insight into eruptive style may be provided by evaluating pre-eruptive temperature, microlite content, and melt viscosity, which may significantly influence the system's rheological properties. Rapid magma ascent can yield high degrees of undercooling, triggering rapid microlite growth, which can increase effective viscosity and explosivity (Shea \& Hammer, 2013; Arzilli et al., 2019). Pre-eruptive temperatures $<1100^{\circ} \mathrm{C}$ additionally favor syneruptive crystallization and thus may play a critical role in Masaya's explosive potential (Arzilli et al., 2019).

To estimate pre-eruptive magma temperature, we applied our inclusion and glass data to a series of mineral-melt geothermometers (Fig. 11; Putirka, 2008; Waters \& Lange, 2015). In particular, pairs of melt inclusion composition with inclusion-adjacent mineral composition were used, which may reflect the pre-eruptive magma temperature during concurrent crystallization and melt inclusion entrapment. The olivine-melt geothermometer (Eq. 15) of Putirka (2008), yields mean temperatures of $1140 \pm 2^{\circ} \mathrm{C}(\mathrm{n}=4)$ for $\mathrm{LL}, 1120 \pm 1^{\circ} \mathrm{C}(\mathrm{n}=3)$ for MTL, and $1120 \pm$ $10^{\circ} \mathrm{C}(\mathrm{n}=7)$ for TIL. The plagioclase-melt hygrometer of Waters \& Lange (2015) was used as a thermometer by inputting known melt inclusion $\mathrm{H}_{2} \mathrm{O}$ contents to deduce the temperature needed for the hygrometer to equal the known $\mathrm{H}_{2} \mathrm{O}$ content. This method yields slightly lower mean magma temperatures of $1130 \pm 30^{\circ} \mathrm{C}(\mathrm{n}=16)$ for $\mathrm{LL}, 1090 \pm 30^{\circ} \mathrm{C}(\mathrm{n}=11)$ for MTL, and $1080^{\circ} \mathrm{C}$ $(\mathrm{n}=1)$ for TIL. Clinopyroxene-melt thermometry (Eq. 33) of Putirka (2008), yields lower temperatures of $1070^{\circ} \mathrm{C}(\mathrm{n}=1)$ for LL and $1020^{\circ} \mathrm{C}(\mathrm{n}=1)$ for TIL. These somewhat variable temperature estimates indicate a subtle range of crystallization conditions. However, the overall similarity in pre-eruptive magma temperatures within error for lava lake and Plinian samples suggest it is unclear if pre-eruptive temperature is an eruptive style control. 


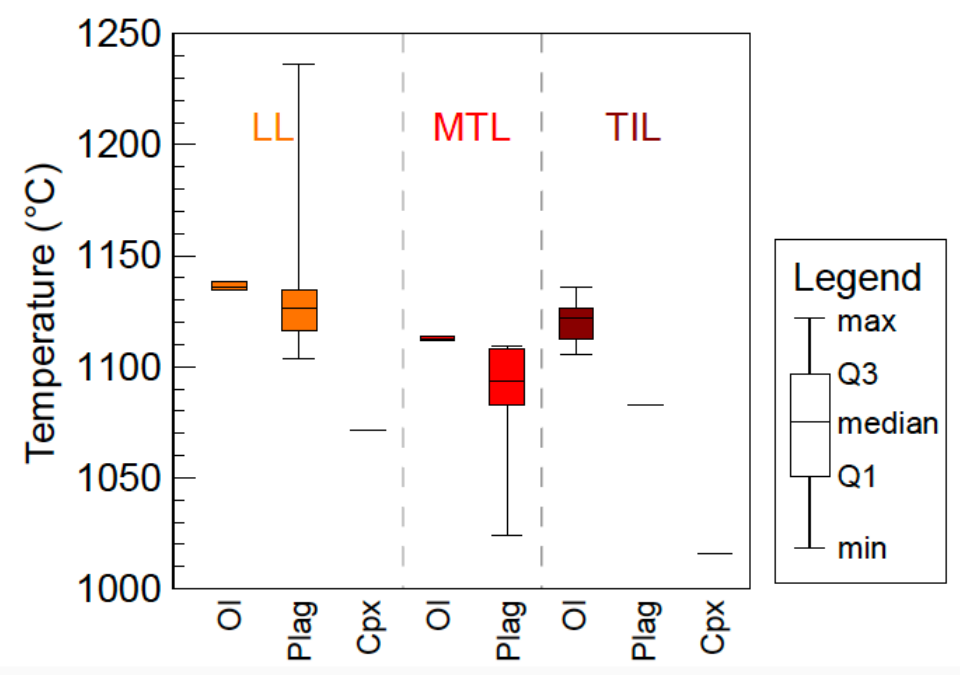

Fig 11. Box and whisker plot display of pre-eruptive magma temperature estimates for lava lake and Plinian samples acquired using a series of mineral-melt geothermometers (Putirka, 2008; Waters \& Lange, 2015) and pairs of melt inclusion composition with inclusion-adjacent mineral composition. Xaxis denotes mineral type.

Evaluation of microlite content from matrix glass BSE images (Fig. 12) indicate syneruptive crystal fraction of approximately 5 vol\% for LL, 15 vol\% for MTL, and 48 vol\% for TIL. We note, however, that our Plinian glasses likely represent a minimum microlite content for each eruption, since glassier samples were preferentially selected for chemical analysis. In comparison, for MTL glass, Bamber et al. (2020) identify heterogeneous inter-mingling regions of 20-50 vol\% microlite content, with adjacent microlite-poor and microlite-rich sections bounded by oxides. Using the crystal-free viscosity model of Giordano et al. (2008), mean glass composition, and magma temperature for each eruption, we calculate melt viscosities of $10^{2} \mathrm{~Pa} \cdot \mathrm{s}$ for both LL and MTL, and $10^{3} \mathrm{~Pa} \cdot \mathrm{s}$ for TIL. By integrating our estimated microlite vol $\%$ to the ConFlow 1.0.5 model (Mastin, 2002), we obtain a minimum effective viscosity of $10^{2} \mathrm{~Pa} \cdot \mathrm{s}$ for both LL and MTL, and $10^{4} \mathrm{~Pa} \cdot \mathrm{s}$ for TIL, indicating that extensive microlite crystallization in the TIL magma likely increased its effective viscosity and potential for explosivity. Likewise, Bamber et al.'s (2020) MTL crystallization experiments estimate a minimum 1-5 minutes of substantial microlite crystallization (20-50 vol\%) during rapid ascent could potentially increasing magma viscosity from $10^{2} \mathrm{~Pa} \cdot \mathrm{s}$ to $10^{6} \mathrm{~Pa} \cdot \mathrm{s}$, promoting fragmentation and increased explosivity.

Lava lake and Plinian temperature estimates, though somewhat variable, approach the critical temperatures favoring syn-eruptive microlite growth. However, only the Plinian glasses contain substantial microlite contents, which may be evidence that Plinian magmas experienced significant viscosity and rheological changes in the conduit during ascent.

\subsection{A thin line between open-conduit conditions and Plinian eruptions at Masaya?}

Overall, our results reveal very little difference between magmas feeding the current lava lake and Holocene Plinian eruptions at Masaya. For both these contrasting styles of activity, we infer that a sustained supply of volatile-rich magma $\left(\sim 5.5 \mathrm{wt} . \% \mathrm{H}_{2} \mathrm{O}\right)$ from depth undergoes extensive pre-eruptive degassing and homogenization in a shallow ( $<4 \mathrm{~km}$ depth) magma reservoir before ascent to the surface. In each case, pre-eruptive temperature estimates generally overlap, and viscosity estimates prior to microlite growth are similarly low, within one order of 


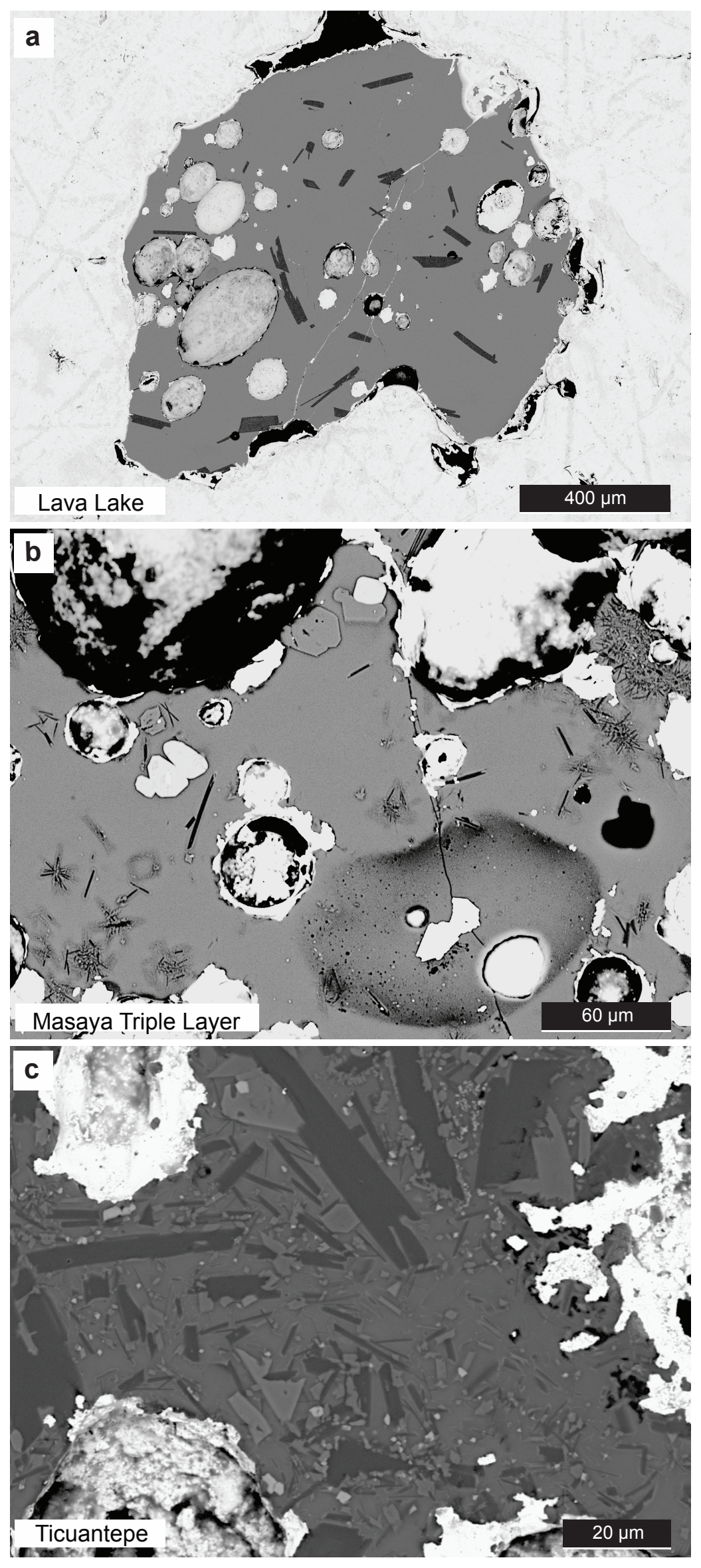

Fig. 12. BSE images of matrix glass chips from lava lake and Plinian samples, illustrating the varying degrees of syneruptive microlite growth. Microlite crystal fraction of approximately $5 \mathrm{vol} \%$ for LL, $15 \mathrm{vol} \%$ for MTL, and $48 \mathrm{vol} \%$ for TIL. 
magnitude. These results are consistent with published geochemical, gas, geophysical, and structural data indicating the presence of a large, shallow reservoir beneath the caldera (Fig. 9b; Bamber et al., 2020; Aiuppa et al., 2018; Stephens et al., 2017; Obermann et al., 2019; Metaxian et al., 1994). Our data confirm that pre-eruptive dissolved volatile contents are not the culprit for eruptive style - basaltic arc magmas commonly show much higher volatile concentrations yet do not erupt as explosively as Masaya's (e.g., Roggensack et al., 1997). However, a key difference between lava lake and Plinian samples is their late-stage degassing history. Lava lake samples endured greater quantities of low-pressure degassing, with respect to Plinian samples, including greater Cl-degassing during second-boiling. We propose a model in which eruptive style is controlled in a top-down manner, whereby the state of the uppermost plumbing system modulates the late-stage decompression path of magma, and temporary sealing of the conduit may lead to transition to explosive behavior (Fig. 13).

During open-conduit conditions, extensive pre-eruptive degassing and homogenization in a shallow reservoir is reflected in the LL melt inclusions which record extremely low volatile concentrations $\left(<0.8 \mathrm{wt} . \% \mathrm{H}_{2} \mathrm{O}\right)$, indicating a $\mathrm{P}_{\text {sat }}$ range of $8-139 \mathrm{MPa}(0.3-5.2 \mathrm{~km})$. Our data suggest that magma is allowed to slowly ascend in the conduit and degas quiescently to really low pressures, with one melt inclusion yielding $\mathrm{P}_{\text {sat }}$ as low as $8 \mathrm{MPa}(0.3 \mathrm{~km})$. Slow ascent yields low degrees of undercooling and prevents significant microlite growth. Within the open-conduit, bi-directional convective flow allows buoyant gas-rich magma to ascend and degas through the open vent, while gas-poor magma descends back into the reservoir, creating a somewhat steadystate of degassing, preventing eruption (Fig. 13a) (Stix, 2007; Stevenson \& Blake, 1998).
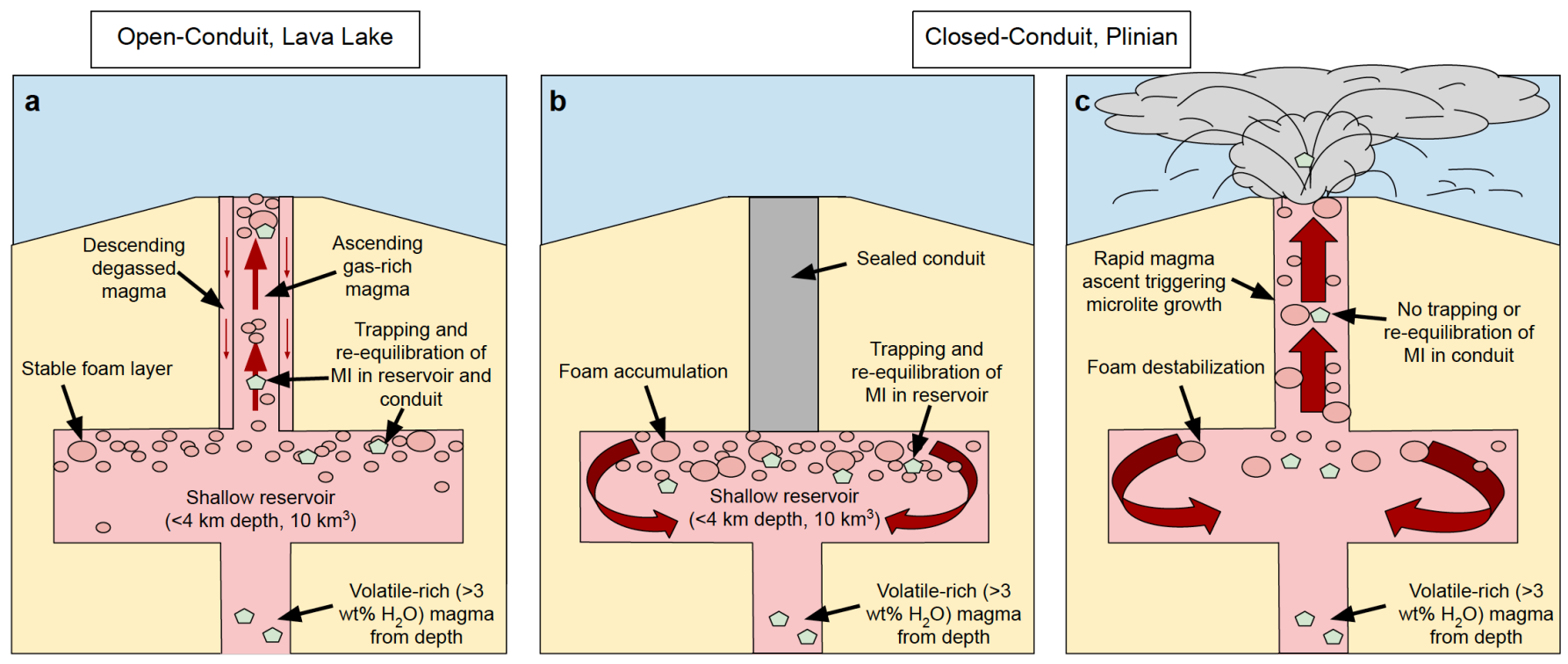

Fig. 13. Schematic diagram of potential storage and ascent conditions within Masaya (Diagram modified from Stix, 2007). We propose eruptive style is modulated in a top-down manner. (a) During open-conduit conditions, deep-sourced volatile-rich magma ascends to a shallow $<4 \mathrm{~km}$ reservoir where melt inclusion trapping, and re-equilibration occur; vigorous convective degassing in the open conduit allows the volcano to remain in a somewhat steady-state, preventing eruption. (b) Assuming closed-conduit conditions and high gas accumulation (similar to modern rates) in the shallow reservoir, pressure build-up and catastrophic foam destabilization could prime the volcano for an explosion eruption. (c) Magma stored at these slightly deeper, though still shallow $<4 \mathrm{~km}$ depths, would then be allowed to ascend rapidly without time for additional melt inclusion trapping or reequilibration, leading to greater undercooling, and promotion of rapid microlite growth. Red circles represent bubbles, green symbols represent crystal-hosts. 
For Plinian eruptions, however, our results suggest the uppermost part of the plumbing system, i.e. the conduit, had become efficiently sealed, such that magma was constrained to the magma reservoir at 1-4 km depth (Fig. 13b). Under such a lid, crystallization and degassinginduced pressure build-up in the shallow magma reservoir, and catastrophic foam destabilization, could prime the volcano for explosive eruption (Burgisser et al. 2011; Roman et al., 2019; Preece et al., 2016). When the conduit seal eventually suddenly breaks, magma rapidly ascends from the reservoir, at rates far exceeding those of open-conduit conditions, without time for additional melt inclusion entrapment or re-equilibration to occur in the shallow conduit (Fig. 13c). Our Plinian inclusions reflect this process by retaining relatively higher volatile concentrations $(<2.3$ wt.\% $\left.\mathrm{H}_{2} \mathrm{O}\right)$ than lava lake inclusions $\left(<0.8 \mathrm{wt} \% \mathrm{H}_{2} \mathrm{O}\right)$. Similarly, Plinian inclusions do not record $\mathrm{P}_{\text {sat }}$ estimates shallower than $31 \mathrm{MPa}(1.2 \mathrm{~km})$ for MTL and $36 \mathrm{MPa}(1.4 \mathrm{~km})$ for TIL (Fig. 9), indicating they have undergone less degassing and homogenization in the shallow conduit prior to eruption. The rapid magma ascent and decompression can induce greater bubble nucleation and growth, which can affect magma density, viscosity, and pressure conditions within the conduit, supporting fragmentation (Gonnermann \& Manga, 2007; Lloyd et al., 2014; Barth et al., 2019). Furthermore, rapid ascent can yield high degrees of undercooling, triggering rapid microlite growth, which can increase effective viscosity and magma explosivity (Shea \& Hammer, 2013; Arzilli et al., 2019; Bamber et al., 2020).

Additional factors such as magma supply rate and tectonic regime might be relevant for interacting with the seal and influencing eruptive style (Cassidy et al., 2018). Even if all Masaya magmas undergo pre-eruptive degassing in a shallow reservoir, we must consider if there are any variations in the total volatile mass supplied by Plinian versus persistent degassing phases that could interact with a seal in different ways. Local tectonics may also play a key role in the multiple occurrence of Plinian-style eruptions at Masaya, as Masaya is proximate to major faults and pull-apart structures that are generated by regional extensional in the Nicaragua depression, and thus may influence the stress field within the system (Funk et al., 2009).

This top-down mechanism, temporarily sealing the system, may explain the explosivity of persistently degassing volcanoes such as Etna and Masaya. We thus propose a thin line between steady-state open-conduit conditions characterized by quiescent degassing and lava lake activity, and transition to highly explosive behavior at Masaya.

\section{Conclusions}

To evaluate the controls on eruptive style at Masaya volcano, we have constrained preeruptive conditions of two Plinian eruptions - the Masaya Triple Layer and Ticuantepe - as compared to recent lava lake activity. Our results reveal systematic differences in pre-eruptive volatile contents for lava lake and Plinian samples, which indicate the culprit for high explosivity does not appear to be high initial volatile contents. In fact, even for Masaya's explosive Plinian eruptions, the magma has been significantly degassed at shallow depth $<4 \mathrm{~km}$ before being mobilized to erupt. The transition between passive degassing and Plinian activity at basaltic volcanoes may only require a subtle change in system behavior. We propose a top-down mechanism, whereby temporary or partial sealing of the uppermost plumbing system coupled with high gas accumulation in a shallow reservoir could drive over pressurization and catastrophic foam destabilization, triggering fragmentation and explosive eruption. 


\section{Acknowledgements}

I would like to thank Dr. Marc-Antoine Longpré, for his valuable mentoring, instruction, and feedback throughout the research process. I am grateful to Instituto Nicaragüense de Estudios Territoriales (INETER) personnel particularly Martha Ibarra Carcache, for providing lava lake samples, as well as colleagues at GEOMAR Helmholtz Centre for Ocean Research, Dr. Steffen Kutterolf and Dr. Wendy Pérez, for proving Plinian samples and data. Dr. Brian Monteleone, Dr. Adrian Fiege, and Dr. Louise Bolge provided valuable support during SIMS, EMPA, and LA-ICP-MS analysis, respectively. Feedback provided by committee members, Dr. Allan Ludman and Dr. Ben Black, and discussions with Samantha Tramontano, John Zayac, and Dr. Shuo Ding helped shape this paper. This work was supported by funding from NSF Award \# 1650379 to M.A. Longpré.

\section{References}

Aiuppa, A., Baker, D. R. \& Webster, J. D. Halogens in volcanic systems. Chemical Geology 263, $1-18$ (2009).

Aiuppa, A. et al. Tracking Formation of a Lava Lake From Ground and Space: Masaya Volcano (Nicaragua), 2014-2017. Geochemistry, Geophysics, Geosystems 496-515 (2018). doi:10.1002/2017GC007227

Aiuppa, A., Fischer, T. P., Plank, T. \& Bani, P. CO 2 flux emissions from the Earth's most actively degassing volcanoes, 2005-2015. Scientific Reports 9, 2005-2015 (2019).

Anderson, A.T., Newman, S., Williams, S.N., Druitt, T.H., Skirius, C., and Stolper, E. $\mathrm{H}_{2} \mathrm{O}, \mathrm{CO}_{2}$, $\mathrm{Cl}$, and gas in Plinian and ash-flow Bishop rhyolite. Geology, 17, 221-225 (1989).

Arzilli, F. et al. Magma fragmentation in highly explosive basaltic eruptions induced by rapid crystallization. Nature Geoscience 12, (2019).

Bamber, E. C. et al. Pre- and syn-eruptive conditions of a basaltic Plinian eruption at Masaya Volcano, Nicaragua: The Masaya Triple Layer (2.1 ka). Journal of Volcanology and Geothermal Research 392, 106761 (2020).

Barth, A., Newcombe, M., Plank, T., Gonnermann, H., Hajimirza, S., Soto, G.J., Saballos, A., Hauri, E. Magma decompression rate correlates with explosivity at basaltic volcanoes constraints from water diffusion in olivine. Journal of Volcanology and Geothermal Research. 387, 106664 (2019).

Bolge L. L., Carr M. J., Milidakis K. I., Lindsay F. N., Fiegenson M. D., Correlating Geochemistry, Tectonics, and Volcanic Volume Along the Central American Volcanic Front. Geochemistry Geophysics Geosystems 10, (2009). doi: 10.1029/2009GC002704 
Bucholz, C. E., Gaetani, G. A., Behn, M. D. \& Shimizu, N. Post-entrapment modification of volatiles and oxygen fugacity in olivine-hosted melt inclusions. Earth and Planetary Science Letters (2013). doi:10.1016/j.eps1.2013.05.033

Burgisser, A., Arbaret, L., Druitt, T. H. \& Giachetti, T. Pre-explosive conduit conditions of the 1997 Vulcanian explosions at Soufrière Hills Volcano, Montserrat: II. Overpressure and depth distributions. Journal of Volcanology and Geothermal Research 199, 193-205 (2011).

Burton, M. R., Horrocks, L. A. \& Francis, P. W. Remote sensing of $\mathrm{CO}_{2}$ and $\mathrm{H}_{2} \mathrm{O}$ emission rates from Masaya volcano Nicaragua. Geology 28, 915-918 (2000).

Carr M. J., Symmetrical and Segmented Variation of Physical and Geochemical Characteristics of the Central American Volcanic Front. Journal of Volcanology and Geothermal Research 20, 231-252 (1984). doi: 10.1016/0377-0273(84)90041-6

Cassidy, M., Manga, M., Cashman, K. \& Bachmann, O. Controls on explosive-effusive volcanic eruption styles. Nature Communications 9, (2018).

Chan L. H., Leeman W. P., You C. F.: Lithium isotopic composition of Central American Volcanic Arc Lavas: Implications for modification of subarc mantle by slab-derived fluids. Chemical Geology 160, 255-280. (1999). doi: 10.1016/S0009-2541(99)00101-1

Colman A., Sinton J.M., Wanless V.D. Constraints from melt inclusions on depths of magma residence at intermediate magma supply along the Galápagos Spreading Center. Earth and Planetary Science Letters 412, 122-131 (2015). doi: 10.1016/j.eps1.2014.12.007

Coltelli, M., Carlo, P. Del \& Vezzoli, L. Discovery of a Plinian basaltic eruption of Roman age at Etna volcano, Italy. Geology 26, 1095-1098 (1998).

Cooper, L. B., Plank T. A., Arculus R. J., Hauri E. H., Hall P. S., Parman S. W. High-Ca Boninites from the active Tonga arc. Journal of Geophysical Research B115 (2010) doi: 10.1029/2009JB006367

Costantini L., Houghton B. F., Bonadonna C. Constraints on eruption dynamics of basaltic explosive activity derived from chemical and microtextural study: The Example of the Fontana Lapilli Plinian Eruption, Nicaragua. Journal of Volcanology and Geothermal Research 189, $207-$ 224 (2010).

Coumans, J. P., Stix, J., Clague, D. A. \& Minarik, W. G. The Magmatic Architecture of Taney Seamount-A, NE Pacific Ocean. Journal of Petrology 56, 1037-1067 (2015).

Danyushevsky, L. V. \& Plechov, P. Petrolog3: Integrated software for modeling crystallization processes. Geochemistry, Geophysics, Geosystems 12, 1-32 (2011). 
de Moor, J. M. et al. Sulfur degassing at Erta Ale (Ethiopia) and Masaya (Nicaragua) volcanoes: Implications for degassing processes and oxygen fugacities of basaltic systems. Geochemistry, Geophysics, Geosystems 14, 4076-4108 (2013).

de Moor, J. M. et al. A New Sulfur and Carbon Degassing Inventory for the Southern Central American Volcanic Arc: The Importance of Accurate Time-Series Data Sets and Possible Tectonic Processes Responsible for Temporal Variations in Arc-Scale Volatile Emissions. Geochemistry, Geophysics, Geosystems 18, 4437-4468 (2017).

Devine, J. D., Sigurdsson, H., Davis, A. N. \& Self, S. Estimates of sulfur and chlorine yield to the atmosphere from volcanic eruptions and potential climatic effects. Journal of Geophysical Research 89, 6309-6325 (1984).

Esposito, R., Hunter, J., Schiffbauer, J. D., Shimizu, N. \& Bodnar, R. J. An assessment of the reliability of melt inclusions as recorders of the pre-eruptive volatile content of magmas. American Mineralogist 99, 976-998 (2014).

Funk, J., Mann, P., McIntosh, K. \& Stephens, J. Cenozoic tectonics of the Nicaraguan depression, Nicaragua, and Median trough, El Salvador, based on seismic-reflection profiling and remote-sensing data. Bulletin of the Geological Society of America 121, 1491-1521 (2009).

Gaetani, G.A., O'Leary, J.A., Shimizu, N., Bucholz, C.E., Newville, M., Rapid reequilibration of $\mathrm{H} 2 \mathrm{O}$ and oxygen fugacity in olivine-hosted melt inclusions. Geology 40 (10), 915-918 (2012)

Gavrilenko, M. et al. A Calcium-in-Olivine Geohygrometer and its Application to Subduction Zone Magmatism. Journal Of Petrology 57, 1811-1832 (2016).

Giordano, D., Russell, J. K. \& Dingwell, D. B. Viscosity of magmatic liquids: A model. Earth and Planetary Science Letters 271, 123-134 (2008).

Girona, T., Costa, F. \& Schubert, G. Degassing during quiescence as a trigger of magma ascent and volcanic eruptions. Scientific Reports 5, 1-7 (2015).

Goepfert, K. \& Gardner, J. E. Influence of pre-eruptive storage conditions and volatile contents on explosive Plinian style eruptions of basic magma. Bulletin of Volcanology 72, 511-521 (2010).

Gonnermann, H. M. \& Manga, M. The Fluid Mechanics Inside a Volcano. Annual Review of Fluid Mechanics 39, 321-356 (2007).

Hauri, E., Wang, J., Dixon, J.E., King, P.L., Mandeville, C., Newman, S., SIMS analysis of volatiles in silicate glasses: 1 . Calibration, matrix effects and comparisons with FTIR. Chemical Geology 183, 99-114 (2002). doi:10.1016/s0009-2541(01)00375-8

Houghton, B. F. \& Gonnermann, H. M. Basaltic explosive volcanism: Constraints from deposits and models. Chemie der Erde 68, 117-140 (2008). 
Iacono-Marziano, G., Morizet, Y., Le Trong, E. \& Gaillard, F. New experimental data and semiempirical parameterization of $\mathrm{H} 2 \mathrm{O}-\mathrm{CO} 2$ solubility in mafic melts. Geochimica et Cosmochimica Acta 97, 1-23 (2012).

Jochum, K. P. et al. Reference Values Following ISO Guidelines for Frequently Requested Rock Reference Materials. Geostandards and Geoanalytical Research 40, 333-350 (2016).

Kent, A. J. R. Melt Inclusions in Basaltic and Related Volcanic Rocks. Reviews in Mineralogy and Geochemistry 69, 273-331 (2008).

Kutterolf, S. et al. Pacific offshore record of plinian arc volcanism in Central America: 3. Application to forearc geology. Geochemistry, Geophysics, Geosystems 9, 1-14 (2008).

Kutterolf, S. et al. Bromine and chlorine emissions from Plinian eruptions along the Central American Volcanic Arc: From source to atmosphere. Earth and Planetary Science Letters 429, 234-246 (2015).

Lanari, P. et al. Computers \& Geosciences XMapTools: A MATLAB (C) -based program for electron microprobe X-ray image processing and geothermobarometry. Computers and Geosciences 62, 227-240 (2014).

Lanari, P., Vho, A., Bovay, T., Airaghi, L., Centrella, S., Quantitative compositional mapping of mineral phases by electron probe micro-analyser. Geological Society of London, Special Publications 478, 39-63 (2019).

Lesne, P. et al. Experimental simulation of closed-system degassing in the system basalt- $\mathrm{H}_{2} \mathrm{O}-$ $\mathrm{CO}_{2}$-S-Cl. Journal of Petrology 52, 1737-1762 (2011).

Lloyd, A. S., Plank, T., Ruprecht, P., Hauri, E. H. \& Rose, W. Volatile loss from melt inclusions in pyroclasts of differing sizes. Contributions to Mineralogy and Petrology 165, 129-153 (2013).

Lloyd, A. S. et al. NanoSIMS results from olivine-hosted melt embayments: Magma ascent rate during explosive basaltic eruptions. Journal of Volcanology and Geothermal Research 283, 1-18 (2014).

Lowenstern, J.B., Melt inclusions come of age: Volatiles, Volcanoes, and Sorby's Legacy. In: De Vivo, B., Bodnar, R.J. (Eds.), Melt Inclusions in Volcanic Systems: Methods, Applications and Problems. Developments in Volcanology. Elsevier Press, Amsterdam, pp. 1-22 (2003). https://doi.org/10.1016/S1871-644X(03)80021-9

Martin, R. S. et al. A total volatile inventory for Masaya Volcano, Nicaragua. Journal of Geophysical Research: Solid Earth 115, 1-12 (2010).

Mastin, L.G. Insights into volcanic conduit flow from an open-source numerical model. Geochemistry, Geophysics, Geosystems 3, 1-18 (2002) 
Metrich, N. \& Wallace, P. J. Volatile Abundances in Basaltic Magmas and Their Degassing Paths Tracked by Melt Inclusions. Reviews in Mineralogy and Geochemistry 69, 363-402 (2008).

Moore, L. R. Bubbles matter: An assessment of the contribution of vapor bubbles to melt inclusion volatile budgets. American Mineralogist 100, 806-823 (2015).

Moune S., Gauthier P.-J., Delmelle P.: Trace elements in the particulate phase of the plume of Masaya volcano, Nicaragua. Journal of Volcanology and Geothermal Research 193, 232-244. (2010). doi: 10.1016/j.jvolgeores.2010.04.004

Newman, S. \& Lowenstern, J. B. Volatile Calc: a silicate melt - H2O - CO2 solution model written in Visual Basic for excel. Computers and Geosciences 28, 597-604 (2002).

Nielsen, R. L., Michael, P. J. \& Sours-Page, R. Chemical and physical indicators of compromised melt inclusions. Geochimica et Cosmochimica Acta 62, 831-839 (1998).

Palma, J. L., S. Blake, and E. S. Calder, Constraints on the rates of degassing and convection in basaltic open-vent volcanoes, Geochemistry Geophysics Geosystems 12, (2011). doi:10.1029/2011GC003715.

Patino L. C., Carr M. J., Feigenson M. D.: Local and regional variations in Central American Arc Lavas controlled by variations in subducted sediment input. Contributions to Mineralogy and Petrology 138, 265-283. (2000). doi: 10.1007/s004100050562

Pérez, W., Freundt, A., Kutterolf, S. \& Schmincke, H. U. The Masaya Triple Layer: A 2100 year old basaltic multi-episodic Plinian eruption from the Masaya Caldera Complex (Nicaragua). Journal of Volcanology and Geothermal Research 179, 191-205 (2009).

Pérez, W. \& Freundt, A. The youngest highly explosive basaltic eruptions from Masaya Caldera (Nicaragua): Stratigraphy and hazard assessment. Geological Society of America Special Paper, 189-207 (2006).

Pérez, W., Freundt, A., \& Kutterolf, S. The basaltic plinian eruption of the $\sim 6$ ka San Antonio Tephra and formation of the Masaya caldera, Nicaragua. Journal of Volcanology and Geothermal Research 401, (2020).

Pering, T. D. et al. A Rapidly Convecting Lava Lake at Masaya Volcano, Nicaragua. Frontiers in Earth Science 6, 1-11 (2019).

Portnyagin, M., Almeev, R., Matveev, S. \& Holtz, F. Experimental evidence for rapid water exchange between melt inclusions in olivine and host magma. Earth and Planetary Science Letters 272, 541-552 (2008).

Preece, K. et al. Transitions between explosive and effusive phases during the cataclysmic 2010 eruption of Merapi volcano, Java, Indonesia. Bulletin of Volcanology 78, (2016). 
Putirka, K. D. Thermometers and Barometers for Volcanic Systems. Reviews in Mineralogy and Geochemistry 69, 61-120 (2008).

Roggensack, K., Hervig, R. L., McKnight, S. B. \& Williams, S. N. Explosive basaltic volcanism from Cerro Negro volcano: Influence of volatiles on eruptive style. Science 277, 1639-1642 (1997).

Roman, D. C., LaFemina, P. C., Bussard, R., Stephens, K., Wauthier, C., Higgins, M., et al. Mechanisms of unrest and eruption at persistently restless volcanoes: Insights from the 2015 eruption of Telica Volcano, Nicaragua. Geochemistry, Geophysics, Geosystems, 20, (2019).

Ruscitto, D. M., Wallace, P. J., Cooper, L. B. \& Plank, T. Global variations in H2O/Ce: 2. Relationships to arc magma geochemistry and volatile fluxes. Geochemistry, Geophysics, Geosystems 13, (2012).

Sadofsky, S. J., Portnyagin, M., Hoernle, K. \& van den Bogaard, P. Subduction cycling of volatiles and trace elements through the Central American volcanic arc: Evidence from melt inclusions. Contributions to Mineralogy and Petrology 155, 433-456 (2007).

Shea, T. \& Hammer, J. E. Kinetics of cooling- and decompression-induced crystallization in hydrous mafic-intermediate magmas. Journal of Volcanology and Geothermal Research 260, $127-145$ (2013).

Shinohara, H. Excess degassing from volcanoes and its role on eruptive and intrusive activity. Reviews of Geophysics 46, 1-31 (2008).

Sides, I. R., Edmonds, M., Maclennan, J., Swanson, D. A. \& Houghton, B. F. Eruption style at Kilauea Volcano in Hawai'i linked to primary melt composition. Nature Geoscience 7, 464-469 (2014).

Spilliaert, N., Métrich, N. \& Allard, P. S-Cl-F degassing pattern of water-rich alkali basalt: Modelling and relationship with eruption styles on Mount Etna volcano. Earth and Planetary Science Letters 248, 772-786 (2006).

Stevenson, D. S. \& Blake, S. Modelling the dynamics and thermodynamics of volcanic degassing. Bulletin of Volcanology 60, 307-317 (1998).

Stix, J., Gauthier, G. \& Ludden, J. N. A critical look at quantitative laser-ablation ICP-MS analysis of natural and synthetic glasses. The Canadian Mineralogist 33, 435-444 (1995).

Stix, J. Stability and instability of quiescently active volcanoes: The case of Masaya, Nicaragua. Geology 35, 535-538 (2007).

Waters, L. E. \& Lange, R. A. An updated calibration of the plagioclase-liquid hygrometerthermometer applicable to basalts through rhyolites. American Mineralogist 100, 2172-2184 (2015). 
Walker, J. A., Williams, S. N., Kalamarides, R. I. \& Feigenson, M. D. Shallow open-system evolution of basaltic magma beneath a subduction zone volcano: The Masaya Caldera Complex, Nicaragua. Journal of Volcanology and Geothermal Research 56, 379-400 (1993).

Webster, J. D., Baker, D. R. \& Aiuppa, A. Halogens in Mafic and Intermediate-Silica Content Magmas. D.E. Harlov and L. Aranovich (eds.), The Role of Halogens in Terrestrial and Extraterrestrial Geochemical Processes, 307-430 (2018).

Wehrmann, H., Hoernle, K. A., Portnyagin, M. V., Wiedenbeck, M., Heydolph, K. Volcanic $\mathrm{CO}_{2}$ output at the Central American subduction zone inferred from melt inclusions in olivine crystals from mafic tephras, Geochemistry Geophysics Geosystems, 12, (2011) doi: 10.1029/2010GC003412

Williams-Jones, G., Rymer, H. \& Rothery, D. A. Gravity changes and passive SO2 degassing at the Masaya caldera complex, Nicaragua. Journal of Volcanology and Geothermal Research 123, $137-160$ (2003).

Williams, S. N. Plinian airfall deposits of basaltic composition. Geology 11, 211-214 (1983).

Williams, S. N. Geology and eruptive mechanisms of Masaya Caldera Complex, Nicaragua. United States: N. P., (1983). Web.

Witham, F. et al. Computers \& Geosciences SolEx: A model for mixed COHSCl-volatile solubilities and exsolved gas compositions in basalt. Computers and Geosciences 1-11 (2011). doi:10.1016/j.cageo.2011.09.021

Zurek, J., Moune, S., Williams-Jones, G., Vigouroux, N. \& Gauthier, P. J. Melt inclusion evidence for long term steady-state volcanism at Las Sierras-Masaya volcano, Nicaragua. Journal of Volcanology and Geothermal Research 378, 16-28 (2019). 


\section{Appendix}

\section{A1. Supplementary Materials}

\section{S1.1. Sample description \& preparation}

In this study, we discuss 21 melt inclusions from the LL ejecta, of which 16 are plagioclase-hosted, 4 olivine-hosted, and 1 clinopyroxene hosted. These LL melt inclusions are free of vapor bubbles and range in diameter from 18 to $70 \mu \mathrm{m}$ along the short axis, and 20 to 110 $\mu \mathrm{m}$ down the long axis. We discuss 14 melt inclusions from MTL tephra, of which 11 are plagioclase-hosted, and 3 olivine-hosted. Of these, 9 contain at least one vapor bubble, 2 show evidence of crystal growth inside the inclusion, and they range in diameter from 25 to $60 \mu \mathrm{m}$ along the short axis, and 30 to 110 down the long axis. We discuss 11 melt inclusions from TIL tephra, of which 1 is plagioclase-hosted, 9 olivine-hosted, and 1 clinopyroxene hosted. These TIL melt inclusions all contain at least one vapor bubble, 2 show evidence of crystal growth inside the inclusion, 1 shows possible sulfide growth. They range in diameter from 15 to $150 \mu \mathrm{m}$ along the short axis, and 25 to $250 \mu \mathrm{m}$ down the long axis. All selected melt inclusions are randomly distributed within the host crystals. Additionally, we analyzed matrix glass from each eruption and lava lake Pele's hairs. The LL Pele's hairs and LL matrix glass have a glassy texture and generally contain no microlites, the MTL matrix glass contains few microlites, and the TIL matrix glass is microlite-rich. Using BSE images from representative glasses, we performed a modal analysis of the visible microlite content. We found the LL, MTL and TIL glasses contained microlite contents of $5 \mathrm{vol} \%, 15 \mathrm{vol} \%$, and $48 \mathrm{vol} \%$, respectively.

Sampling locations for lava lake lapilli and Plinian tephra are displayed in Figure 1. Lava lake lapilli and Pele's hair samples were collected by Martha Ibarra Carcache on the western part of the Santiago crater, as well as near the crater lookout 2. TIL tephra samples W28A8a2 were collected from E1 layer at outcrop W28 located at $12^{\circ} 11^{\prime} 35.12^{\prime \prime} \mathrm{N}, 86^{\circ} 12^{\prime} 24.45^{\prime \prime} \mathrm{W}$ (cf. Pérez \& Freundt, 2006). At outcrop W12 located at $12^{\circ} 4^{\prime} 3.22^{\prime \prime} \mathrm{N}, 86^{\circ} 16^{\prime} 15.12^{\prime \prime} \mathrm{W}$, MTL tephra samples W12E3 were collected from the C3 layer and samples W12E14 were collected from C10 layer (cf. Pérez \& Freundt, 2006; Pérez et al., 2009).

\section{S1.2. Secondary ion mass spectrometry (SIMS)}

$\mathrm{CO}_{2}, \mathrm{H}_{2} \mathrm{O}, \mathrm{S}, \mathrm{F}$ and $\mathrm{Cl}$ concentrations in 31 plagioclase hosted melt inclusions, 18 olivine hosted melt inclusions, 2 clinopyroxene hosted melt inclusions, 6 matrix glass chips, and 6 Pele's hairs were measured by secondary ion mass spectrometry (SIMS) on a CAMECA IMS 1280 instrument at Woods Hole Oceanographic Institution. Olivine, plagioclase, and clinopyroxene grains with exposed melt inclusions were transferred into an indium metal mount, then given a final polish with a $0.3 \mu \mathrm{m}$ alumina oxide suspension prior to gold coating. We took care to clean the mounts with DI and MilliQ water. The mount was dried and stored overnight in a vacuum oven at $100{ }^{\circ} \mathrm{C}$. The mount was further allowed to outgas in the SIMS machine airlock for $\sim 24$ hours prior to analysis. Sample chamber pressures during analysis were $<7.20 \times 10^{-10} \mathrm{mbar}$.

The main analytical procedure followed that of Hauri et al. (2002). A primary ${ }^{133} \mathrm{Cs}^{+}$ beam was used to produce the detected secondary ions $\left({ }^{12} \mathrm{C},{ }^{16} \mathrm{O}{ }^{1} \mathrm{H},{ }^{19} \mathrm{~F},{ }^{30} \mathrm{Si},{ }^{32} \mathrm{~S}\right.$ and $\left.{ }^{35} \mathrm{Cl}\right)$ under the following analytical conditions: beam current of $\sim 1.18 \mathrm{nA}$, an acceleration voltage of $10 \mathrm{kV}$, a $20 \times 20 \mu \mathrm{m}$ raster area, and $240 \mathrm{~s}$ of pre-sputter. To compensate for any positive charging of the sample surface, an electron beam was used. Counting times of $10 \mathrm{~s}$ were used for ${ }^{12} \mathrm{C}$, and 5 
$\mathrm{s}$ for ${ }^{16} \mathrm{O}^{1} \mathrm{H},{ }^{19} \mathrm{~F},{ }^{30} \mathrm{Si}$ (reference mass), ${ }^{32} \mathrm{~S}$ and ${ }^{35} \mathrm{Cl}$. Data were acquired over five blocks. Calibration curves for ${ }^{12} \mathrm{C} /{ }^{30} \mathrm{Si},{ }^{16} \mathrm{O}{ }^{1} \mathrm{H} /{ }^{30} \mathrm{Si},{ }^{19} \mathrm{~F} /{ }^{30} \mathrm{Si},{ }^{32} \mathrm{~S} /{ }^{30} \mathrm{Si}$ and ${ }^{35} \mathrm{Cl} /{ }^{30} \mathrm{Si}$ versus the respective volatile component were established using eight basaltic to basaltic andesite glass standards (Fig. $\mathrm{S} 1)$. The standard error on the slope of the calibration curves is $1.2 \%$ for $\mathrm{CO}_{2}, 0.6 \%$ for $\mathrm{H}_{2} \mathrm{O}$, $1.0 \%$ for $\mathrm{F}, 1.3 \%$ for $\mathrm{S}$ and $1.8 \%$ for $\mathrm{Cl}$. Spot analysis of the host mineral adjacent to melt inclusions gave $<3$ ppm $\mathrm{CO}_{2},<0.003$ wt. $\% \mathrm{H}_{2} \mathrm{O},<1$ ppm $\mathrm{F},<1 \mathrm{ppm} \mathrm{S}$, and $<1 \mathrm{ppm} \mathrm{Cl}$, demonstrating low analytical backgrounds. To check data quality, relative standard deviation (rsd in \%) vs. the measured isotope ratio (in counts per second) was plotted. The rsd reflects the stability of the signal during the five analysis blocks. Analyses exhibiting rsd larger than 5\% were evaluated block by block to determine if there were any outliers or indications of surface contamination, in such a case the measurement would be discarded.

During our analytical sessions we performed a total of 85 analyses, including 8 in-run standards, 3 mineral "blanks," 11 matrix glass, 9 Pele's hairs, and 54 melt inclusions. The ${ }^{30} \mathrm{Si}$ signal ranged between $6.21 \mathrm{E}+04$ and $4.65 \mathrm{E}+05$ counts per second indicating consistency during our analysis. Repeated in-run analysis $(\mathrm{n}=8)$ of secondary standard ALV519-4-1, a Mid-Ocean Ridge Basaltic glass, during our analytical session produced $162 \pm 4$ ppm $\mathrm{CO}_{2}, 0.15 \pm 0.01 \mathrm{wt} \%$ $\mathrm{H}_{2} 0,105 \pm 2$ ppm F, $862 \pm 14$ ppm S, and $43 \pm 1$ ppm Cl (Fig. S2, Table S5). This agrees well with reference values obtained by Colman et al. (2015), producing a standard error of $1.1 \%$ for $\mathrm{CO}_{2}, 4.0 \%$ for $\mathrm{H}_{2} \mathrm{O}, 2.6 \%$ for $\mathrm{F}, 1.6 \%$ for $\mathrm{S}$, and $2.8 \%$ for $\mathrm{Cl}$.

\section{S1.3. Electron probe micro-analysis (EPMA)}

After SIMS analysis, our samples gold coating was carefully removed, and a carbon coating was applied prior to EPMA analyses. Major element compositions of 31 plagioclase hosted melt inclusions, 18 olivine hosted melt inclusions, 2 clinopyroxene hosted melt inclusions, the 51 host minerals, 6 matrix glass chips, and 6 Pele's hairs were acquired using a 5spectrometer Cameca SX-100 electron microprobe (EPMA) at the American Museum of Natural History. Elements analyzed include $\mathrm{Na}, \mathrm{Al}, \mathrm{Mg}, \mathrm{Si}, \mathrm{K}, \mathrm{P}, \mathrm{Ca}, \mathrm{Ti}, \mathrm{Mn}$, and Fe. The analyses were done using a beam current of $10 \mathrm{nA}$, an acceleration voltage of $15 \mathrm{kV}$, and beam diameters of 5 $\mu \mathrm{m}, 10 \mu \mathrm{m}$, or $15 \mu \mathrm{m}$, depending on the size of the available glass patches. Element signals were calibrated using the following glass standards and element intensity: Jadeite (Na : $96.2 \mathrm{cps} / \mathrm{nA}$ ), Wakefield Diopside (Si : $545.9 \mathrm{cps} / \mathrm{nA}, \mathrm{Ca}: 131.4 \mathrm{cps} / \mathrm{nA})$, Rhodonite (Mn : $157.7 \mathrm{cps} / \mathrm{nA})$, Fayalite (Fe : $280.1 \mathrm{cps} / \mathrm{nA})$, Potassium feldspar (K : $243.4 \mathrm{cps} / \mathrm{nA})$, Lake County Plagioclase (Al : $268.7 \mathrm{cps} / \mathrm{nA})$, San Carlos Olivine (Mg : $372.7 \mathrm{cps} / \mathrm{nA})$, Rutile (Ti : $434.5 \mathrm{cps} / \mathrm{nA}$ ), and $\mathrm{AlPO}_{4}(\mathrm{P}: 159.7 \mathrm{cps} / \mathrm{nA})$.

Throughout our analytical session we performed a total of 378 analyses, including: 107 analyses of in-run glass standards, 78 analyses of in-run mineral standards, 137 of host mineral, 53 of melt inclusions, and 10 of Pele's hairs (Table S1, S4). We utilized the following in-run glass standards: andesite glass AGV-1, basaltic glass VG-2, and basaltic glass P-1326-2. Major elements $>1 \mathrm{wt} . \%$ concentration are measured with accuracy and precision, the standard error (\%) on each in-run standard as compared to known reference values is summarized in Table S6. When measuring the host mineral major element compositions, we chose locations adjacent to the melt inclusions for analysis of any post-entrapment modifications to the melt inclusion chemistry, as well as the host mineral core and rim.

Following EPMA point analysis, we acquired X-ray maps for 12 representative melt inclusions to test for compositional homogeneity within each melt inclusion and across the melt 
inclusion-host interface. The analyses were done using a beam current of $40 \mathrm{nA}$, an acceleration voltage of $15 \mathrm{kV}$, and dwell time of $0.2 \mathrm{sec}$. The beam was rastered over each melt inclusion, recording relative concentration intensity using a step size of $1 \mu \mathrm{m}$. Throughout our analytical session, we used the following in-run mineral standards: San Carlos Olivine, Lake County Plagioclase, Biotite-3, and Hornblende-Kakanui (Table S6).

\section{S1.4. Laser Ablation Inductively Coupled Plasma Mass Spectrometry (LA-ICP-MS)}

After EPMA analysis, our samples carbon coating was carefully removed prior to LAICP-MS analysis. As a final analytical step, trace element concentrations in melt inclusions and matrix glasses were acquired by laser ablation inductively coupled plasma mass spectrometry (LA-ICP-MS) at the Lamont-Doherty Earth Observatory, with a New Wave UP193-FX laser ablation system paired with a Thermo VG PQ ExCell mass spectrometer. Analytical conditions consist of $8-\mathrm{Hz}$ repetition rate and a fluency of $\sim 9.8 \mathrm{~J} / \mathrm{cm}^{2}$ on the sample surface. Melt inclusions were analyzed at various spot sizes $(40 \mu \mathrm{m}, 25 \mu \mathrm{m}$ and $10 \mu \mathrm{m})$ depending on the diameter of the inclusion. Calibration curves were established using three basaltic glass standards, BIR-1, BHVO-2, and BCR-2. Repeated in-run analyses of three calibration standards and two secondary glass standards, P-1326-2 and 519-4-1, indicate that our measurements lie within 4\% standard error for most trace elements.

\section{S1.5. Correction Methods}

To assess potential post-entrapment modification of our melt inclusions, we compared uncorrected melt inclusion compositions with a suite of published bulk rock and matrix glass data and found that some of the olivine-hosted melt inclusions from the TIL eruption fall below the $\mathrm{FeO}$ vs. $\mathrm{SiO}_{2}$ trend defined by these data, indicating post-entrapment Fe loss (Fig. S3). We utilized Petrolog3 (Danyushevsy and Plechov, 2011) to calculate the correction factor required for the olivine-hosted melt inclusions assuming an oxygen fugacity of $1.7 \mathrm{log}$ units above the fayalite-magnetite-quartz buffer (de Moor et al., 2013), host Fo\% content adjacent to melt inclusion, and initial melt $\mathrm{FeO}^{*}$ estimated from a $\mathrm{SiO}_{2}-\mathrm{FeO}_{\mathrm{t}}$ linear regression of the liquid line of descent. The model used for olivine is Danyushevsky (2001); olivine composition is calculated using $\mathrm{K}_{\mathrm{D}}(\mathrm{Fe}-\mathrm{Mg})$ after Toplis 2005; oxygen fugacity is calculated following the model of Kress and Carmichael (1988). The majority of the olivine-hosted melt inclusions fell within a 5\% range for correction indicating little to no Fe loss, except for a few outliers from the TIL eruption indicating up to a $23 \%$ correction (Table S1). These melt inclusions are not considered in our discussion henceforth. Fig. S4 illustrates the melt inclusion compositions before and after performing post-entrapment crystallization and Fe loss corrections.

Using EPMA data and XMapTools 2.5.2 (Lanari et al. 2014; 2019), we acquired X-ray intensity maps of twelve melt inclusions selected to reflect the full compositional range of our samples. A comparison of $\mathrm{Fe}, \mathrm{Mg}$, and $\mathrm{Al}$ intensity across these melt inclusions reveals similar insights to our first method regarding potential concerns of diffusive Fe loss. Most olivine-hosted inclusions display a sharp compositional boundary between the melt inclusion wall and host mineral indicating little to no evidence of diffusive loss (Fig. 3a-c); however, those few that do suffer from diffusive loss show an obvious compositional gradient between the melt inclusion wall and host mineral (Fig. 3d-f). A similar phenomenon is observed with Al in plagioclasehosted melt inclusions, however not as strongly as the Fe-loss in olivine. In the plagioclase- 
hosted melt inclusions, panels (g-i) display relatively homogeneous compositions, while some samples such as panels $(\mathrm{j}-1)$ display compositional gradients approaching the melt inclusion wall. The uncorrected composition of plagioclase-hosted melt inclusions is in good agreement with the corrected composition of olivine-hosted melt inclusions, suggesting that PEC of melt inclusions in plagioclase is limited, if any, and likely does not exceed a few percent. Thus, no correction for PEC in plagioclase-hosted melt inclusions has been undertaken.

\section{S1.6. Degassing Simulations}

We find $\mathrm{P}_{\text {sat }}$ values derived from VolatileCalc (Newman and Lowenstern, 2002) and from the solubility model of Iacono-Marziano (2012) are in general agreement. In the main text, we report the $\mathrm{P}_{\text {sat }}$ from Iacono-Marziano (2012) since this model incorporates melt composition and may thus be somewhat more accurate. We then performed degassing simulations utilizing SolEx (Witham et al., 2011) which is based on Dixon's (1995) model, on which VolatileCalc is also based. Therefore, the isobars derived with SolEx (Fig. 7) should be comparable with $\mathrm{P}_{\text {sat }}$ derived from VolatileCalc. Lesne et al. (2011) shows that VolatileCalc works well for Masaya compositions. We calculate degassing models with SolEx to try to reproduce $\mathrm{H}_{2} \mathrm{O}-\mathrm{Cl}$ and $\mathrm{H}_{2} \mathrm{O}-\mathrm{S}$ trends observed in our melt inclusions (Fig. 7, S7). We simulated both an open system and closed system scenario, though the open system scenario is likely to be more realistic. Our models are calculated using our average matrix glass melt composition $\left(52.38 \mathrm{wt} . \% \mathrm{SiO}_{2}, 14.80\right.$ wt. $\% \mathrm{Al}_{2} \mathrm{O}_{3}, 8.51$ wt. $\% \mathrm{CaO}, 1.61$ wt. $\% \mathrm{~K}_{2} \mathrm{O}, 2.85$ wt. $\% \mathrm{Na}_{2} \mathrm{O}, 4.14$ wt. $\% \mathrm{MgO}, 13.59$ wt.\% $\mathrm{FeO}$ ), and representative starting volatile compositions of 800 ppm $\mathrm{CO}_{2}, 2.3$ wt. $\% \mathrm{H}_{2} \mathrm{O}, 1000$ ppm S, $800 \mathrm{ppm} \mathrm{Cl}$. We used $\mathrm{fO}_{2}$ estimates of $\Delta \mathrm{FMQ}+1.7$ (de Moor et al., 2013). We input an average temperature estimate of $1115^{\circ} \mathrm{C}$ from mineral-liquid geothermometry (Putirka, 2008; Waters \& Lange, 2015) consistent with pre-eruptive temperature estimates of 1097 to $1127^{\circ} \mathrm{C}$ based on olivine-liquid equilibria (de Moor et al., 2013). 


\section{A2. Supplementary Figures}
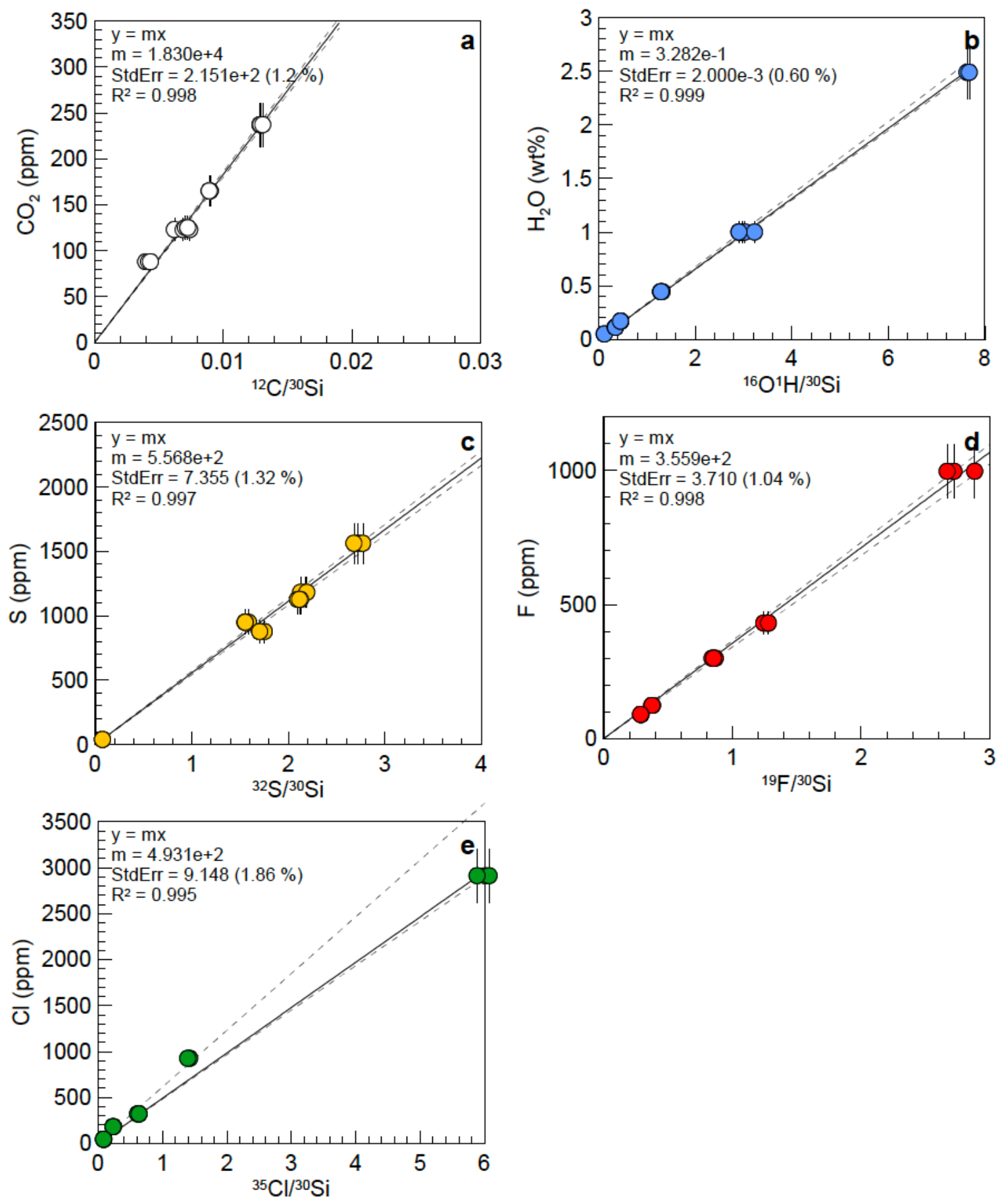

Fig. S1. SIMS analysis standard calibration curves for volatiles. Known concentrations for standards, with $10 \%$ vertical error bars, are plotted against measured isotope ratios (counts per second/counts per second). Linear regression (solid line), with 95\% confidence interval (dashed line), were plotted through the origin. The slope $(\mathrm{m})$, its standard error (StdErr), and coefficient of determine $\left(\mathrm{R}^{2}\right)$, are given for each curve. 

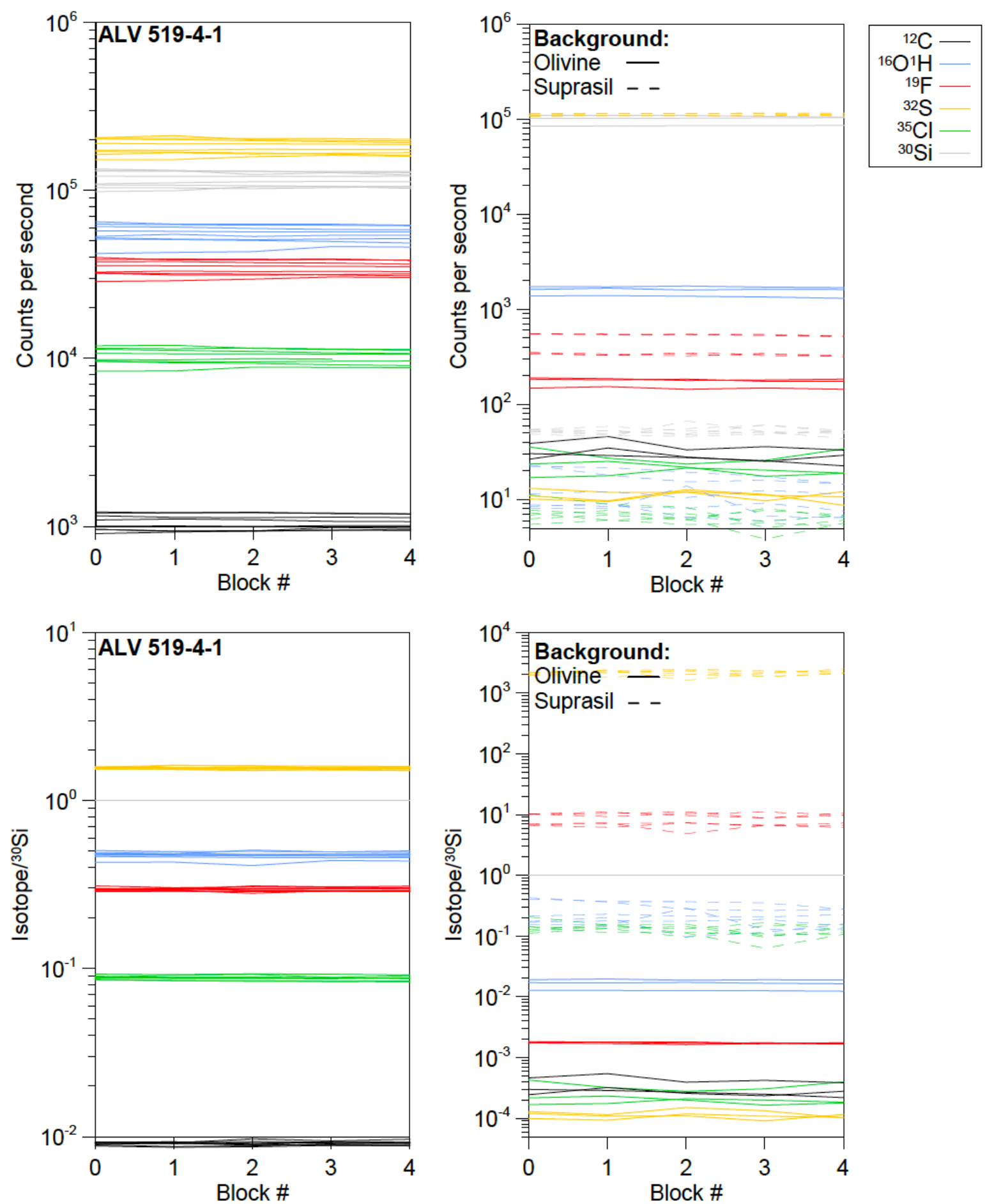

Fig. S2. SIMS in-run analyses of glass standard, ALV 519-4-1 $(\mathrm{n}=8)$, and background, represented by values of olivine host mineral ( $n=3$, solid line) and Suprasil synthetic glass $(n=6$, dashed line). The upper panels present raw counts for all isotopes, while the bottom panels display isotope ${ }^{30} \mathrm{Si}$ ratios. Data were acquired over five blocks. 

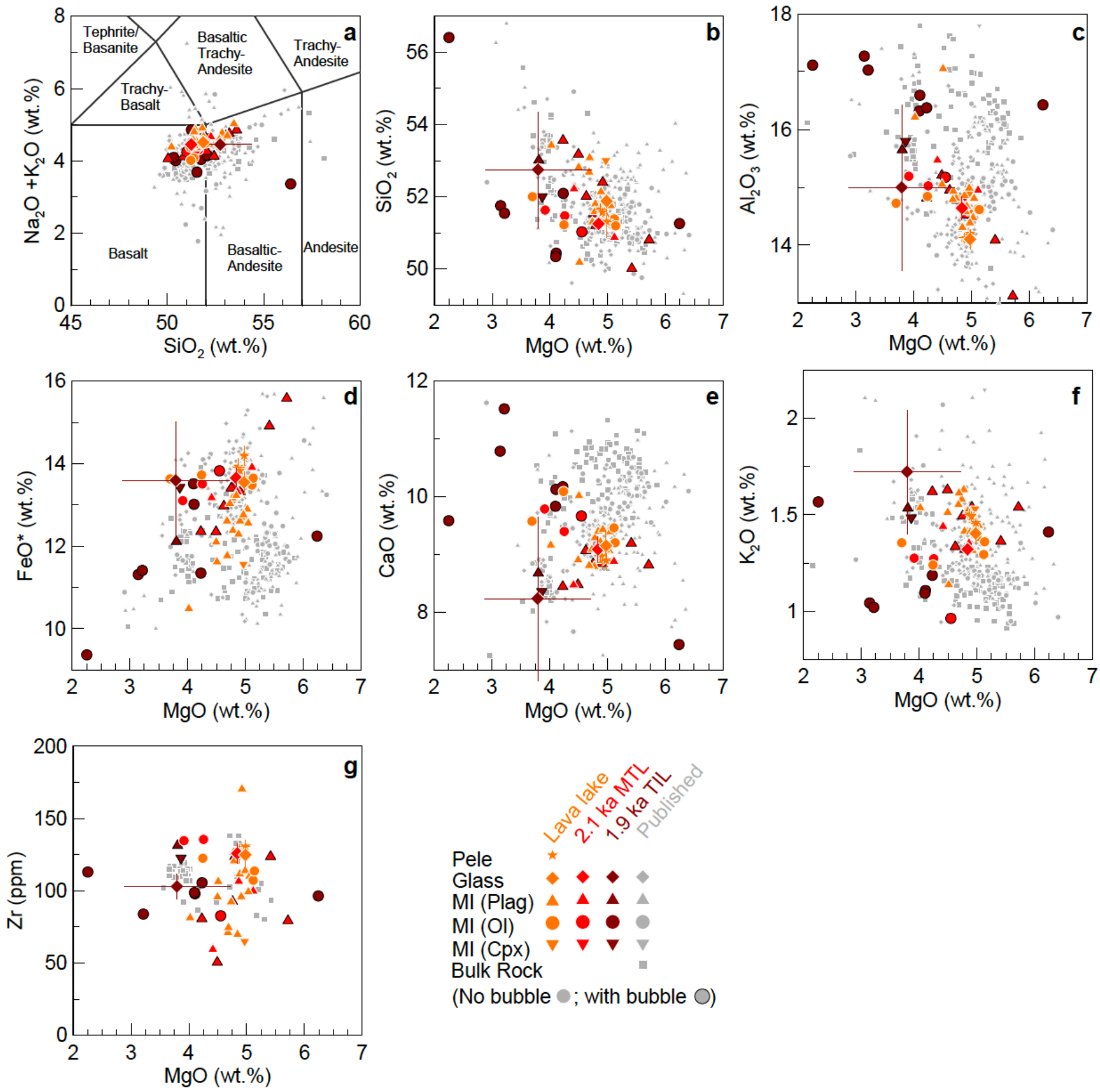

Fig. S3. Normalized major element composition, not yet corrected for PEC, for olivine-, plagioclase-, and clinopyroxene-hosted melt inclusions and matrix glasses for each eruption as compared to previously published bulk rock and glass data from Masaya (Williams, 1983; Carr, 1984; Walker et al., 1993; Sadofsky et al., 2007; Costantini et al., 2010; Goepfert and Gardner, 2010; Zurek et al., 2020; Pérez, unpublished data). (a) TAS diagram, (b) $\mathrm{SiO}_{2}$ vs. $\mathrm{MgO}$, (c) $\mathrm{Al}_{2} \mathrm{O}_{3}$ vs. $\mathrm{MgO}$, (d) $\mathrm{FeO}^{*}$ vs. $\mathrm{MgO}$, (e) $\mathrm{CaO}$ vs. $\mathrm{MgO}$, (f) $\mathrm{K}_{2} \mathrm{O}$ vs. $\mathrm{MgO}$, (g) $\mathrm{Zr}$ vs. $\mathrm{MgO}$. Mean matrix glass and Pele's hair compositions are shown with $1 \sigma$ error bars (not shown when smaller than symbol size). 

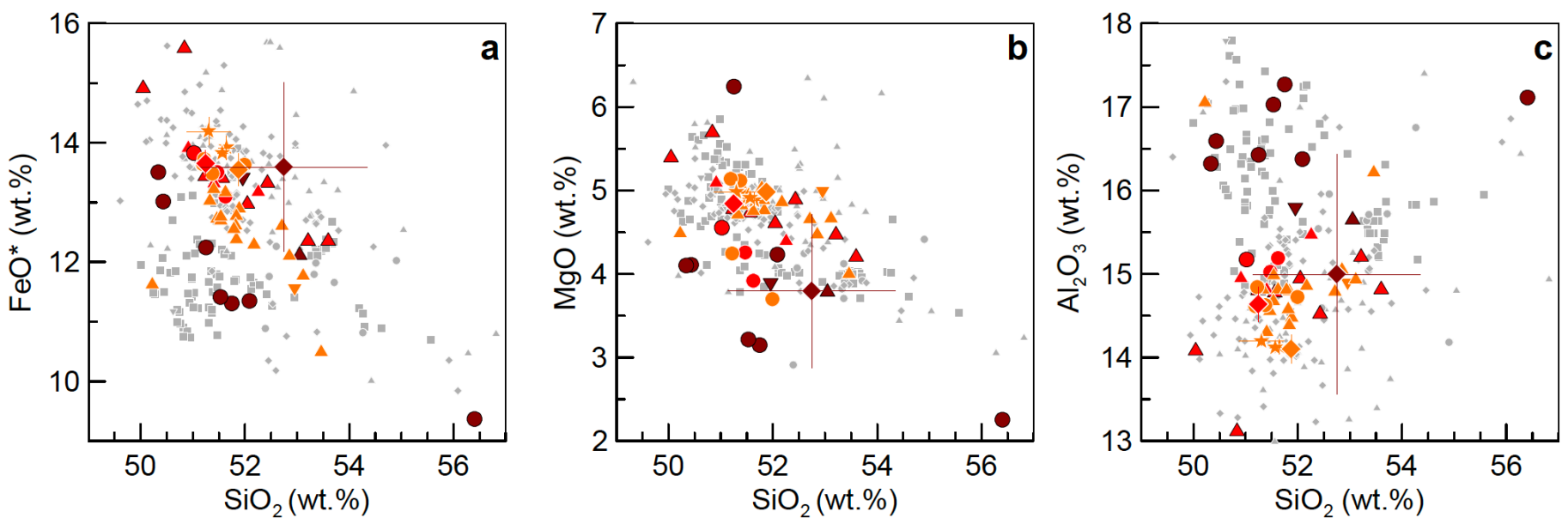

Fig. S4. Normalized major element composition, not yet corrected for PEC, of melt inclusions compared to matrix glass and published bulk rock values to flag any anomalous composition with respect to the liquid line of descent. $\mathrm{FeO}$ vs. $\mathrm{SiO}_{2}$ plot, indicating post-entrapment Fe-loss. Some of the olivine-hosted melt inclusions from the TIL eruption fall below the trend. Symbols as noted in Fig. S3. Mean matrix glass and Pele's hair compositions are shown with $1 \sigma$ error bars (not shown when smaller than symbol size).
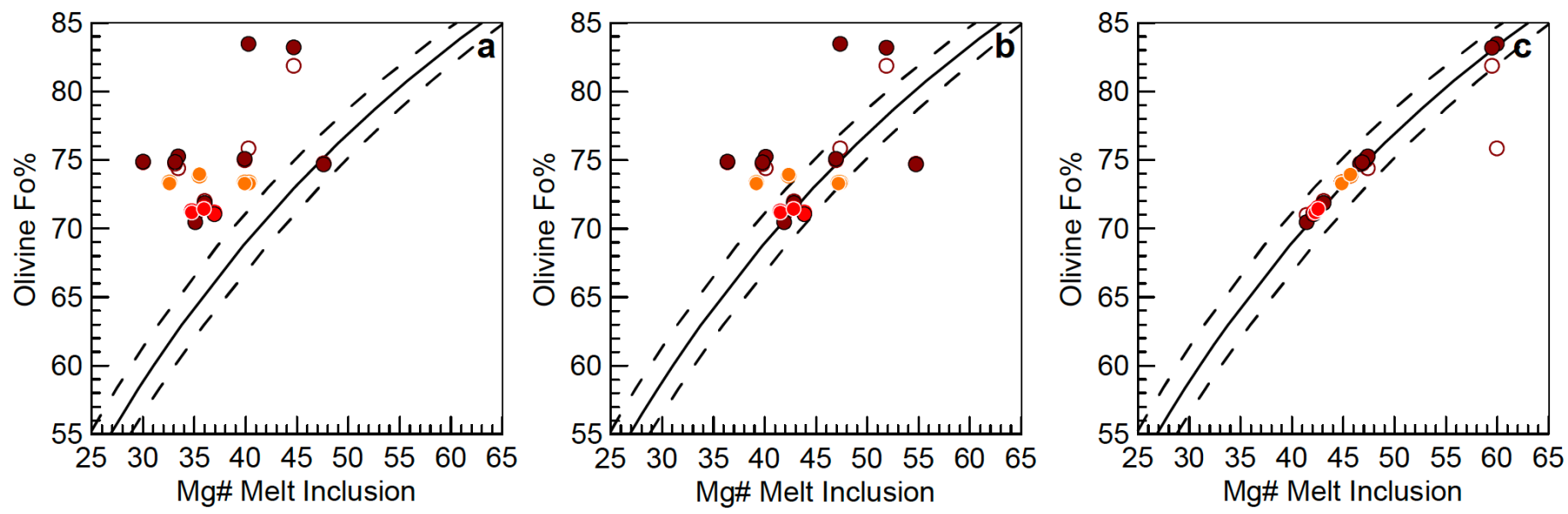

Fig. S5. Rhodes diagram test for mineral-melt equilibrium. Melt inclusion Mg\# vs. olivine forsterite content $(\mathrm{Fo} \%=\mathrm{Mg} \#$ in the olivine). $\mathrm{Fo} \%$ analyzed in the mineral core (filled circle) and in the mineral rim (open circle). Symbols as noted in Fig. 4, S3. Symbols with black rim indicate melt inclusions with vapor bubbles. Olivine-liquid equilibrium field modeled after Roeder and Emslie (1970), using a $\mathrm{K}_{\mathrm{D}}(\mathrm{Fe}-\mathrm{Mg}$ ) of $0.30 \pm 0.03$. Panel (a) shows uncorrected melt $\mathrm{Mg} \#$ calculated assuming all $\mathrm{Fe}$ as $\mathrm{FeO}$. Panel (b) shows uncorrected melt Mg\# calculated using Fe3+/ $\mathrm{Fe}$ obtained assuming $\Delta \mathrm{FMQ}+1.7$ and the model of Kress and Carmichael. Panel (c) shows PEC corrected data using the correction coefficient calculated with Petrolog as described in section 2.5. 

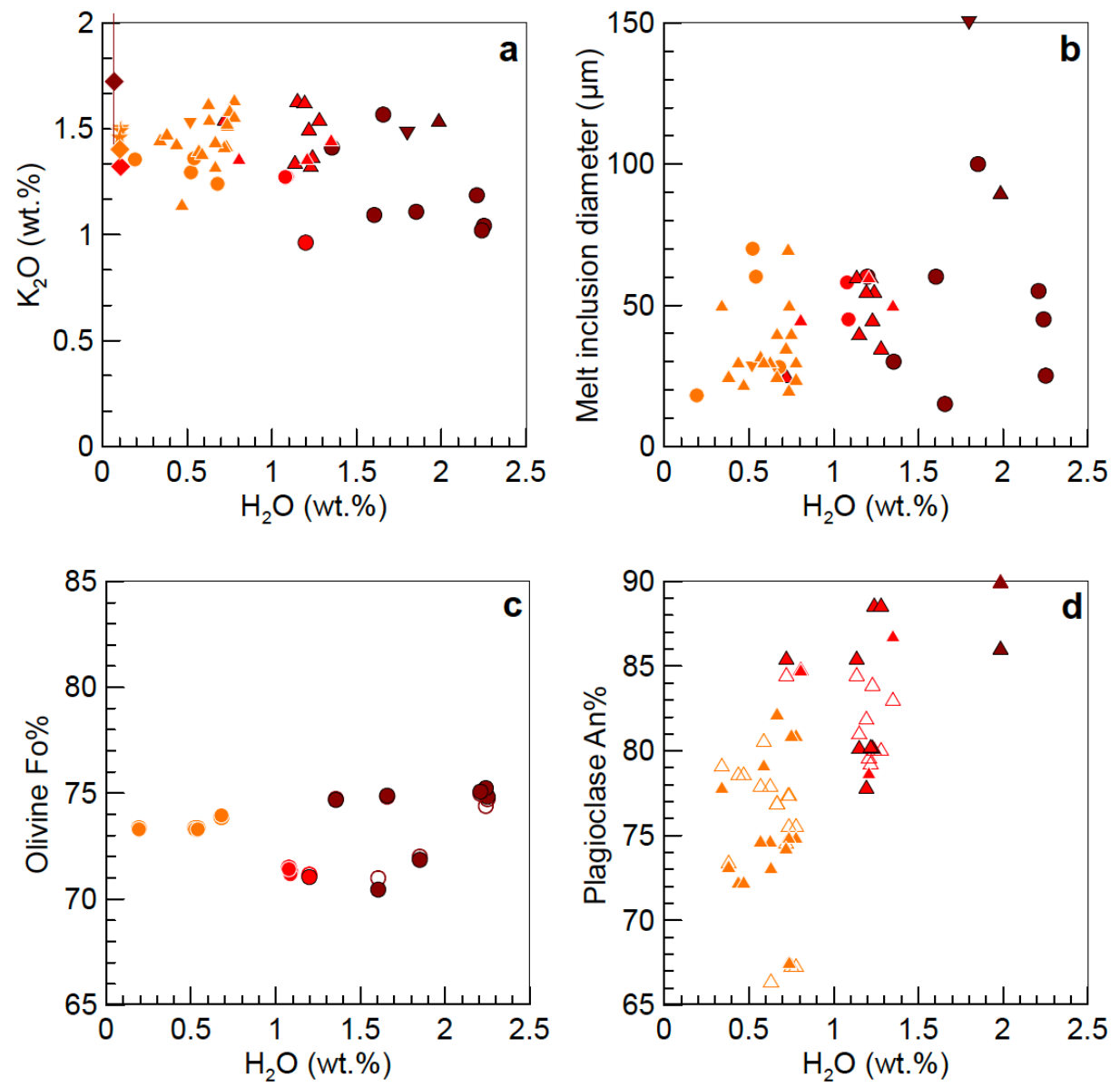

Fig. S6. (a) $\mathrm{H}_{2} \mathrm{O}$ vs. $\mathrm{K}_{2} \mathrm{O}$ variation in all melt inclusions from this study. (b) $\mathrm{H}_{2} \mathrm{O}$ vs. diameter (um) of melt inclusions measured along shortest axis. (c) $\mathrm{H}_{2} \mathrm{O}$ vs. Fo\% variation in olivine host mineral cores (filled circles) and rims (open circles). (d) $\mathrm{H}_{2} \mathrm{O}$ vs. An\% variation in plagioclase host minerals cores (filled circles) and rims (open circles). Symbols as noted in Fig. 4, S3.
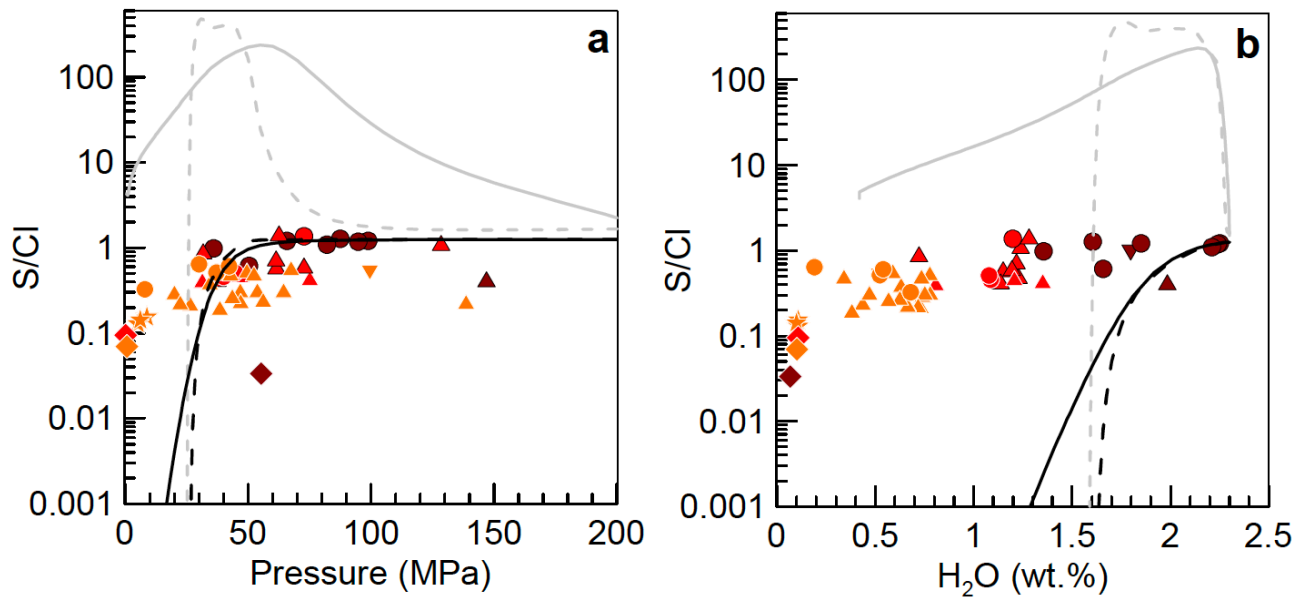

Fig. S7. S/Cl degassing trends calculated with SolEx (Witham et al., 2011). Black line is $\mathrm{S} / \mathrm{Cl}$ melt, gray line is $\mathrm{S} / \mathrm{Cl}$ fluid (mol), solid line is closed system, dashed line is open system. Symbols as noted in Fig. 4, S3. (a) $\mathrm{S} / \mathrm{Cl}$ vs. $\mathrm{P}_{\text {sat }}$ and (b) $\mathrm{S} / \mathrm{Cl}$ vs. $\mathrm{H}_{2} \mathrm{O}$ for melt inclusions, matrix glass, and Pele's hairs. 


\section{A3. Supplementary Tables}

Table S1. Major- and minor element composition of Masaya melt inclusions and glasses obtained by EPMA. Includes raw data, data normalized to $100 \%$, and PEC corrected data from Petrolog3 (Danyushevsy and Plechov, 2011).

\begin{tabular}{|c|c|c|c|c|c|c|c|c|c|c|c|c|c|c|c|}
\hline \multirow[b]{2}{*}{ Sample } & \multirow{2}{*}{$\begin{array}{c}\text { Sample } \\
\text { Type }\end{array}$} & \multirow[b]{2}{*}{ Eruption } & \multirow[b]{2}{*}{$\mathrm{n}$} & \multicolumn{12}{|c|}{ Raw Data (wt.\%) } \\
\hline & & & & $\mathrm{Na}_{2} \mathrm{O}$ & $1 \sigma$ & $\mathrm{Al}_{2} \mathrm{O}_{3}$ & $1 \sigma$ & $\mathrm{MgO}$ & $1 \sigma$ & $\mathrm{SiO}_{2}$ & $1 \sigma$ & $\mathrm{K}_{2} \mathrm{O}$ & $1 \sigma$ & $\mathrm{P}_{2} \mathrm{O}_{5}$ & $1 \sigma$ \\
\hline 23_LL_3A & MI (Plag) & LL & $\mathrm{n}=2$ & 3.17 & 0.11 & 14.58 & 0.03 & 4.71 & 0.07 & 51.01 & 0.09 & 1.40 & 0.00 & 0.38 & 0.01 \\
\hline 23_LL_3B & MI (Plag) & LL & $\mathrm{n}=2$ & 3.22 & 0.16 & 14.74 & 0.06 & 4.40 & 0.11 & 51.68 & 0.14 & 1.49 & 0.01 & 0.27 & 0.03 \\
\hline 39_LL_39_A & MI (Plag) & LL & & 2.77 & & 14.57 & & 4.69 & & 50.70 & & 1.61 & & 0.44 & \\
\hline 39_LL_39_B & MI (Plag) & LL & & 2.97 & & 14.48 & & 4.62 & & 50.11 & & 1.55 & & 0.38 & \\
\hline 38_LL_10_A & MI (Plag) & LL & & 3.41 & & 14.34 & & 4.92 & & 50.63 & & 1.41 & & 0.41 & \\
\hline 38_LL_10_B & MI (Plag) & LL & & 3.25 & & 16.94 & & 4.48 & & 49.83 & & 1.14 & & 0.38 & \\
\hline 37_LL_50_A & MI (Plag) & LL & & 3.01 & & 14.54 & & 4.60 & & 51.75 & & 1.53 & & 0.29 & \\
\hline 37_LL_50_B & MI (Plag) & LL & & 3.18 & & 13.76 & & 4.65 & & 49.36 & & 1.47 & & 0.34 & \\
\hline 32_LL_27 & MI (Plag) & LL & & 3.19 & & 14.19 & & 4.93 & & 50.79 & & 1.42 & & 0.33 & \\
\hline 31_LL_40 & MI (Plag) & LL & & 3.49 & & 16.12 & & 3.99 & & 53.06 & & 1.53 & & 0.24 & \\
\hline 27_LL_19 & MI (Plag) & LL & & 3.02 & & 14.58 & & 4.79 & & 51.13 & & 1.39 & & 0.29 & \\
\hline 25_LL_9 & MI (Plag) & LL & & 3.02 & & 14.44 & & 4.84 & & 50.64 & & 1.30 & & 0.37 & \\
\hline 25_LL_9_B & MI (Plag) & LL & & 3.08 & & 14.15 & & 4.89 & & 50.92 & & 1.42 & & 0.34 & \\
\hline 24_LL_8 & MI (Plag) & LL & & 3.43 & & 14.43 & & 4.85 & & 51.20 & & 1.46 & & 0.36 & \\
\hline 42-LL-20 & MI (Plag) & LL & & 3.05 & & 14.66 & & 4.60 & & 52.06 & & 1.59 & & 0.30 & \\
\hline 42-LL-20-B & MI (Plag) & LL & & 2.95 & & 14.75 & & 4.88 & & 50.65 & & 1.38 & & 0.36 & \\
\hline 33_LL_42 & MI (Plag) & LL & & 3.04 & & 14.35 & & 4.89 & & 50.12 & & 1.34 & & 0.22 & \\
\hline 26_LL_11A & MI (Ol) & LL & & 2.75 & & 14.43 & & 5.05 & & 50.69 & & 1.28 & & 0.31 & \\
\hline 26_LL_11B & $\mathrm{MI}(\mathrm{Ol})$ & LL & $\mathrm{n}=2$ & 2.97 & 0.08 & 14.40 & 0.02 & 5.06 & 0.11 & 50.46 & 0.04 & 1.34 & 0.01 & 0.33 & 0.00 \\
\hline 26_LL_11C & MI (Ol) & LL & & 3.09 & & 14.53 & & 3.65 & & 51.33 & & 1.34 & & 0.27 & \\
\hline 34_LL2_5 & MI (Ol) & LL & & 2.73 & & 14.61 & & 4.18 & & 50.41 & & 1.22 & & 0.33 & \\
\hline 46_LL2_37 & MI (Cpx) & LL & & 2.98 & & 14.35 & & 4.80 & & 51.10 & & 1.47 & & 0.32 & \\
\hline Pele_1116 & Pele & LL & $\mathrm{n}=4$ & 2.90 & 0.09 & 13.91 & 0.07 & 4.80 & 0.10 & 50.85 & 0.16 & 1.48 & 0.03 & 0.32 & 0.04 \\
\hline Pele_0117 & Pele & LL & $\mathrm{n}=4$ & 2.96 & 0.18 & 13.91 & 0.05 & 4.84 & 0.02 & 50.80 & 0.25 & 1.47 & 0.03 & 0.33 & 0.02 \\
\hline Pele_0118 & Pele & LL & $\mathrm{n}=4$ & 2.94 & 0.02 & 13.93 & 0.14 & 4.89 & 0.03 & 50.36 & 0.99 & 1.43 & 0.02 & 0.31 & 0.06 \\
\hline LL-MG & Glass & LL & $\mathrm{n}=4$ & 3.07 & 0.10 & 13.92 & 0.15 & 4.92 & 0.04 & 51.22 & 0.17 & 1.38 & 0.05 & 0.31 & 0.02 \\
\hline
\end{tabular}


Table S1. Continued. Major- and minor element composition of Masaya melt inclusions and glasses obtained by EPMA. Includes raw data, data normalized to 100\%, and PEC corrected data from Petrolog3 (Danyushevsy and Plechov, 2011).

\begin{tabular}{|c|c|c|c|c|c|c|c|c|c|c|c|c|c|}
\hline \multirow[b]{2}{*}{ Sample } & \multirow{2}{*}{$\begin{array}{c}\text { Sample } \\
\text { Type }\end{array}$} & \multirow[b]{2}{*}{ Eruption } & \multirow[b]{2}{*}{$\mathrm{n}$} & \multicolumn{10}{|c|}{ Raw Data (wt.\%) } \\
\hline & & & & $\mathrm{CaO}$ & $1 \sigma$ & $\mathrm{TiO}_{2}$ & $1 \sigma$ & $\mathrm{MnO}$ & $1 \sigma$ & $\mathrm{FeO}$ & $1 \sigma$ & Total & $1 \sigma$ \\
\hline 23_LL_3A & MI (Plag) & LL & $n=2$ & 9.16 & 0.08 & 1.51 & 0.04 & 0.27 & 0.02 & 12.22 & 0.11 & 98.41 & 0.44 \\
\hline $23{ }^{-} \mathrm{LL}^{-} 3 \mathrm{~B}$ & MI (Plag) & LL & $\mathrm{n}=2$ & 8.73 & 0.07 & 1.16 & 0.05 & 0.24 & 0.02 & 11.87 & 0.08 & 97.79 & 0.06 \\
\hline 39_L̄L_39_A & MI (Plag) & LL & & 8.65 & & 1.61 & & 0.20 & & 12.96 & & 98.20 & \\
\hline 39-LL_39_B & MI (Plag) & LL & & 8.90 & & 1.60 & & 0.26 & & 12.75 & & 97.61 & \\
\hline $38 \mathrm{LL} 10 \mathrm{~A}$ & MI (Plag) & LL & & 9.01 & & 1.45 & & 0.25 & & 12.55 & & 98.37 & \\
\hline 38_LL_10_B & MI (Plag) & LL & & 9.96 & & 1.43 & & 0.25 & & 11.56 & & 99.21 & \\
\hline 37_LL_50_A & MI (Plag) & LL & & 8.67 & & 1.11 & & 0.26 & & 12.41 & & 98.16 & \\
\hline 37_LL_50_B & MI (Plag) & LL & & 9.05 & & 1.22 & & 0.26 & & 12.73 & & 96.02 & \\
\hline $3 \overline{2} \_\bar{L} \_27$ & MI (Plag) & LL & & 8.89 & & 1.22 & & 0.27 & & 12.65 & & 97.89 & \\
\hline 31_LL_40 & MI (Plag) & LL & & 9.11 & & 0.99 & & 0.26 & & 10.44 & & 99.25 & \\
\hline 27_LL_19 & MI (Plag) & LL & & 9.05 & & 1.38 & & 0.29 & & 12.08 & & 97.99 & \\
\hline $2 \overline{5} \mathrm{LL}^{-} 9$ & MI (Plag) & LL & & 9.29 & & 1.59 & & 0.27 & & 12.51 & & 98.26 & \\
\hline 25_LL_9_B & MI (Plag) & LL & & 8.94 & & 1.67 & & 0.25 & & 12.58 & & 98.24 & \\
\hline $24 \_L \bar{L} \_\overline{8}$ & MI (Plag) & LL & & 8.81 & & 1.52 & & 0.26 & & 12.49 & & 98.80 & \\
\hline 42--LL-20 & MI (Plag) & LL & & 8.66 & & 1.27 & & 0.27 & & 11.57 & & 98.02 & \\
\hline 42-LL-20-B & MI (Plag) & LL & & 9.06 & & 1.43 & & 0.25 & & 12.57 & & 98.28 & \\
\hline 33_LL_42 & MI (Plag) & LL & & 9.11 & & 1.26 & & 0.26 & & 12.18 & & 96.78 & \\
\hline $26 \overline{\mathrm{L} L} \_11 \mathrm{~A}$ & $\mathrm{MI}(\mathrm{Ol})$ & LL & & 9.33 & & 1.26 & & 0.27 & & 13.30 & & 98.67 & \\
\hline $26 \mathrm{LL}^{-} 11 \mathrm{~B}$ & $\mathrm{MI}(\mathrm{Ol})$ & LL & $\mathrm{n}=2$ & 9.07 & 0.21 & 1.25 & 0.00 & 0.24 & 0.07 & 13.45 & 0.16 & 98.58 & 0.25 \\
\hline 26_LL_11C & MI (Ol) & LL & & 9.45 & & 1.34 & & 0.27 & & 13.45 & & 98.71 & \\
\hline $3 \overline{4} \_$LL2_5 & MI (Ol) & LL & & 9.92 & & 1.24 & & 0.28 & & 13.50 & & 98.42 & \\
\hline 46_LL2_37 & MI (Cpx) & LL & & 8.80 & & 1.26 & & 0.30 & & 11.12 & & 96.50 & \\
\hline Pele_1116 & Pele & LL & $\mathrm{n}=4$ & 8.84 & 0.11 & 1.40 & 0.04 & 0.26 & 0.05 & 13.70 & 0.20 & 98.46 & 0.13 \\
\hline Pele_0117 & Pele & LL & $\mathrm{n}=4$ & 8.84 & 0.19 & 1.45 & 0.04 & 0.31 & 0.03 & 13.62 & 0.09 & 98.52 & 0.42 \\
\hline Pele_0118 & Pele & LL & $\mathrm{n}=4$ & 8.73 & 0.12 & 1.39 & 0.06 & 0.24 & 0.04 & 13.93 & 0.11 & 98.15 & 1.14 \\
\hline LL-MG & Glass & LL & $\mathrm{n}=4$ & 9.04 & 0.06 & 1.30 & 0.06 & 0.21 & 0.07 & 13.38 & 0.27 & 98.75 & 0.16 \\
\hline
\end{tabular}


Table S1. Continued. Major- and minor element composition of Masaya melt inclusions and glasses obtained by EPMA. Includes raw data, data normalized to 100\%, and PEC corrected data from Petrolog3 (Danyushevsy and Plechov, 2011).

\begin{tabular}{|c|c|c|c|c|c|c|c|c|c|c|c|c|c|c|c|}
\hline Sample & $\begin{array}{c}\text { Sample } \\
\text { Type }\end{array}$ & Eruption & $\mathrm{n}$ & $\begin{array}{l}\text { Raw D } \\
\mathrm{Na}_{2} \mathrm{O}\end{array}$ & ta $(\mathrm{wt}$ & $\mathrm{Al}_{2} \mathrm{O}_{3}$ & $1 \sigma$ & $\mathrm{MgO}$ & $1 \sigma$ & $\mathrm{SiO}_{2}$ & $1 \sigma$ & $\mathrm{K}_{2} \mathrm{O}$ & $1 \sigma$ & $\mathrm{P}_{2} \mathrm{O}_{5}$ & $1 \sigma$ \\
\hline 15_MTL_8_4 & MI (Plag) & MTL & & 2.89 & & 14.68 & & 5.02 & & 49.93 & & 1.33 & & 0.33 & \\
\hline 7 MTL $3 \_\overline{10}$ & MI (Plag) & MTL & & 2.88 & & 14.49 & & 4.75 & & 50.22 & & 1.33 & & 0.29 & \\
\hline 8_MTL_5_10 & MI (Plag) & MTL & & 3.19 & & 14.53 & & 4.14 & & 52.48 & & 1.59 & & 0.21 & \\
\hline 19_MTL_3 38 & MI (Plag) & MTL & $\mathrm{n}=2$ & 3.17 & 0.19 & 15.06 & 0.01 & 4.29 & 0.03 & 50.81 & 0.57 & 1.41 & 0.01 & 0.16 & 0.00 \\
\hline 20 MTL 39 & MI (Plag) & MTL & & 3.07 & & 14.79 & & 4.36 & & 51.67 & & 1.59 & & 0.15 & \\
\hline 6_MTL_5_7_A & MI (Plag) & MTL & & 2.54 & & 14.11 & & 4.77 & & 50.88 & & 1.50 & & 0.25 & \\
\hline 6_MTL_5_7_B & MI (Plag) & MTL & $\mathrm{n}=2$ & 2.87 & 0.01 & 14.54 & 0.05 & 4.49 & 0.04 & 50.54 & 0.17 & 1.30 & 0.03 & 0.31 & 0.03 \\
\hline 13_MTL_4_4 & MI (Plag) & MTL & & 3.03 & & 14.37 & & 4.65 & & 49.69 & & 1.29 & & 0.29 & \\
\hline 11_MTL_5_2_A & MI (Plag) & MTL & & 2.65 & & 13.69 & & 5.25 & & 48.55 & & 1.33 & & 0.34 & \\
\hline 11_MTL_5_2_B & MI (Plag) & MTL & & 2.53 & & 12.75 & & 5.55 & & 49.31 & & 1.50 & & 0.26 & \\
\hline 9_MTL_2_6_A & MI (Plag) & MTL & & 2.95 & & 14.43 & & 4.64 & & 50.27 & & 1.46 & & 0.35 & \\
\hline 21_MTL_3_1 & $\mathrm{MI}(\mathrm{Ol})$ & MTL & & 2.97 & & 14.93 & & 3.85 & & 50.74 & & 1.25 & & 0.31 & \\
\hline 22_MTL_7_6 & MI (Ol) & MTL & $\mathrm{n}=2$ & 2.97 & 0.00 & 14.73 & 0.10 & 4.17 & 0.15 & 50.46 & 0.08 & 1.25 & 0.04 & 0.31 & 0.04 \\
\hline 12_MTL_7_2 & MI (Ol) & MTL & & 3.25 & & 15.02 & & 4.51 & & 50.51 & & 0.95 & & 0.24 & \\
\hline MTL-MG & Glass & MTL & $n=4$ & 3.10 & 0.08 & 14.50 & 0.29 & 4.79 & 0.07 & 50.77 & 0.25 & 1.31 & 0.03 & 0.33 & 0.04 \\
\hline 65_TIL_9_9 & MI (Plag) & TIL & & 3.09 & & 15.22 & & 3.70 & & 51.51 & & 1.50 & & 0.31 & \\
\hline 55_TIL_2_8 & $\mathrm{MI}(\mathrm{Ol})$ & TIL & $\mathrm{n}=2$ & 2.85 & 0.11 & 15.76 & 0.11 & 4.07 & 0.18 & 50.14 & 0.44 & 1.14 & 0.00 & 0.27 & 0.02 \\
\hline 58_TIL_4_4 & MI (Ol) & TIL & & 2.36 & & 19.57 & & 3.14 & & 48.55 & & 0.64 & & 0.16 & \\
\hline 61_TIL_4_8 & $\mathrm{MI}(\mathrm{Ol})$ & TIL & & 3.41 & & 16.25 & & 6.17 & & 50.70 & & 1.40 & & 0.28 & \\
\hline 71_TIL 74 & $\mathrm{MI}(\mathrm{Ol})$ & TIL & & 1.75 & & 16.66 & & 2.20 & & 54.92 & & 1.53 & & 0.39 & \\
\hline 54_TIL_4_5 & MI (Ol) & TIL & & 2.56 & & 16.36 & & 3.09 & & 49.53 & & 0.98 & & 0.23 & \\
\hline 73_TIL_2_10 & $\mathrm{MI}(\mathrm{Ol})$ & TIL & & 2.17 & & 19.26 & & 3.82 & & 46.61 & & 0.56 & & 0.13 & \\
\hline 64_TIL_4_6 & MI (Ol) & TIL & & 2.88 & & 16.63 & & 3.03 & & 49.85 & & 1.00 & & 0.26 & \\
\hline 79-TIL-2-4 & $\mathrm{MI}(\mathrm{Ol})$ & TIL & $\mathrm{n}=2$ & 2.82 & 0.03 & 16.15 & 0.06 & 4.00 & 0.09 & 49.11 & 0.02 & 1.08 & 0.04 & 0.30 & 0.00 \\
\hline 80-TIL-7-5 & MI (Ol) & TIL & $\mathrm{n}=2$ & 2.92 & 0.03 & 15.89 & 0.01 & 3.99 & 0.10 & 49.01 & 0.04 & 1.06 & 0.02 & 0.32 & 0.03 \\
\hline 70_TIL_1_8_2 & MI (Cpx) & TIL & $\mathrm{n}=2$ & 3.05 & 0.02 & 15.25 & 0.05 & 3.74 & 0.54 & 50.25 & 0.22 & 1.43 & 0.06 & 0.35 & 0.00 \\
\hline TIL-MG & Glass & TIL & $\mathrm{n}=18$ & 2.56 & 0.45 & 14.11 & 1.16 & 3.56 & 0.82 & 49.79 & 3.57 & 1.63 & 0.36 & 0.39 & 0.07 \\
\hline
\end{tabular}


Table S1. Continued. Major- and minor element composition of Masaya melt inclusions and glasses obtained by EPMA. Includes raw data, data normalized to 100\%, and PEC corrected data from Petrolog3 (Danyushevsy and Plechov, 2011).

\begin{tabular}{|c|c|c|c|c|c|c|c|c|c|c|c|c|c|}
\hline \multirow[b]{2}{*}{ Sample } & \multirow{2}{*}{$\begin{array}{l}\text { Sample } \\
\text { Type }\end{array}$} & \multirow[b]{2}{*}{ Eruption } & \multirow[b]{2}{*}{$\mathrm{n}$} & \multicolumn{10}{|c|}{ Raw Data (wt.\%) } \\
\hline & & & & $\mathrm{CaO}$ & $1 \sigma$ & $\mathrm{TiO}_{2}$ & $1 \sigma$ & $\mathrm{MnO}$ & $1 \sigma$ & $\mathrm{FeO}$ & $1 \sigma$ & Total & $1 \sigma$ \\
\hline 15_MTL_8_4 & MI (Plag) & MTL & & 8.73 & & 1.25 & & 0.24 & & 13.67 & & 98.07 & \\
\hline 7_MTL_3_10 & MI (Plag) & MTL & & 9.03 & & 1.41 & & 0.24 & & 13.04 & & 97.69 & \\
\hline 8_MTL_5_10 & MI (Plag) & MTL & & 8.29 & & 1.13 & & 0.21 & & 12.13 & & 97.91 & \\
\hline 19_MTL_3_8 & MI (Plag) & MTL & $\mathrm{n}=2$ & 8.26 & 0.09 & 0.93 & 0.06 & 0.30 & 0.05 & 12.84 & 0.05 & 97.22 & 0.50 \\
\hline 20_MTL_3_9 & MI (Plag) & MTL & & 8.25 & & 0.97 & & 0.23 & & 12.02 & & 97.10 & \\
\hline 6_MTL55_7_A & MI (Plag) & MTL & & 8.60 & & 1.23 & & 0.19 & & 12.96 & & 97.03 & \\
\hline 6_MTL_5_7_B & MI (Plag) & MTL & $\mathrm{n}=2$ & 8.83 & 0.16 & 1.38 & 0.03 & 0.22 & 0.03 & 12.63 & 0.16 & 97.11 & 0.20 \\
\hline 13_MTL_4_4 & MI (Plag) & MTL & & 8.87 & & 1.46 & & 0.26 & & 13.06 & & 96.97 & \\
\hline 11_MTL_5 $5 \_\overline{2} \_\mathrm{A}$ & MI (Plag) & MTL & & 8.94 & & 1.49 & & 0.28 & & 14.50 & & 97.02 & \\
\hline 11_MTL_5_2_B & MI (Plag) & MTL & & 8.58 & & 1.10 & & 0.29 & & 15.14 & & 96.99 & \\
\hline 9_MTL_2_6_A & MI (Plag) & MTL & & 8.64 & & 1.44 & & 0.21 & & 13.10 & & 97.49 & \\
\hline 21_MTL_3_1 & MI (Ol) & MTL & & 9.62 & & 1.49 & & 0.25 & & 12.87 & & 98.28 & \\
\hline 22_MTL_7_6 & MI (Ol) & MTL & $\mathrm{n}=2$ & 9.21 & 0.05 & 1.42 & 0.09 & 0.26 & 0.02 & 13.24 & 0.13 & 98.03 & 0.10 \\
\hline 12_MTL_7_2 & MI (Ol) & MTL & & 9.57 & & 0.93 & & 0.33 & & 13.69 & & 99.00 & \\
\hline$\overline{\mathrm{M}} \mathrm{TL}-\overline{\mathrm{M}} \overline{\mathrm{C}}$ & Glass & MTL & $\mathrm{n}=4$ & 9.00 & 0.06 & 1.44 & 0.06 & 0.29 & 0.07 & 13.53 & 0.18 & 99.07 & 0.58 \\
\hline 65_TIL_9_9 & MI (Plag) & TIL & & 8.45 & & 1.23 & & 0.31 & & 11.79 & & 97.09 & \\
\hline 55_TIL_2_8 & MI (Ol) & TIL & $\mathrm{n}=2$ & 9.79 & 0.16 & 1.12 & 0.02 & 0.19 & 0.01 & 10.92 & 0.03 & 96.26 & 0.67 \\
\hline 58_TIL_4_4 & MI (Ol) & TIL & & 13.47 & & 0.80 & & 0.20 & & 8.30 & & 97.19 & \\
\hline 61_TIL_4_8 & MI (Ol) & TIL & & 7.36 & & 0.99 & & 0.25 & & 12.11 & & 98.92 & \\
\hline 71_TIL_7_4 & MI (Ol) & TIL & & 9.33 & & 1.29 & & 0.20 & & 9.12 & & 97.37 & \\
\hline 54_TIL_4_5 & MI (Ol) & TIL & & 11.07 & & 1.12 & & 0.20 & & 10.97 & & 96.11 & \\
\hline 73_TIL_2_10 & MI (Ol) & TIL & & 14.61 & & 0.75 & & 0.18 & & 8.42 & & 96.50 & \\
\hline 64_TIL_4_6 & MI (Ol) & TIL & & 10.39 & & 1.18 & & 0.21 & & 10.89 & & 96.33 & \\
\hline 79-TIL-2-4 & MI (Ol) & TIL & $\mathrm{n}=2$ & 9.85 & 0.11 & 1.17 & 0.04 & 0.21 & 0.05 & 12.67 & 0.08 & 97.36 & 0.16 \\
\hline 80-TIL-7-5 & MI (Ol) & TIL & $\mathrm{n}=2$ & 9.57 & 0.05 & 1.17 & 0.06 & 0.27 & 0.02 & 13.15 & 0.22 & 97.36 & 0.14 \\
\hline 70_TIL_1_8_2 & MI (Cpx) & TIL & $\mathrm{n}=2$ & 8.06 & 0.01 & 1.41 & 0.00 & 0.24 & 0.04 & 12.94 & 0.00 & 96.71 & 0.38 \\
\hline TIL-MG & Glass & TIL & $\mathrm{n}=18$ & 7.70 & 0.57 & 1.40 & 0.24 & 0.28 & 0.06 & 12.84 & 1.65 & 94.30 & 4.41 \\
\hline
\end{tabular}


Table S1. Continued. Major- and minor element composition of Masaya melt inclusions and glasses obtained by EPMA. Includes raw data, data normalized to 100\%, and PEC corrected data from Petrolog3 (Danyushevsy and Plechov, 2011).

\begin{tabular}{|c|c|c|c|c|c|c|c|c|c|c|c|c|c|c|c|}
\hline \multirow[b]{2}{*}{ Sample } & \multirow{2}{*}{$\begin{array}{c}\text { Sample } \\
\text { Type }\end{array}$} & \multirow[b]{2}{*}{ Eruption } & \multirow[b]{2}{*}{$\mathrm{n}$} & \multicolumn{12}{|c|}{ Normalized data (wt.\%) } \\
\hline & & & & $\mathrm{Na}_{2} \mathrm{O}$ & $1 \sigma$ & $\mathrm{Al}_{2} \mathrm{O}_{3}$ & $1 \sigma$ & $\mathrm{MgO}$ & $1 \sigma$ & $\mathrm{SiO}_{2}$ & $1 \sigma$ & $\mathrm{K}_{2} \mathrm{O}$ & $1 \sigma$ & $\mathrm{P}_{2} \mathrm{O}_{5}$ & $1 \sigma$ \\
\hline 23_LL_3A & MI (Plag) & LL & $\mathrm{n}=2$ & 3.22 & 0.10 & 14.82 & 0.10 & 4.79 & 0.05 & 51.84 & 0.14 & 1.42 & 0.00 & 0.38 & 0.01 \\
\hline 23_LL_3B & MI (Plag) & LL & $\mathrm{n}=2$ & 3.29 & 0.16 & 15.07 & 0.05 & 4.50 & 0.11 & 52.85 & 0.11 & 1.52 & 0.00 & 0.28 & 0.03 \\
\hline 39_LL_39_A & MI (Plag) & LL & & 2.82 & & 14.84 & & 4.78 & & 51.62 & & 1.64 & & 0.45 & \\
\hline 39_LL_39_B & MI (Plag) & LL & & 3.04 & & 14.84 & & 4.74 & & 51.33 & & 1.59 & & 0.39 & \\
\hline 38_LL_10_A & MI (Plag) & LL & & 3.46 & & 14.58 & & 5.00 & & 51.47 & & 1.43 & & 0.41 & \\
\hline 38_LL_10_B & MI (Plag) & LL & & 3.28 & & 17.08 & & 4.51 & & 50.22 & & 1.14 & & 0.38 & \\
\hline 37_LL_50_A & MI (Plag) & LL & & 3.07 & & 14.81 & & 4.68 & & 52.71 & & 1.56 & & 0.30 & \\
\hline 37_LL_50_B & MI (Plag) & LL & & 3.32 & & 14.33 & & 4.84 & & 51.40 & & 1.53 & & 0.36 & \\
\hline 32_LL_27 & MI (Plag) & LL & & 3.26 & & 14.50 & & 5.03 & & 51.89 & & 1.45 & & 0.34 & \\
\hline 31_LL_40 & MI (Plag) & LL & & 3.52 & & 16.24 & & 4.02 & & 53.46 & & 1.54 & & 0.24 & \\
\hline 27_LL_19 & MI (Plag) & LL & & 3.08 & & 14.88 & & 4.88 & & 52.17 & & 1.42 & & 0.30 & \\
\hline 25_LL_9 & MI (Plag) & LL & & 3.07 & & 14.70 & & 4.92 & & 51.54 & & 1.32 & & 0.37 & \\
\hline 25_LL_9_B & MI (Plag) & LL & & 3.14 & & 14.41 & & 4.98 & & 51.84 & & 1.44 & & 0.34 & \\
\hline $2 \overline{4} \_$LL_ 8 & MI (Plag) & LL & & 3.47 & & 14.60 & & 4.91 & & 51.82 & & 1.48 & & 0.36 & \\
\hline 42-LL-20 & MI (Plag) & LL & & 3.11 & & 14.96 & & 4.69 & & 53.12 & & 1.62 & & 0.31 & \\
\hline 42-LL-20-B & MI (Plag) & LL & & 3.00 & & 15.01 & & 4.97 & & 51.54 & & 1.40 & & 0.37 & \\
\hline 33_LL_42 & MI (Plag) & LL & & 3.14 & & 14.83 & & 5.05 & & 51.79 & & 1.39 & & 0.23 & \\
\hline 26_LL_11A & MI (Ol) & LL & & 2.78 & & 14.63 & & 5.12 & & 51.38 & & 1.29 & & 0.31 & \\
\hline 26_LL_11B & MI (Ol) & LL & $\mathrm{n}=2$ & 3.02 & 0.09 & 14.61 & 0.02 & 5.14 & 0.12 & 51.19 & 0.17 & 1.36 & 0.01 & 0.34 & 0.01 \\
\hline 26_LL_11C & MI (Ol) & LL & & 3.13 & & 14.72 & & 3.70 & & 52.00 & & 1.35 & & 0.27 & \\
\hline 34_LL2_5 & MI (Ol) & LL & & 2.77 & & 14.84 & & 4.24 & & 51.22 & & 1.24 & & 0.34 & \\
\hline 46_LL2_37 & MI (Cpx) & LL & & 3.09 & & 14.87 & & 4.97 & & 52.96 & & 1.52 & & 0.33 & \\
\hline Pele_1116 & Pele & LL & $\mathrm{n}=4$ & 2.94 & 0.09 & 14.13 & 0.08 & 4.88 & 0.10 & 51.65 & 0.15 & 1.50 & 0.03 & 0.32 & 0.04 \\
\hline Pele_0117 & Pele & LL & $\mathrm{n}=4$ & 3.00 & 0.17 & 14.12 & 0.01 & 4.91 & 0.02 & 51.57 & 0.10 & 1.49 & 0.03 & 0.34 & 0.02 \\
\hline Pele_0118 & Pele & LL & $n=4$ & 3.00 & 0.02 & 14.19 & 0.05 & 4.98 & 0.07 & 51.31 & 0.43 & 1.46 & 0.02 & 0.32 & 0.05 \\
\hline LL-MG & Glass & $\mathrm{LL}$ & $\mathrm{n}=4$ & 3.11 & 0.10 & 14.10 & 0.17 & 4.98 & 0.04 & 51.88 & 0.17 & 1.40 & 0.05 & 0.32 & 0.02 \\
\hline
\end{tabular}

Continued 
Table S1. Continued. Major- and minor element composition of Masaya melt inclusions and glasses obtained by EPMA. Includes raw data, data normalized to 100\%, and PEC corrected data from Petrolog3 (Danyushevsy and Plechov, 2011).

\begin{tabular}{|c|c|c|c|c|c|c|c|c|c|c|c|c|c|}
\hline \multirow[b]{2}{*}{ Sample } & \multirow{2}{*}{$\begin{array}{c}\text { Sample } \\
\text { Type }\end{array}$} & \multirow[b]{2}{*}{ Eruption } & \multirow[b]{2}{*}{$\mathrm{n}$} & \multicolumn{10}{|c|}{ Normalized data (wt.\%) } \\
\hline & & & & $\mathrm{CaO}$ & $1 \sigma$ & $\mathrm{TiO}_{2}$ & $1 \sigma$ & $\mathrm{MnO}$ & $1 \sigma$ & $\mathrm{FeO}$ & $1 \sigma$ & Total & $1 \sigma$ \\
\hline 23_LL_3A & MI (Plag) & LL & $\mathrm{n}=2$ & 9.31 & 0.04 & 1.54 & 0.30 & 0.27 & 0.02 & 12.41 & 0.05 & 100.00 & 0.00 \\
\hline 23_LL_3B & MI (Plag) & LL & $\mathrm{n}=2$ & 8.93 & 0.07 & 1.19 & 0.05 & 0.24 & 0.02 & 12.14 & 0.08 & 100.00 & 0.00 \\
\hline 39_LL_39_A & MI (Plag) & LL & & 8.81 & & 1.64 & & 0.20 & & 13.20 & & 100.00 & \\
\hline 39_LL_39_B & MI (Plag) & LL & & 9.11 & & 1.63 & & 0.27 & & 13.06 & & 100.00 & \\
\hline 38_LL_10_A & MI (Plag) & LL & & 9.16 & & 1.47 & & 0.25 & & 12.76 & & 100.00 & \\
\hline 38_LL_10_B & MI (Plag) & LL & & 10.04 & & 1.44 & & 0.25 & & 11.65 & & 100.00 & \\
\hline 37_LL_50_A & MI (Plag) & LL & & 8.83 & & 1.13 & & 0.27 & & 12.64 & & 100.00 & \\
\hline 37_LL_50_B & MI (Plag) & LL & & 9.42 & & 1.27 & & 0.27 & & 13.26 & & 100.00 & \\
\hline 32_LL_27 & MI (Plag) & LL & & 9.09 & & 1.25 & & 0.27 & & 12.93 & & 100.00 & \\
\hline 31_LL_40 & MI (Plag) & LL & & 9.18 & & 1.00 & & 0.26 & & 10.52 & & 100.00 & \\
\hline 27_LL_19 & MI (Plag) & LL & & 9.24 & & 1.41 & & 0.29 & & 12.32 & & 100.00 & \\
\hline 25_LL_9 & MI (Plag) & LL & & 9.45 & & 1.62 & & 0.27 & & 12.73 & & 100.00 & \\
\hline 25_LL_9_B & MI (Plag) & LL & & 9.10 & & 1.70 & & 0.25 & & 12.80 & & 100.00 & \\
\hline 24_LL_8 & MI (Plag) & LL & & 8.92 & & 1.54 & & 0.27 & & 12.64 & & 100.00 & \\
\hline 42-LL-20 & MI (Plag) & LL & & 8.83 & & 1.29 & & 0.28 & & 11.80 & & 100.00 & \\
\hline 42-LL-20-B & MI (Plag) & LL & & 9.21 & & 1.45 & & 0.25 & & 12.79 & & 100.00 & \\
\hline 33_LL_42 & MI (Plag) & LL & & 9.42 & & 1.30 & & 0.27 & & 12.59 & & 100.00 & \\
\hline 26_LL_11A & $\mathrm{MI}(\mathrm{Ol})$ & LL & & 9.46 & & 1.28 & & 0.27 & & 13.48 & & 100.00 & \\
\hline 26_LL_11B & MI (Ol) & LL & $\mathrm{n}=2$ & 9.20 & 0.19 & 1.26 & 0.00 & 0.24 & 0.07 & 13.64 & 0.13 & 100.00 & \\
\hline 26_LL_11C & MI (Ol) & LL & & 9.57 & & 1.35 & & 0.28 & & 13.63 & & 100.00 & \\
\hline 34_LL2_5 & MI (Ol) & LL & & 10.08 & & 1.26 & & 0.28 & & 13.72 & & 100.00 & \\
\hline 46_LL2_37 & MI (Cpx) & LL & & 9.12 & & 1.31 & & 0.31 & & 11.52 & & 100.00 & \\
\hline Pele_1116 & Pele & LL & $\mathrm{n}=4$ & 8.98 & 0.12 & 1.42 & 0.04 & 0.27 & 0.05 & 13.92 & 0.20 & 100.00 & 0.00 \\
\hline Pele_0117 & Pele & LL & $\mathrm{n}=4$ & 8.97 & 0.22 & 1.47 & 0.04 & 0.31 & 0.03 & 13.82 & 0.06 & 100.00 & 0.00 \\
\hline Pele_0118 & Pele & LL & $\mathrm{n}=4$ & 8.89 & 0.18 & 1.42 & 0.05 & 0.25 & 0.04 & 14.19 & 0.24 & 100.00 & 0.00 \\
\hline LL-MG & Glass & LL & $\mathrm{n}=4$ & 9.15 & 0.07 & 1.32 & 0.06 & 0.21 & 0.07 & 13.55 & 0.27 & 100.00 & 0.00 \\
\hline
\end{tabular}


Table S1. Continued. Major- and minor element composition of Masaya melt inclusions and glasses obtained by EPMA. Includes raw data, data normalized to 100\%, and PEC corrected data from Petrolog3 (Danyushevsy and Plechov, 2011).

\begin{tabular}{|c|c|c|c|c|c|c|c|c|c|c|c|c|c|c|c|}
\hline Sample & $\begin{array}{c}\text { Sample } \\
\text { Type }\end{array}$ & Eruption & $\mathrm{n}$ & Norma & zed dc & a (wt.\% & $1 \sigma$ & $\mathrm{MgO}$ & $1 \sigma$ & $\mathrm{SiO}_{2}$ & $1 \sigma$ & $\mathrm{K}_{2} \mathrm{O}$ & $1 \sigma$ & $\mathrm{P}_{2} \mathrm{O}_{5}$ & $1 \sigma$ \\
\hline 15_MTL_8_4 & MI (Plag) & MTL & & 2.95 & & 14.97 & & 5.12 & & 50.91 & & 1.36 & & 0.33 & \\
\hline 7_MTL_3_10 & MI (Plag) & MTL & & 2.95 & & 14.83 & & 4.86 & & 51.41 & & 1.36 & & 0.29 & \\
\hline 8_MTL_5_10 & MI (Plag) & MTL & & 3.26 & & 14.84 & & 4.23 & & 53.60 & & 1.63 & & 0.22 & \\
\hline 19_MTL_3_8 & MI (Plag) & MTL & $\mathrm{n}=2$ & 3.26 & 0.21 & 15.49 & 0.07 & 4.42 & 0.01 & 52.26 & 0.31 & 1.45 & 0.00 & 0.16 & 0.00 \\
\hline 20_MTL_3_9 & MI (Plag) & MTL & & 3.16 & & 15.23 & & 4.49 & & 53.21 & & 1.64 & & 0.15 & \\
\hline 6_MTL_5_7_A & MI (Plag) & MTL & & 2.62 & & 14.55 & & 4.91 & & 52.43 & & 1.55 & & 0.26 & \\
\hline 6_MTL_5_7_B & MI (Plag) & MTL & $\mathrm{n}=2$ & 2.96 & 0.00 & 14.97 & 0.02 & 4.63 & 0.03 & 52.05 & 0.06 & 1.34 & 0.04 & 0.32 & 0.03 \\
\hline 13_MTL_4_4 & MI (Plag) & MTL & & 3.12 & & 14.82 & & 4.80 & & 51.24 & & 1.33 & & 0.30 & \\
\hline 11_MTL_5_2_A & MI (Plag) & MTL & & 2.73 & & 14.11 & & 5.42 & & 50.05 & & 1.37 & & 0.35 & \\
\hline 11_MTL_5_2_B & MI (Plag) & MTL & & 2.60 & & 13.14 & & 5.72 & & 50.84 & & 1.55 & & 0.26 & \\
\hline 9_MTL_2_6_A & MI (Plag) & MTL & & 3.03 & & 14.80 & & 4.75 & & 51.57 & & 1.50 & & 0.36 & \\
\hline 21_MTL_3_1 & MI (Ol) & MTL & & 3.03 & & 15.19 & & 3.92 & & 51.62 & & 1.27 & & 0.32 & \\
\hline 22_MTL_7_6 & $\mathrm{MI}(\mathrm{Ol})$ & MTL & $\mathrm{n}=2$ & 3.03 & 0.00 & 15.02 & 0.09 & 4.26 & 0.16 & 51.47 & 0.03 & 1.27 & 0.04 & 0.32 & 0.04 \\
\hline 12_MTL_7_2 & $\mathrm{MI}(\mathrm{Ol})$ & MTL & & 3.28 & & 15.17 & & 4.55 & & 51.02 & & 0.96 & & 0.24 & \\
\hline MTL-MG & Glass & MTL & $\mathrm{n}=4$ & 3.13 & 0.07 & 14.64 & 0.21 & 4.84 & 0.07 & 51.25 & 0.10 & 1.32 & 0.03 & 0.33 & 0.04 \\
\hline 65_TIL_9_9 & MI (Plag) & TIL & & 3.18 & & 15.67 & & 3.81 & & 53.05 & & 1.54 & & 0.32 & \\
\hline 55_TIL_2_8 & MI (Ol) & TIL & $\mathrm{n}=2$ & 2.96 & 0.10 & 16.37 & 0.00 & 4.23 & 0.22 & 52.09 & 0.09 & 1.19 & 0.01 & 0.28 & 0.02 \\
\hline 58_TIL_4_4 & MI (Ol) & TIL & & 2.42 & & 20.14 & & 3.23 & & 49.95 & & 0.66 & & 0.16 & \\
\hline 61_TIL_4_8 & MI (O1) & TIL & & 3.45 & & 16.42 & & 6.24 & & 51.25 & & 1.41 & & 0.29 & \\
\hline 71_TIL_7_4 & MI (Ol) & TIL & & 1.79 & & 17.11 & & 2.25 & & 56.40 & & 1.57 & & 0.40 & \\
\hline 54_TIL_4_5 & MI (Ol) & TIL & & 2.67 & & 17.03 & & 3.22 & & 51.53 & & 1.02 & & 0.24 & \\
\hline 73_TIL_2_10 & MI (Ol) & TIL & & 2.25 & & 19.96 & & 3.96 & & 48.30 & & 0.58 & & 0.14 & \\
\hline 64_TIL_4_6 & MI (Ol) & TIL & & 2.99 & & 17.27 & & 3.15 & & 51.75 & & 1.04 & & 0.27 & \\
\hline 79-TIL-2-4 & MI (Ol) & TIL & $\mathrm{n}=2$ & 2.90 & 0.02 & 16.59 & 0.03 & 4.11 & 0.10 & 50.44 & 0.07 & 1.11 & 0.03 & 0.31 & 0.01 \\
\hline 80-TIL-7-5 & MI (O1) & TIL & $\mathrm{n}=2$ & 3.00 & 0.04 & 16.32 & 0.03 & 4.10 & 0.10 & 50.34 & 0.04 & 1.09 & 0.02 & 0.33 & 0.03 \\
\hline 70_TIL_1_8_2 & MI (Cpx) & TIL & $\mathrm{n}=2$ & 3.15 & 0.01 & 15.77 & 0.12 & 3.87 & 0.54 & 51.96 & 0.43 & 1.48 & 0.05 & 0.37 & 0.00 \\
\hline TIL-MG & Glass & TIL & $\mathrm{n}=18$ & 2.73 & 0.55 & 15.00 & 1.43 & 3.79 & 0.92 & 52.75 & 1.60 & 1.72 & 0.32 & 0.41 & 0.07 \\
\hline
\end{tabular}


Table S1. Continued. Major- and minor element composition of Masaya melt inclusions and glasses obtained by EPMA. Includes raw data, data normalized to 100\%, and PEC corrected data from Petrolog3 (Danyushevsy and Plechov, 2011).

\begin{tabular}{|c|c|c|c|c|c|c|c|c|c|c|c|c|c|}
\hline \multirow[b]{2}{*}{ Sample } & \multirow{2}{*}{$\begin{array}{l}\text { Sample } \\
\text { Type }\end{array}$} & \multirow[b]{2}{*}{ Eruption } & \multirow[b]{2}{*}{$\mathrm{n}$} & \multicolumn{10}{|c|}{ Normalized data (wt.\%) } \\
\hline & & & & $\mathrm{CaO}$ & $1 \sigma$ & $\mathrm{TiO}_{2}$ & $1 \sigma$ & $\mathrm{MnO}$ & $1 \sigma$ & $\mathrm{FeO}$ & $1 \sigma$ & Total & $1 \sigma$ \\
\hline 15_MTL_8_4 & MI (Plag) & MTL & & 8.90 & & 1.27 & & 0.24 & & 13.94 & & 100.00 & \\
\hline 7_MTL_3_10 & MI (Plag) & MTL & & 9.25 & & 1.45 & & 0.25 & & 13.35 & & 100.00 & \\
\hline 8_MTL_5_10 & MI (Plag) & MTL & & 8.47 & & 1.16 & & 0.22 & & 12.39 & & 100.00 & \\
\hline 19_MTL_3_8 & MI (Plag) & MTL & $\mathrm{n}=2$ & 8.50 & 0.14 & 0.95 & 0.06 & 0.31 & 0.05 & 13.21 & 0.01 & 100.00 & 0.00 \\
\hline 20_MTL_3_9 & MI (Plag) & MTL & & 8.50 & & 1.00 & & 0.23 & & 12.38 & & 100.00 & \\
\hline 6_MTL_5_7_A & MI (Plag) & MTL & & 8.87 & & 1.26 & & 0.20 & & 13.36 & & 100.00 & \\
\hline 6_MTL_5_7_B & MI (Plag) & MTL & $\mathrm{n}=2$ & 9.09 & 0.18 & 1.42 & 0.03 & 0.23 & 0.03 & 13.01 & 0.14 & 100.00 & 0.00 \\
\hline 13_MTL_4_4 & MI (Plag) & MTL & & 9.15 & & 1.51 & & 0.27 & & 13.47 & & 100.00 & \\
\hline 11_MTL_5 $5 \_\overline{2} \_\mathrm{A}$ & MI (Plag) & MTL & & 9.22 & & 1.54 & & 0.29 & & 14.94 & & 100.00 & \\
\hline 11_MTL_5_2_B & MI (Plag) & MTL & & 8.84 & & 1.14 & & 0.30 & & 15.61 & & 100.00 & \\
\hline 9_MTL_2_6_A & MI (Plag) & MTL & & 8.86 & & 1.48 & & 0.22 & & 13.44 & & 100.00 & \\
\hline 21_MTL_3_1 & $\mathrm{MI}(\mathrm{Ol})$ & MTL & & 9.79 & & 1.52 & & 0.25 & & 13.10 & & 100.00 & \\
\hline 22_MTL_7_6 & MI (Ol) & MTL & $\mathrm{n}=2$ & 9.40 & 0.04 & 1.45 & 0.09 & 0.27 & 0.02 & 13.50 & 0.15 & 100.00 & 0.00 \\
\hline 12_MTL_7_2 & MI (Ol) & MTL & & 9.66 & & 0.94 & & 0.33 & & 13.83 & & 100.00 & \\
\hline$\overline{\mathrm{MTL}}-\overline{\mathrm{M}} \overline{\mathrm{C}}$ & Glass & MTL & $\mathrm{n}=4$ & 9.09 & 0.05 & 1.46 & 0.05 & 0.29 & 0.07 & 13.65 & 0.22 & 100.00 & 0.00 \\
\hline 65_TIL_9_9 & MI (Plag) & TIL & & 8.70 & & 1.27 & & 0.32 & & 12.15 & & 100.00 & \\
\hline 55_TIL_2_8 & MI (Ol) & TIL & $\mathrm{n}=2$ & 10.17 & 0.09 & 1.17 & 0.01 & 0.20 & 0.01 & 11.35 & 0.04 & 100.00 & 0.00 \\
\hline 58_TIL_4_4 & MI (Ol) & TIL & & 13.86 & & 0.82 & & 0.21 & & 8.54 & & 100.00 & \\
\hline 61_TIL_4_8 & MI (Ol) & TIL & & 7.44 & & 1.00 & & 0.26 & & 12.24 & & 100.00 & \\
\hline 71_TIL_7_4 & MI (Ol) & TIL & & 9.58 & & 1.32 & & 0.20 & & 9.37 & & 100.00 & \\
\hline 54_TIL_4_5 & MI (Ol) & TIL & & 11.51 & & 1.17 & & 0.20 & & 11.41 & & 100.00 & \\
\hline 73_TIL_2_10 & MI (Ol) & TIL & & 15.14 & & 0.77 & & 0.19 & & 8.72 & & 100.00 & \\
\hline 64_TIL_4_6 & MI (Ol) & TIL & & 10.78 & & 1.22 & & 0.22 & & 11.31 & & 100.00 & \\
\hline 79-TIL-2-4 & MI (Ol) & TIL & $\mathrm{n}=2$ & 10.12 & 0.10 & 1.20 & 0.04 & 0.22 & 0.05 & 13.01 & 0.11 & 100.00 & 0.00 \\
\hline 80-TIL-7-5 & MI (Ol) & TIL & $\mathrm{n}=2$ & 9.83 & 0.07 & 1.21 & 0.07 & 0.28 & 0.02 & 13.51 & 0.20 & 100.00 & 0.00 \\
\hline 70_TIL_1_8_2 & MI (Cpx) & TIL & $\mathrm{n}=2$ & 8.33 & 0.04 & 1.45 & 0.01 & 0.24 & 0.04 & 13.38 & 0.06 & 100.00 & 0.00 \\
\hline TIL-MG & Glass & TIL & $\mathrm{n}=18$ & 8.23 & 0.80 & 1.48 & 0.21 & 0.29 & 0.06 & 13.59 & 1.42 & 100.00 & 0.00 \\
\hline
\end{tabular}


Table S1. Continued. Major- and minor element composition of Masaya melt inclusions and glasses obtained by EPMA. Includes raw data, data normalized to 100\%, and PEC corrected data from Petrolog3 (Danyushevsy and Plechov, 2011).

\begin{tabular}{|c|c|c|c|c|c|c|c|c|c|c|c|c|c|c|c|}
\hline \multirow[b]{2}{*}{ Sample } & \multirow{2}{*}{$\begin{array}{c}\text { Sample } \\
\text { Type }\end{array}$} & \multirow[b]{2}{*}{ Eruption } & \multirow[b]{2}{*}{$\mathrm{n}$} & \multicolumn{12}{|c|}{ PEC Corrected data (wt.\%) } \\
\hline & & & & $\mathrm{Na}_{2} \mathrm{O}$ & $1 \sigma$ & $\mathrm{Al}_{2} \mathrm{O}_{3}$ & $1 \sigma$ & $\mathrm{MgO}$ & $1 \sigma$ & $\mathrm{SiO}_{2}$ & $1 \sigma$ & $\mathrm{K}_{2} \mathrm{O}$ & $1 \sigma$ & $\mathrm{P}_{2} \mathrm{O}_{5}$ & $1 \sigma$ \\
\hline 26_LL_11A & MI (Ol) & LL & & 2.81 & & 14.74 & & 5.07 & & 51.41 & & 1.30 & & 0.31 & \\
\hline 26_LL_11B & MI (Ol) & LL & $\mathrm{n}=2$ & 3.05 & 0.10 & 14.79 & 0.06 & 4.98 & 0.05 & 51.28 & 0.19 & 1.38 & 0.00 & 0.34 & 0.01 \\
\hline 26_LL_11C & MI (Ol) & LL & & 3.08 & & 14.46 & & 4.92 & & 51.77 & & 1.33 & & 0.27 & \\
\hline 34_LL2_5 & MI (Ol) & LL & & 2.73 & & 14.60 & & 5.29 & & 51.02 & & 1.22 & & 0.33 & \\
\hline 21_MTL_3_1 & $\mathrm{MI}(\mathrm{Ol})$ & MTL & & 2.98 & & 14.93 & & 4.49 & & 51.27 & & 1.25 & & 0.31 & \\
\hline 22_MTL_7_6 & MI (Ol) & MTL & $\mathrm{n}=2$ & 3.03 & 0.02 & 15.00 & 0.00 & 4.54 & 0.02 & 51.38 & 0.08 & 1.27 & 0.03 & 0.32 & 0.04 \\
\hline 12_MTL_7_2 & MI (Ol) & MTL & & 3.32 & & 15.34 & & 4.53 & & 51.12 & & 0.97 & & 0.25 & \\
\hline 55 TIL_2_8 & MI (Ol) & TIL & $\mathrm{n}=2$ & 2.78 & 0.08 & 15.38 & 0.04 & 5.55 & 0.07 & 50.98 & 0.06 & 1.11 & 0.01 & 0.27 & 0.02 \\
\hline 58_TIL_4_4 & MI (Ol) & TIL & & 1.86 & & 15.47 & & 9.78 & & 46.81 & & 0.51 & & 0.13 & \\
\hline 61_TIL_4_8 & $\mathrm{MI}(\mathrm{Ol})$ & TIL & & 3.46 & & 16.49 & & 5.30 & & 51.01 & & 1.42 & & 0.29 & \\
\hline 71_TIL_7_4 & MI (Ol) & TIL & & 1.62 & & 15.42 & & 5.34 & & 54.43 & & 1.41 & & 0.36 & \\
\hline 54_TIL_4_5 & MI (Ol) & TIL & & 2.43 & & 15.52 & & 5.75 & & 50.14 & & 0.93 & & 0.22 & \\
\hline 73_TIL_2_10 & MI (Ol) & TIL & & 1.73 & & 15.40 & & 9.79 & & 45.47 & & 0.45 & & 0.11 & \\
\hline 64_TIL_4_6 & MI (Ol) & TIL & & 2.74 & & 15.79 & & 5.52 & & 50.36 & & 0.95 & & 0.24 & \\
\hline 79-TIL-2-4 & $\mathrm{MI}(\mathrm{Ol})$ & TIL & $\mathrm{n}=2$ & 2.81 & 0.03 & 16.07 & 0.05 & 4.88 & 0.09 & 49.87 & 0.05 & 1.07 & 0.03 & 0.30 & 0.00 \\
\hline 80-TIL-7-5 & $\mathrm{MI}(\mathrm{Ol})$ & TIL & $\mathrm{n}=2$ & 2.96 & 0.03 & 16.11 & 0.02 & 4.50 & 0.05 & 50.06 & 0.02 & 1.08 & 0.01 & 0.33 & 0.03 \\
\hline
\end{tabular}

Continued 
Table S1. Continued. Major- and minor element composition of Masaya melt inclusions and glasses obtained by EPMA. Includes raw data, data normalized to 100\%, and PEC corrected data from Petrolog3 (Danyushevsy and Plechov, 2011).

\begin{tabular}{|c|c|c|c|c|c|c|c|c|c|c|c|c|c|c|c|c|}
\hline \multirow[b]{2}{*}{ Sample } & \multirow[b]{2}{*}{$\begin{array}{c}\text { Sample } \\
\text { Type }\end{array}$} & \multirow[b]{2}{*}{ Eruption } & \multirow[b]{2}{*}{$\mathrm{n}$} & \multicolumn{13}{|c|}{ PEC Corrected data (wt.\%) } \\
\hline & & & & $\mathrm{CaO}$ & $1 \sigma$ & $\mathrm{TiO}_{2}$ & $1 \sigma$ & $\mathrm{MnO}$ & $1 \sigma$ & $\mathrm{FeO}$ & $1 \sigma$ & $\mathrm{Fe}_{2} \mathrm{O}_{3}$ & $1 \sigma$ & Total & $1 \sigma$ & $\begin{array}{l}\text { Corr } \\
\text { Coef }\end{array}$ \\
\hline 26_LL_11A & MI (Ol) & $\mathrm{LL}$ & & 9.53 & & 1.29 & & 0.27 & & 9.46 & & 3.83 & & 100.00 & & 1.012 \\
\hline $26{ }^{-} L^{-} 11 \mathrm{~B}$ & $\mathrm{MI}(\mathrm{Ol})$ & LL & $\mathrm{n}=2$ & 9.31 & 0.16 & 1.28 & 0.00 & 0.23 & 0.08 & 9.38 & 0.05 & 3.98 & 0.01 & 100.00 & 0.00 & 1.016 \\
\hline 26_LL_11C & MI (Ol) & LL & & 9.40 & & 1.33 & & 0.28 & & 9.25 & & 3.92 & & 100.00 & & 0.987 \\
\hline $3 \overline{4} \_$LL2_5 & MI (Ol) & LL & & 9.92 & & 1.24 & & 0.29 & & 9.56 & & 3.80 & & 100.00 & & 0.988 \\
\hline $21 \overline{\mathrm{MTL}} 31$ & MI (Ol) & MTL & & 9.62 & & 1.49 & & 0.26 & & 9.27 & & 4.13 & & 100.00 & & 0.987 \\
\hline 22_MTL_7_6 & MI (Ol) & MTL & $\mathrm{n}=2$ & 9.38 & 0.01 & 1.45 & 0.08 & 0.27 & 0.02 & 9.27 & 0.03 & 4.09 & 0.04 & 100.00 & 0.00 & 1.003 \\
\hline 12_MTL_7_2 & MI (Ol) & MTL & & 9.76 & & 0.95 & & 0.33 & & 9.45 & & 3.98 & & 100.00 & & 1.015 \\
\hline $5 \overline{5}$ TIL_2 -8 & MI (Ol) & TIL & $\mathrm{n}=2$ & 9.57 & 0.06 & 1.10 & 0.01 & 0.23 & 0.01 & 9.56 & 0.09 & 3.49 & 0.01 & 100.00 & 0.00 & 0.942 \\
\hline 58_TIL_4 4 & MI (Ol) & TIL & & 10.80 & & 0.63 & & 0.26 & & 10.66 & & 3.09 & & 100.00 & & 0.770 \\
\hline 61_TIL_4_8 & MI (Ol) & TIL & & 7.47 & & 1.00 & & 0.24 & & 9.56 & & 3.76 & & 100.00 & & 1.007 \\
\hline 71_TIL_7_4 & MI (Ol) & TIL & & 8.65 & & 1.19 & & 0.25 & & 8.88 & & 2.45 & & 100.00 & & 0.903 \\
\hline 54 TIL 45 & $\mathrm{MI}(\mathrm{Ol})$ & TIL & & 10.51 & & 1.06 & & 0.24 & & 9.79 & & 3.41 & & 100.00 & & 0.915 \\
\hline 73_TIL_2_10 & MI (Ol) & TIL & & 11.83 & & 0.60 & & 0.25 & & 11.05 & & 3.33 & & 100.00 & & 0.773 \\
\hline 64_TIL_4_6 & MI (Ol) & TIL & & 9.88 & & 1.12 & & 0.26 & & 9.65 & & 3.48 & & 100.00 & & 0.918 \\
\hline 79-TIL-2-4 & MI (Ol) & TIL & $\mathrm{n}=2$ & 9.81 & 0.10 & 1.16 & 0.04 & 0.23 & 0.05 & 9.80 & 0.15 & 3.99 & 0.01 & 100.00 & 0.00 & 0.973 \\
\hline 80-TIL-7-5 & $\mathrm{MI}(\mathrm{Ol})$ & TIL & $\mathrm{n}=2$ & 9.71 & 0.03 & 1.19 & 0.06 & 0.28 & 0.02 & 9.64 & 0.10 & 4.14 & 0.02 & 100.00 & 0.00 & 0.992 \\
\hline
\end{tabular}


Table S2. Volatile contents of Masaya melt inclusions and glasses obtained by SIMS. Includes raw data and PEC correction coefficient derived from Petrolog3 (Danyushevsy and Plechov, 2011).

\begin{tabular}{|c|c|c|c|c|c|c|c|c|c|c|c|c|c|c|}
\hline Sample & $\begin{array}{c}\text { Sample } \\
\text { Type }\end{array}$ & Eruption & $\mathrm{n}$ & $\begin{array}{l}\mathrm{CO}_{2} \\
\mathrm{ppm} \\
\end{array}$ & $1 \sigma$ & $\begin{array}{l}\mathrm{H}_{2} \mathrm{O} \\
\text { wt. } \% \\
\end{array}$ & $1 \sigma$ & $\begin{array}{c}\mathrm{F} \\
\mathrm{ppm}\end{array}$ & $1 \sigma$ & $\begin{array}{c}\mathrm{S} \\
\mathrm{ppm}\end{array}$ & $1 \sigma$ & $\begin{array}{c}\mathrm{Cl} \\
\mathrm{ppm}\end{array}$ & $1 \sigma$ & $\begin{array}{l}\text { Corr } \\
\text { Coef }\end{array}$ \\
\hline 23_LL_3 & MI (Plag) & LL & & 104.09 & & 0.73 & & 308.82 & & 81.44 & & 366.40 & & \\
\hline 23_LL_3_B & MI (Plag) & LL & & 63.07 & & 0.74 & & 323.35 & & 101.82 & & 338.38 & & \\
\hline 39_LL_39 & MI (Plag) & LL & & 250.11 & & 0.78 & & 343.02 & & 110.86 & & 348.14 & & \\
\hline 39_LL_39_B & MI (Plag) & LL & & 223.93 & & 0.75 & & 333.81 & & 109.43 & & 343.51 & & \\
\hline 38_LL_10 & MI (Plag) & LL & & 324.28 & & 0.44 & & 323.36 & & 86.14 & & 352.16 & & \\
\hline 38_LL_10_B & MI (Plag) & LL & & 241.46 & & 0.47 & & 329.18 & & 115.54 & & 362.11 & & \\
\hline 37_LL_50_A & MI (Plag) & LL & & 224.69 & & 0.78 & & 353.52 & & 197.59 & & 365.24 & & \\
\hline 37_LL_50_B & MI (Plag) & LL & & 219.35 & & 0.74 & & 398.43 & & 195.08 & & 392.62 & & \\
\hline 32_LL_27 & MI (Plag) & LL & & 288.71 & & 0.34 & & 375.44 & & 186.58 & & 374.69 & & \\
\hline 31_LL_40 & MI (Plag) & LL & & 155.96 & & 0.63 & & 244.78 & & 134.78 & & 341.65 & & \\
\hline 27_LL_19 & MI (Plag) & LL & & 78.70 & & 0.72 & & 310.26 & & 80.53 & & 352.16 & & \\
\hline 25_LL_9 & MI (Plag) & LL & & 222.72 & & 0.67 & & 258.90 & & 75.22 & & 316.70 & & \\
\hline 25_LL_9_B & MI (Plag) & LL & & 801.01 & & 0.67 & & 275.54 & & 84.88 & & 367.17 & & \\
\hline 24_LL_8 & MI (Plag) & LL & & 214.16 & & 0.38 & & 317.20 & & 62.30 & & 315.76 & & \\
\hline 42_LL_20 & MI (Plag) & LL & & & & 0.63 & & 293.63 & & 82.33 & & 294.63 & & \\
\hline 42_LL_20_B & MI (Plag) & LL & & 212.36 & & 0.57 & & 290.00 & & 82.49 & & 305.26 & & \\
\hline 33_LL_42_A & MI (Plag) & LL & & 358.08 & & 0.59 & & 299.18 & & 211.31 & & 367.34 & & \\
\hline 26_LL_11_A & MI (Ol) & LL & & 164.41 & & 0.52 & & 354.07 & & 184.42 & & 360.72 & & 1.012 \\
\hline 26_LL_11_B & MI (Ol) & LL & & 203.43 & & 0.53 & & 369.13 & & 217.20 & & 362.01 & & 1.016 \\
\hline 26_LL_11_C & $\mathrm{MI}(\mathrm{Ol})$ & LL & & 151.46 & & 0.19 & & 215.34 & & 132.55 & & 208.40 & & 0.987 \\
\hline 34_LL2_5 & MI (Ol) & LL & & 6.50 & & 0.69 & & 395.12 & & 129.02 & & 399.23 & & 0.988 \\
\hline 46_LL2_37 & MI (Cpx) & LL & & 528.59 & & 0.52 & & 377.89 & & 186.17 & & 366.07 & & \\
\hline PELE_1116 & Pele & LL & $n=3$ & 43.96 & 21.27 & 0.11 & 0.00 & 377.97 & 0.92 & 43.48 & 9.34 & 285.47 & 5.01 & \\
\hline PELE_0117 & Pele & LL & $\mathrm{n}=3$ & 25.52 & 12.38 & 0.11 & 0.01 & 379.97 & 7.98 & 37.08 & 11.40 & 290.46 & 5.09 & \\
\hline PELE_0118 & Pele & LL & $\mathrm{n}=3$ & 31.87 & 21.86 & 0.10 & 0.00 & 362.03 & 3.45 & 38.79 & 24.48 & 275.05 & 10.77 & \\
\hline LL MG & Glass & LL & $\mathrm{n}=3$ & 2.87 & 2.91 & 0.10 & 0.01 & 350.15 & 22.66 & 21.22 & 5.66 & 305.61 & 9.58 & \\
\hline
\end{tabular}

Continued 
Table S2. Continued. Volatile contents of Masaya melt inclusions and glasses obtained by SIMS. Includes raw data and PEC correction coefficient derived from Petrolog3 (Danyushevsy and Plechov, 2011).

\begin{tabular}{|c|c|c|c|c|c|c|c|c|c|c|c|c|c|c|}
\hline & Sample & & & $\mathrm{CO}_{2}$ & & $\mathrm{H}_{2} \mathrm{O}$ & & $\mathrm{F}$ & & $\mathrm{S}$ & & $\mathrm{Cl}$ & & Corr \\
\hline Sample & Type & Eruption & $\mathrm{n}$ & ppm & $1 \sigma$ & wt.\% & $1 \sigma$ & $\mathrm{ppm}$ & $1 \sigma$ & ppm & $1 \sigma$ & ppm & $1 \sigma$ & Coef \\
\hline 15_MTL_8_4 & MI (Plag) & MTL & & 129.83 & & 0.81 & & 673.92 & & 540.83 & & 1307.06 & & \\
\hline 7_MTL_3_10 & MI (Plag) & MTL & & 160.49 & & 1.21 & & 433.68 & & 272.82 & & 576.13 & & \\
\hline 8_MTL_5_10 & MI (Plag) & MTL & & 305.92 & & 1.20 & & 402.64 & & 315.95 & & 510.39 & & \\
\hline 19_MTL_3_8 & MI (Plag) & MTL & & 324.57 & & 1.35 & & 374.13 & & 371.10 & & 842.76 & & \\
\hline 20_MTL_3_9 & MI (Plag) & MTL & & 251.51 & & 1.15 & & 390.17 & & 289.68 & & 482.42 & & \\
\hline 6_MTL_5_7 & MI (Plag) & MTL & & 121.74 & & 0.72 & & 246.36 & & 288.00 & & 318.75 & & \\
\hline 6_MTL_5_7_B & MI (Plag) & MTL & & 106.80 & & 1.14 & & 376.52 & & 222.93 & & 515.91 & & \\
\hline 13_MTL_4_4 & MI (Plag) & MTL & & 165.11 & & 1.23 & & 412.33 & & 271.67 & & 543.19 & & \\
\hline 11_MTL_5_2 & MI (Plag) & MTL & & 733.65 & & 1.24 & & 450.99 & & 660.52 & & 584.36 & & \\
\hline 11_MTL_5_2_B & MI (Plag) & MTL & & 277.19 & & 1.28 & & 449.62 & & 920.98 & & 626.66 & & \\
\hline 9_MTL_2_6 & MI (Plag) & MTL & & 253.28 & & 1.22 & & 412.95 & & 396.35 & & 531.22 & & \\
\hline 21_MTL_3_1 & $\mathrm{MI}(\mathrm{Ol})$ & MTL & & 127.92 & & 1.10 & & 412.86 & & 234.92 & & 516.84 & & 0.987 \\
\hline 22_MTL_7_6B & $\mathrm{MI}(\mathrm{Ol})$ & MTL & & 153.47 & & 1.08 & & 419.63 & & 263.89 & & 517.98 & & 1.003 \\
\hline 12_MTL_7_2 & MI (Ol) & MTL & & 316.50 & & 1.18 & & 475.73 & & 858.71 & & 630.59 & & 1.015 \\
\hline MTL_MG & Glass & MTL & $\mathrm{n}=3$ & 0.62 & 1.37 & 0.11 & 0.01 & 362.82 & 6.16 & 38.10 & 9.56 & 403.85 & 12.51 & \\
\hline 65_TIL_9_9 & MI (Plag) & TIL & & 629.25 & & 1.99 & & 499.47 & & 351.48 & & 826.51 & & \\
\hline 55_TIL_2_8 & $\mathrm{MI}(\mathrm{Ol})$ & TIL & & 175.80 & & 2.35 & & 361.58 & & 789.94 & & 728.79 & & 0.942 \\
\hline 58_TIL_4_4 & $\mathrm{MI}(\mathrm{Ol})$ & TIL & & 257.06 & & 2.18 & & 291.39 & & 1175.50 & & 831.44 & & 0.770 \\
\hline 61_TIL_4_8 & $\mathrm{MI}(\mathrm{Ol})$ & TIL & & 63.91 & & 1.35 & & 452.63 & & 784.63 & & 800.77 & & 1.007 \\
\hline 71_TIL_74 & MI (Ol) & TIL & & 39.66 & & 1.84 & & 282.71 & & 492.66 & & 811.44 & & 0.903 \\
\hline 54_TIL_4_5 & $\mathrm{MI}(\mathrm{Ol})$ & TIL & & 268.80 & & 2.45 & & 415.67 & & 847.56 & & 719.40 & & 0.915 \\
\hline 73_TIL_2_10 & $\mathrm{MI}(\mathrm{Ol})$ & TIL & & 568.24 & & 1.99 & & 366.26 & & 1409.58 & & 1220.73 & & 0.773 \\
\hline 64_TIL_4_6 & $\mathrm{MI}(\mathrm{Ol})$ & TIL & & 291.98 & & 2.45 & & 398.39 & & 870.52 & & 722.47 & & 0.918 \\
\hline 79_TIL_2_4 & MI (Ol) & TIL & & 151.40 & & 1.90 & & 439.55 & & 822.54 & & 684.88 & & 0.973 \\
\hline 80_TIL_7_5 & $\mathrm{MI}(\mathrm{Ol})$ & TIL & & 340.74 & & 1.62 & & 451.43 & & 822.75 & & 648.15 & & 0.992 \\
\hline 70_TIL_1_8 & MI (Cpx) & TIL & & 361.89 & & 1.80 & & 473.37 & & 570.34 & & 603.07 & & \\
\hline TIL MG & Glass & TIL & $\mathrm{n}=3$ & 144.00 & 166.33 & 0.07 & 0.03 & 368.84 & 161.76 & 16.25 & 6.31 & 531.54 & 199.85 & \\
\hline
\end{tabular}


Table S3. Trace element composition of Masaya melt inclusions and glasses obtained by LA-ICP-MS. Includes raw data and PEC correction coefficient derived from Petrolog3 (Danyushevsy and Plechov, 2011). Data given in ppm unless noted otherwise.

\begin{tabular}{|c|c|c|c|c|c|c|c|c|c|c|c|c|c|c|c|}
\hline Sample & $\begin{array}{c}\text { Sample } \\
\text { Type }\end{array}$ & Eruption & $\mathrm{n}$ & $\mathrm{Li}$ & $1 \sigma$ & $\mathrm{SiO}_{2} \%$ & $1 \sigma$ & $\mathrm{CaO} \%$ & $1 \sigma$ & $\mathrm{Sc}$ & $1 \sigma$ & $\mathrm{TiO}_{2} \%$ & $1 \sigma$ & $\mathrm{V}$ & $1 \sigma$ \\
\hline 23_LL_3A & MI (Plag) & LL & & 20.26 & & 46.26 & & 9.10 & & 40.08 & & 1.14 & & 420.61 & \\
\hline 23_LL_3B & MI (Plag) & LL & & 19.73 & & 48.43 & & 8.78 & & 33.66 & & 0.92 & & 318.26 & \\
\hline 39_LL_39_A & MI (Plag) & LL & & 15.85 & & 46.74 & & 8.65 & & 48.88 & & 1.38 & & 533.76 & \\
\hline 39_LL_39_B & MI (Plag) & LL & & 10.13 & & 39.31 & & 8.90 & & 32.74 & & 1.01 & & 393.45 & \\
\hline 38_LL_10_A & MI (Plag) & LL & & 14.39 & & 43.60 & & 9.01 & & 40.72 & & 1.24 & & 457.28 & \\
\hline 38_LL_10_B & MI (Plag) & LL & & 6.76 & & 42.07 & & 9.96 & & 36.90 & & 1.15 & & 438.79 & \\
\hline 37_LL_50_A & MI (Plag) & LL & & 21.22 & & 38.63 & & 8.67 & & 27.01 & & 0.82 & & 301.14 & \\
\hline 37_LL_50_B & MI (Plag) & LL & & 14.80 & & 37.97 & & 9.05 & & 23.91 & & 0.75 & & 259.41 & \\
\hline 32_LL_27 & MI (Plag) & LL & & 11.44 & & 34.23 & & 8.89 & & 29.64 & & 0.86 & & 296.31 & \\
\hline 31_LL_40 & MI (Plag) & LL & & 18.31 & & 44.03 & & 9.11 & & 29.41 & & 0.88 & & 302.57 & \\
\hline 27_LL_19 & MI (Plag) & LL & & 20.42 & & 42.14 & & 9.05 & & 38.71 & & 1.07 & & 389.80 & \\
\hline 25_LL_9 & MI (Plag) & LL & & 20.53 & & 43.67 & & 9.29 & & 52.99 & & 1.44 & & 549.77 & \\
\hline 25_LL_9_B & MI (Plag) & LL & & 16.50 & & 38.35 & & 8.94 & & 39.24 & & 1.02 & & 386.90 & \\
\hline 24_LL_8 & MI (Plag) & LL & & 11.38 & & 36.34 & & 8.81 & & 28.96 & & 0.87 & & 303.11 & \\
\hline 42-LL-20 & MI (Plag) & LL & & 19.00 & & 36.81 & & 8.66 & & 31.02 & & 0.89 & & 312.20 & \\
\hline 42-LL-20-B & MI (Plag) & LL & & 19.01 & & 43.42 & & 9.06 & & 44.33 & & 1.18 & & 441.86 & \\
\hline 33_LL_42 & MI (Plag) & LL & & 12.82 & & 40.96 & & 9.11 & & 36.16 & & 1.00 & & 358.02 & \\
\hline 26_LL_11A & MI (Ol) & LL & & 5.19 & & 42.80 & & 9.33 & & 44.15 & & 1.05 & & 384.66 & \\
\hline 26_LL_11B & MI (Ol) & LL & & 14.91 & & 48.14 & & 8.92 & & 40.57 & & 1.03 & & 381.00 & \\
\hline 34_LL2_5 & MI (Ol) & LL & & 9.39 & & 49.00 & & 9.92 & & 43.15 & & 1.13 & & 412.95 & \\
\hline 46_LL2_37 & MI (Cpx) & LL & & 4.88 & & 30.78 & & 8.80 & & 49.01 & & 0.65 & & 249.90 & \\
\hline Pele_1116 & Pele & LL & $\mathrm{n}=2$ & 11.99 & 0.26 & 46.70 & 2.14 & 8.85 & 0.06 & 41.95 & 0.98 & 1.44 & 0.00 & 479.20 & 54.07 \\
\hline Pele_0117 & Pele & LL & $\mathrm{n}=2$ & 11.43 & 0.18 & 43.86 & 0.26 & 8.73 & 0.12 & 41.07 & 0.96 & 1.36 & 0.08 & 434.11 & 27.35 \\
\hline Pele_0118 & Pele & LL & $\mathrm{n}=2$ & 12.79 & 0.47 & 47.52 & 1.10 & 8.65 & 0.13 & 42.62 & 0.49 & 1.40 & 0.02 & 504.15 & 7.37 \\
\hline LL-MG & Glass & LL & $\mathrm{n}=4$ & 11.85 & 0.44 & 48.71 & 1.84 & 9.02 & 0.02 & 44.72 & 2.64 & 1.32 & 0.04 & 481.07 & 12.60 \\
\hline
\end{tabular}


Table S3. Continued. Trace element composition of Masaya melt inclusions and glasses obtained by LA-ICP-MS. Includes raw data and PEC correction coefficient derived from Petrolog3 (Danyushevsy and Plechov, 2011). Data given in ppm unless noted otherwise.

\begin{tabular}{|c|c|c|c|c|c|c|c|c|c|c|c|c|c|c|c|}
\hline Sample & $\begin{array}{c}\text { Sample } \\
\text { Type }\end{array}$ & Eruption & $\mathrm{n}$ & $\mathrm{Cr}$ & $1 \sigma$ & $\mathrm{Co}$ & $1 \sigma$ & $\mathrm{Ni}$ & $1 \sigma$ & $\mathrm{Cu}$ & $1 \sigma$ & $\mathrm{Zn}$ & $1 \sigma$ & $\mathrm{Rb}$ & $1 \sigma$ \\
\hline 23_LL_3A & MI (Plag) & $\mathrm{LL}$ & & 13.59 & & 29.25 & & 13.70 & & 389.31 & & 109.19 & & 25.15 & \\
\hline 23_LL_3B & MI (Plag) & LL & & 15.64 & & 29.09 & & 1.16 & & 373.68 & & 106.77 & & 26.78 & \\
\hline 39_LL_39_A & MI (Plag) & LL & & 13.79 & & 34.68 & & -0.19 & & 336.14 & & 124.28 & & 31.13 & \\
\hline 39_LL_39_B & MI (Plag) & LL & & 7.46 & & 27.27 & & 10.24 & & 231.12 & & 95.97 & & 18.93 & \\
\hline 38_LL_10_A & MI (Plag) & LL & & 14.24 & & 34.87 & & -51.67 & & 344.79 & & 116.04 & & 25.22 & \\
\hline 38_LL_10_B & MI (Plag) & LL & & 14.84 & & 29.01 & & 15.07 & & 290.84 & & 104.51 & & 22.13 & \\
\hline 37_LL_50_A & MI (Plag) & LL & & 7.76 & & 23.52 & & -0.76 & & 312.19 & & 85.97 & & 19.79 & \\
\hline 37_LL_50_B & MI (Plag) & LL & & 5.05 & & 21.62 & & -9.42 & & 254.69 & & 85.47 & & 16.43 & \\
\hline 32_LL_27 & MI (Plag) & LL & & 14.95 & & 23.89 & & -9.52 & & 226.13 & & 72.97 & & 15.19 & \\
\hline 31_LL_40 & MI (Plag) & LL & & 7.25 & & 24.80 & & -23.65 & & 456.46 & & 100.09 & & 24.24 & \\
\hline 27_LL_19 & MI (Plag) & LL & & 6.59 & & 29.53 & & -2.18 & & 346.70 & & 105.43 & & 24.33 & \\
\hline 25_LL_9 & MI (Plag) & LL & & 26.03 & & 35.16 & & 2.02 & & 481.10 & & 124.00 & & 27.44 & \\
\hline 25_LL_9_B & MI (Plag) & LL & & 14.64 & & 21.42 & & -25.16 & & 329.16 & & 89.42 & & 19.94 & \\
\hline 24_LL_8 & MI (Plag) & LL & & 8.78 & & 20.57 & & 40.93 & & 216.04 & & 84.06 & & 17.15 & \\
\hline 42-LL-20-B & MI (Plag) & LL & & 10.13 & & 30.05 & & -13.06 & & 378.03 & & 112.55 & & 25.84 & \\
\hline 33_LL_42 & MI (Plag) & LL & & 27.46 & & 30.13 & & -14.62 & & 373.79 & & 109.61 & & 23.19 & \\
\hline 26_LL_11A & MI (Ol) & LL & & 27.45 & & 51.16 & & 30.18 & & 270.36 & & 150.53 & & 23.26 & \\
\hline 26_LL_11B & $\mathrm{MI}(\mathrm{Ol})$ & LL & & 18.73 & & 35.32 & & 16.37 & & 293.95 & & 122.98 & & 24.71 & \\
\hline 34_LL2_5 & MI (Ol) & LL & & 30.29 & & 67.86 & & 18.64 & & 300.30 & & 162.32 & & 25.80 & \\
\hline 46_LL2_37 & MI (Cpx) & LL & & 128.29 & & 23.06 & & -12.16 & & 147.61 & & 77.10 & & 13.16 & \\
\hline Pele_1116 & Pele & LL & $\mathrm{n}=2$ & 18.67 & 1.39 & 34.17 & 1.40 & 20.67 & 5.70 & 293.64 & 23.30 & 123.96 & 2.94 & 26.77 & 2.55 \\
\hline Pele_0117 & Pele & LL & $\mathrm{n}=2$ & 19.14 & 1.46 & 32.43 & 0.02 & 24.29 & 0.48 & 269.31 & 2.06 & 115.91 & 0.11 & 24.47 & 0.31 \\
\hline Pele_0118 & Pele & LL & $\mathrm{n}=2$ & 22.20 & 2.82 & 35.35 & 0.35 & 26.46 & 0.77 & 304.56 & 1.30 & 125.45 & 0.39 & 27.69 & 0.32 \\
\hline LL-MG & Glass & LL & $\mathrm{n}=4$ & 22.61 & 1.33 & 39.27 & 9.87 & 32.30 & 13.53 & 288.14 & 5.76 & 121.99 & 9.49 & 25.99 & 0.68 \\
\hline
\end{tabular}

Continued 
Table S3. Continued. Trace element composition of Masaya melt inclusions and glasses obtained by LA-ICP-MS. Includes raw data and PEC correction coefficient derived from Petrolog3 (Danyushevsy and Plechov, 2011). Data given in ppm unless noted otherwise.

\begin{tabular}{|c|c|c|c|c|c|c|c|c|c|c|c|c|c|c|c|}
\hline Sample & $\begin{array}{c}\text { Sample } \\
\text { Type }\end{array}$ & Eruption & $\mathrm{n}$ & $\mathrm{Sr}(\mathrm{Kr})$ & $1 \sigma$ & $\mathrm{Y}$ & $1 \sigma$ & $\mathrm{Zr}$ & $1 \sigma$ & $\mathrm{Nb}$ & $1 \sigma$ & $\mathrm{Ba}$ & $1 \sigma$ & $\mathrm{La}$ & $1 \sigma$ \\
\hline 23_LL_3A & MI (Plag) & LL & & 400.84 & & 33.31 & & 121.59 & & 3.33 & & 948.58 & & 12.09 & \\
\hline 23_LL_3B & MI (Plag) & LL & & 389.65 & & 26.16 & & 96.64 & & 2.25 & & 964.54 & & 10.31 & \\
\hline 39_LL_39_A & MI (Plag) & LL & & 368.90 & & 34.06 & & 127.62 & & 4.51 & & 877.16 & & 11.25 & \\
\hline 39_LL_39_B & MI (Plag) & LL & & 456.77 & & 22.50 & & 93.34 & & 3.28 & & 890.30 & & 9.48 & \\
\hline 38_LL_10_A & MI (Plag) & LL & & 369.36 & & 31.70 & & 127.07 & & 3.40 & & 917.20 & & 12.02 & \\
\hline 38_LL_10_B & MI (Plag) & LL & & 380.30 & & 27.30 & & 107.32 & & 3.19 & & 754.93 & & 10.52 & \\
\hline 37_LL_50_A & MI (Plag) & LL & & 312.79 & & 19.00 & & 72.15 & & 2.27 & & 619.30 & & 8.22 & \\
\hline 37_LL_50_B & MI (Plag) & LL & & 407.36 & & 18.52 & & 70.69 & & 2.02 & & 545.09 & & 7.79 & \\
\hline 32_LL_27 & MI (Plag) & LL & & 380.50 & & 22.38 & & 100.28 & & 2.47 & & 617.56 & & 9.28 & \\
\hline 31_LL_40 & MI (Plag) & LL & & 393.88 & & 22.40 & & 82.33 & & 2.26 & & 814.91 & & 8.88 & \\
\hline 27_LL_19 & MI (Plag) & LL & & 400.82 & & 30.96 & & 112.63 & & 3.07 & & 746.09 & & 11.35 & \\
\hline 25_LL_9 & MI (Plag) & LL & & 354.02 & & 46.90 & & 171.41 & & 4.33 & & 845.56 & & 14.81 & \\
\hline 25_LL_9_B & MI (Plag) & LL & & 381.32 & & 33.32 & & 114.74 & & 2.88 & & 645.72 & & 10.80 & \\
\hline 24_LL_8 & MI (Plag) & LL & & 358.36 & & 25.37 & & 96.91 & & 2.44 & & 628.53 & & 9.86 & \\
\hline 42-LL-20 & MI (Plag) & LL & & 335.69 & & 23.76 & & 75.54 & & 2.02 & & 667.07 & & 11.25 & \\
\hline 42-LL-20-B & MI (Plag) & LL & & 417.29 & & 34.84 & & 131.47 & & 3.73 & & 804.79 & & 12.35 & \\
\hline 33_LL_42 & MI (Plag) & LL & & 376.77 & & 29.14 & & 111.10 & & 2.80 & & 714.16 & & 11.38 & \\
\hline 26_LL_11A & MI (Ol) & LL & & 371.07 & & 28.78 & & 107.26 & & 3.32 & & 745.33 & & 10.72 & \\
\hline 26_LL_11B & MI (Ol) & LL & & 378.41 & & 30.67 & & 113.62 & & 2.89 & & 932.16 & & 11.92 & \\
\hline 34_LL2_5 & MI (Ol) & LL & & 357.87 & & 32.38 & & 122.50 & & 3.19 & & 830.65 & & 13.21 & \\
\hline 46_LL2_37 & MI (Cpx) & LL & & 196.21 & & 19.51 & & 63.79 & & 1.89 & & 460.16 & & 6.59 & \\
\hline Pele_1116 & Pele & LL & $\mathrm{n}=2$ & 386.63 & 9.12 & 33.45 & 2.08 & 125.47 & 6.76 & 3.40 & 0.04 & 1012.55 & 21.55 & 13.09 & 0.51 \\
\hline Pele_0117 & Pele & LL & $\mathrm{n}=2$ & 379.92 & 3.29 & 32.99 & 0.71 & 124.34 & 2.05 & 3.44 & 0.06 & 993.73 & 24.59 & 12.77 & 0.17 \\
\hline Pele_0118 & Pele & LL & $\mathrm{n}=2$ & 381.57 & 2.75 & 34.70 & 1.00 & 130.56 & 2.57 & 3.42 & 0.12 & 990.62 & 13.69 & 13.18 & 0.07 \\
\hline LL-MG & Glass & LL & $\mathrm{n}=4$ & 393.28 & 3.82 & 33.72 & 3.01 & 124.77 & 10.07 & 3.22 & 0.11 & 951.11 & 43.17 & 12.42 & 0.76 \\
\hline
\end{tabular}


Table S3. Continued. Trace element composition of Masaya melt inclusions and glasses obtained by LA-ICP-MS. Includes raw data and PEC correction coefficient derived from Petrolog3 (Danyushevsy and Plechov, 2011). Data given in ppm unless noted otherwise.

\begin{tabular}{|c|c|c|c|c|c|c|c|c|c|c|c|c|c|c|c|}
\hline Sample & $\begin{array}{c}\text { Sample } \\
\text { Type }\end{array}$ & Eruption & $\mathrm{n}$ & $\mathrm{Ce}$ & $1 \sigma$ & $\operatorname{Pr}$ & $1 \sigma$ & $\mathrm{Nd}$ & $1 \sigma$ & $\mathrm{Sm}$ & $1 \sigma$ & $\mathrm{Eu}$ & $1 \sigma$ & Gd(Dy) & $1 \sigma$ \\
\hline 23_LL_3A & MI (Plag) & $\mathrm{LL}$ & & 24.99 & & 4.15 & & 17.92 & & 5.41 & & 1.22 & & 5.39 & \\
\hline 23_LL_3B & MI (Plag) & LL & & 21.15 & & 3.30 & & 14.23 & & 4.42 & & 1.27 & & 3.79 & \\
\hline 39_LL_39_A & MI (Plag) & LL & & 25.76 & & 3.99 & & 20.04 & & 5.41 & & 1.84 & & 4.83 & \\
\hline 39_LL_39_B & MI (Plag) & LL & & 21.11 & & 3.22 & & 14.02 & & 3.82 & & 1.80 & & 5.34 & \\
\hline 38_LL_10_A & MI (Plag) & LL & & 26.95 & & 3.92 & & 17.12 & & 5.55 & & 1.64 & & 4.99 & \\
\hline 38_LL_10_B & MI (Plag) & LL & & 24.66 & & 3.88 & & 24.91 & & 4.25 & & 0.35 & & 4.24 & \\
\hline 37_LL_50_A & MI (Plag) & LL & & 17.38 & & 2.75 & & 10.10 & & 3.73 & & 1.33 & & 2.86 & \\
\hline 37_LL_50_B & MI (Plag) & LL & & 14.98 & & 2.41 & & 11.70 & & 3.23 & & 0.89 & & 2.80 & \\
\hline 32_LL_27 & MI (Plag) & LL & & 19.10 & & 2.41 & & 12.92 & & 4.90 & & 1.70 & & 4.41 & \\
\hline 31_LL_40 & MI (Plag) & LL & & 20.77 & & 3.08 & & 14.04 & & 2.99 & & 1.26 & & 3.46 & \\
\hline 27_LL_19 & MI (Plag) & LL & & 22.44 & & 3.18 & & 19.00 & & 4.60 & & 1.44 & & 5.27 & \\
\hline 25_LL_9 & MI (Plag) & LL & & 29.63 & & 4.66 & & 20.78 & & 6.29 & & 1.71 & & 6.76 & \\
\hline 25_LL_9_B & MI (Plag) & LL & & 21.63 & & 3.36 & & 16.45 & & 5.60 & & 1.09 & & 4.95 & \\
\hline 24_LL_8 & MI (Plag) & LL & & 19.47 & & 2.77 & & 17.98 & & 3.81 & & 1.11 & & 3.31 & \\
\hline 42-LL-20 & MI (Plag) & LL & & 18.98 & & 3.09 & & 9.46 & & 1.58 & & 1.33 & & 2.78 & \\
\hline 42-LL-20-B & MI (Plag) & LL & & 26.42 & & 3.95 & & 19.25 & & 5.26 & & 1.55 & & 4.43 & \\
\hline 33_LL_42 & MI (Plag) & LL & & 22.11 & & 3.70 & & 16.58 & & 4.01 & & 1.65 & & 4.85 & \\
\hline 26_LL_11A & MI (Ol) & LL & & 23.49 & & 3.64 & & 16.92 & & 4.33 & & 1.40 & & 5.01 & \\
\hline 26_LL_11B & $\mathrm{MI}(\mathrm{Ol})$ & LL & & 24.27 & & 3.74 & & 19.43 & & 4.81 & & 1.55 & & 5.74 & \\
\hline 34_LL2_5 & MI (Ol) & LL & & 26.44 & & 4.16 & & 18.99 & & 4.65 & & 1.24 & & 6.26 & \\
\hline 46_LL2_37 & MI (Cpx) & LL & & 15.52 & & 2.32 & & 11.53 & & 3.69 & & 0.85 & & 3.23 & \\
\hline Pele_1116 & Pele & LL & $\mathrm{n}=2$ & 26.57 & 0.49 & 4.12 & 0.07 & 19.65 & 0.35 & 5.15 & 0.36 & 1.57 & 0.03 & 5.54 & 0.47 \\
\hline Pele_0117 & Pele & LL & $\mathrm{n}=2$ & 26.21 & 0.49 & 4.12 & 0.04 & 19.61 & 0.46 & 4.92 & 0.11 & 1.53 & 0.01 & 5.38 & 0.29 \\
\hline Pele_0118 & Pele & LL & $\mathrm{n}=2$ & 26.49 & 0.29 & 4.17 & 0.01 & 19.82 & 0.18 & 5.34 & 0.09 & 1.61 & 0.00 & 6.07 & 0.10 \\
\hline LL-MG & Glass & LL & $\mathrm{n}=4$ & 25.17 & 0.96 & 3.88 & 0.19 & 19.19 & 1.15 & 5.13 & 0.38 & 1.51 & 0.04 & 5.76 & 0.49 \\
\hline
\end{tabular}


Table S3. Continued. Trace element composition of Masaya melt inclusions and glasses obtained by LA-ICP-MS. Includes raw data and PEC correction coefficient derived from Petrolog3 (Danyushevsy and Plechov, 2011). Data given in ppm unless noted otherwise.

\begin{tabular}{|c|c|c|c|c|c|c|c|c|c|c|c|c|c|c|c|}
\hline Sample & $\begin{array}{c}\text { Sample } \\
\text { Type }\end{array}$ & Eruption & $\mathrm{n}$ & $\mathrm{Tb}$ & $1 \sigma$ & Dy & $1 \sigma$ & Ho & $1 \sigma$ & $\mathrm{Er}$ & $1 \sigma$ & $\mathrm{Tm}$ & $1 \sigma$ & $\mathrm{Yb}$ & $1 \sigma$ \\
\hline $23 \mathrm{LL} 3 \mathrm{~A}$ & MI (Plag) & $\mathrm{LL}$ & & 0.76 & & 5.63 & & 0.99 & & 3.29 & & 0.40 & & 3.21 & \\
\hline 23_LL_3B & MI (Plag) & LL & & 0.61 & & 4.00 & & 0.97 & & 2.33 & & 0.30 & & 2.55 & \\
\hline 39_LL_39_A & MI (Plag) & LL & & 1.09 & & 5.17 & & 1.26 & & 3.23 & & 0.50 & & 3.62 & \\
\hline 39_LL_39_B & MI (Plag) & LL & & 0.72 & & 3.22 & & 1.02 & & 2.20 & & 0.42 & & 2.58 & \\
\hline 38_LL_10_A & MI (Plag) & LL & & 0.64 & & 5.92 & & 1.26 & & 2.87 & & 0.38 & & 2.59 & \\
\hline 38_LL_10_B & MI (Plag) & LL & & 0.61 & & 2.83 & & 1.03 & & 3.18 & & 0.56 & & 2.70 & \\
\hline 37_LL_50_A & MI (Plag) & LL & & 0.47 & & 2.92 & & 0.78 & & 2.08 & & 0.08 & & 1.42 & \\
\hline 37_LL_50_B & MI (Plag) & LL & & 0.60 & & 3.00 & & 0.73 & & 1.93 & & 0.38 & & 2.28 & \\
\hline 32_LL_27 & MI (Plag) & LL & & 0.70 & & 4.35 & & 0.89 & & 2.29 & & 0.39 & & 3.10 & \\
\hline 31_LL_40 & MI (Plag) & LL & & 0.57 & & 2.72 & & 0.67 & & 1.66 & & 0.35 & & 1.35 & \\
\hline 27_LL_19 & MI (Plag) & LL & & 0.80 & & 5.58 & & 0.73 & & 2.94 & & 0.32 & & 3.08 & \\
\hline 25_LL_9 & MI (Plag) & LL & & 1.20 & & 7.12 & & 1.35 & & 4.35 & & 0.62 & & 4.47 & \\
\hline 25_LL_9_B & MI (Plag) & LL & & 0.83 & & 6.18 & & 1.22 & & 3.46 & & 0.40 & & 2.63 & \\
\hline $2 \overline{4} \_\bar{L} \_\overline{8}$ & MI (Plag) & LL & & 0.35 & & 4.84 & & 0.73 & & 2.87 & & 0.38 & & 2.21 & \\
\hline 42-LL-20 & MI (Plag) & LL & & 0.64 & & 4.47 & & 0.54 & & 2.53 & & 0.34 & & 3.56 & \\
\hline 42-LL-20-B & MI (Plag) & LL & & 0.83 & & 5.13 & & 1.24 & & 3.44 & & 0.60 & & 3.02 & \\
\hline 33_LL_42 & MI (Plag) & LL & & 0.55 & & 5.61 & & 1.14 & & 3.38 & & 0.52 & & 3.99 & \\
\hline 26_LL_11A & $\mathrm{MI}(\mathrm{Ol})$ & LL & & 0.95 & & 3.65 & & 0.95 & & 4.15 & & 0.42 & & 3.35 & \\
\hline 26_LL_11B & MI (Ol) & LL & & 0.95 & & 5.57 & & 1.26 & & 3.53 & & 0.49 & & 3.00 & \\
\hline 34 LL2_5 & MI (Ol) & LL & & 0.76 & & 6.81 & & 0.87 & & 3.52 & & 0.65 & & 3.02 & \\
\hline 46_LL2_37 & MI (Cpx) & LL & & 0.59 & & 3.27 & & 0.73 & & 2.56 & & 0.20 & & 2.77 & \\
\hline Pele_1116 & Pele & LL & $\mathrm{n}=2$ & 0.87 & 0.06 & 5.53 & 0.59 & 1.14 & 0.10 & 3.41 & 0.36 & 0.48 & 0.05 & 3.21 & 0.07 \\
\hline Pele_0117 & Pele & LL & $\mathrm{n}=2$ & 0.82 & 0.02 & 5.33 & 0.04 & 1.11 & 0.02 & 3.37 & 0.09 & 0.46 & 0.02 & 3.08 & 0.13 \\
\hline Pele_0118 & Pele & LL & $n=2$ & 0.90 & 0.02 & 5.77 & 0.02 & 1.24 & 0.02 & 3.65 & 0.10 & 0.51 & 0.02 & 3.32 & 0.04 \\
\hline LL-MG & Glass & $\mathrm{LL}$ & $\mathrm{n}=4$ & 0.86 & 0.09 & 5.59 & 0.53 & 1.18 & 0.13 & 3.53 & 0.41 & 0.49 & 0.04 & 3.24 & 0.26 \\
\hline
\end{tabular}


Table S3. Continued. Trace element composition of Masaya melt inclusions and glasses obtained by LA-ICP-MS. Includes raw data and PEC correction coefficient derived from Petrolog3 (Danyushevsy and Plechov, 2011). Data given in ppm unless noted otherwise.

\begin{tabular}{|c|c|c|c|c|c|c|c|c|c|c|c|c|}
\hline Sample & $\begin{array}{c}\text { Sample } \\
\text { Type } \\
\end{array}$ & Eruption & $\mathrm{n}$ & $\mathrm{Lu}$ & $1 \sigma$ & $\mathrm{Pb}$ & $1 \sigma$ & Th & $1 \sigma$ & $\mathrm{U}$ & $1 \sigma$ & Corr Coef \\
\hline 23_LL_3A & MI (Plag) & LL & & 0.38 & & 3.68 & & 1.86 & & 1.35 & & \\
\hline 23_LL_3B & MI (Plag) & LL & & 0.32 & & 4.44 & & 1.93 & & 1.10 & & \\
\hline 39_LL_39_A & MI (Plag) & LL & & 0.59 & & 5.70 & & 2.30 & & 1.74 & & \\
\hline 39_LL_39_B & MI (Plag) & LL & & 0.42 & & 4.01 & & 1.43 & & 1.38 & & \\
\hline 38_LL_10_A & MI (Plag) & LL & & 0.51 & & 3.92 & & 2.05 & & 1.66 & & \\
\hline 38_LL_10_B & MI (Plag) & LL & & 0.35 & & 3.36 & & 1.33 & & 1.11 & & \\
\hline 37_LL_50_A & MI (Plag) & LL & & 0.36 & & 4.56 & & 1.35 & & 0.79 & & \\
\hline 37_LL_50_B & MI (Plag) & $\mathrm{LL}$ & & 0.17 & & 2.63 & & 1.35 & & 1.07 & & \\
\hline 32_LL_27 & MI (Plag) & LL & & 0.49 & & 3.45 & & 1.52 & & 1.55 & & \\
\hline 31_LL_40 & MI (Plag) & LL & & 0.34 & & 4.63 & & 1.07 & & 0.69 & & \\
\hline 27_LL_19 & MI (Plag) & LL & & 0.45 & & 4.29 & & 1.86 & & 1.43 & & \\
\hline 25_LL_9 & MI (Plag) & LL & & 0.60 & & 4.38 & & 2.70 & & 1.75 & & \\
\hline 25_LL_9_B & MI (Plag) & LL & & 0.69 & & 3.03 & & 1.78 & & 1.37 & & \\
\hline $2 \overline{4} \_\bar{L} \bar{L} \_\overline{8}$ & MI (Plag) & LL & & 0.39 & & 2.83 & & 1.63 & & 1.18 & & \\
\hline 42-LL-20 & MI (Plag) & LL & & 0.36 & & 3.86 & & 1.10 & & 1.25 & & \\
\hline 42-LL-20-B & MI (Plag) & LL & & 0.56 & & 3.67 & & 2.12 & & 1.46 & & \\
\hline 33_LL_42 & MI (Plag) & LL & & 0.43 & & 4.42 & & 2.26 & & 1.39 & & \\
\hline $26 \_\mathrm{LL} \_11 \mathrm{~A}$ & MI (Ol) & LL & & 0.26 & & 5.63 & & 1.47 & & 1.62 & & 1.012 \\
\hline 26_LL_11B & MI (Ol) & LL & & 0.48 & & 3.98 & & 2.35 & & 1.47 & & 1.016 \\
\hline 34 -LL2_5 & MI (Ol) & LL & & 0.57 & & 4.53 & & 1.94 & & 1.80 & & 0.988 \\
\hline 46_LL2_37 & MI (Cpx) & LL & & 0.36 & & 2.72 & & 1.05 & & 0.90 & & \\
\hline Pele_1116 & Pele & LL & $\mathrm{n}=2$ & 0.51 & 0.08 & 4.38 & 0.49 & 2.18 & 0.15 & 1.58 & 0.12 & \\
\hline Pele_0117 & Pele & LL & $\mathrm{n}=2$ & 0.49 & 0.00 & 4.04 & 0.11 & 2.12 & 0.01 & 1.55 & 0.02 & \\
\hline Pele_0118 & Pele & LL & $\mathrm{n}=2$ & 0.54 & 0.05 & 4.61 & 0.04 & 2.26 & 0.03 & 1.57 & 0.01 & \\
\hline LL-MG & Glass & LL & $\mathrm{n}=4$ & 0.50 & 0.04 & 4.34 & 0.19 & 2.17 & 0.22 & 1.48 & 0.06 & \\
\hline
\end{tabular}

Continued 
Table S3. Continued. Trace element composition of Masaya melt inclusions and glasses obtained by LA-ICP-MS. Includes raw data and PEC correction coefficient derived from Petrolog3 (Danyushevsy and Plechov, 2011). Data given in ppm unless noted otherwise.

\begin{tabular}{|c|c|c|c|c|c|c|c|c|c|c|c|c|c|c|c|}
\hline Sample & $\begin{array}{c}\text { Sample } \\
\text { Type }\end{array}$ & Eruption & $\mathrm{n}$ & $\mathrm{Li}$ & $1 \sigma$ & $\mathrm{SiO}_{2} \%$ & $1 \sigma$ & $\mathrm{CaO} \%$ & $1 \sigma$ & Sc & $1 \sigma$ & $\mathrm{TiO}_{2} \%$ & $1 \sigma$ & $\mathrm{V}$ & $1 \sigma$ \\
\hline 15_MTL_8_4 & MI (Plag) & MTL & & 14.99 & & 40.13 & & 8.73 & & 37.84 & & 0.98 & & 364.61 & \\
\hline 7_MTL_3_10 & MI (Plag) & MTL & & 9.82 & & 37.32 & & 9.03 & & 35.79 & & 1.13 & & 368.78 & \\
\hline 8_MTL_5_10 & MI (Plag) & MTL & & 13.94 & & 50.01 & & 8.29 & & 31.21 & & 0.94 & & 307.15 & \\
\hline 19_MTL_3_8 & MI (Plag) & MTL & & 16.49 & & 44.53 & & 8.20 & & 30.03 & & 0.69 & & 247.00 & \\
\hline 20_MTL_3_9 & MI (Plag) & MTL & & 7.47 & & 41.57 & & 8.25 & & 20.42 & & 0.62 & & 196.90 & \\
\hline 6_MTL_5_7_A & MI (Plag) & MTL & & 8.48 & & 42.96 & & 8.71 & & 36.19 & & 1.19 & & 396.85 & \\
\hline 13_MTL_4_4 & MI (Plag) & MTL & & 13.25 & & 47.94 & & 8.87 & & 38.99 & & 1.22 & & 420.41 & \\
\hline 11_MTL_5_2_A & MI (Plag) & MTL & & 10.59 & & 49.97 & & 8.94 & & 46.05 & & 1.22 & & 428.50 & \\
\hline 11_MTL_5_2_B & MI (Plag) & MTL & & 8.14 & & 43.26 & & 8.58 & & 48.18 & & 0.91 & & 391.03 & \\
\hline 9_MTL_2_6_A & MI (Plag) & MTL & & 11.45 & & 45.74 & & 8.64 & & 30.14 & & 1.00 & & 332.09 & \\
\hline 21_MTL_3_1 & MI (Ol) & MTL & & 13.42 & & 51.72 & & 9.62 & & 41.29 & & 1.22 & & 391.54 & \\
\hline 22_MTL_7_6 & MI (Ol) & MTL & & 11.80 & & 51.65 & & 9.25 & & 42.56 & & 1.20 & & 409.35 & \\
\hline 12_MTL_7_2 & $\mathrm{MI}(\mathrm{Ol})$ & MTL & & 12.26 & & 53.40 & & 9.57 & & 40.94 & & 0.78 & & 549.04 & \\
\hline MTL-MG & Glass & MTL & $\mathrm{n}=4$ & 11.69 & 1.23 & 48.72 & 4.25 & 9.02 & 0.02 & 40.05 & 2.30 & 1.20 & 0.03 & 399.66 & 13.28 \\
\hline 55_TIL_2_8 & MI (Ol) & TIL & & 10.64 & & 53.55 & & 9.90 & & 34.83 & & 1.04 & & 308.93 & \\
\hline 58_TIL_4_4 & MI (Ol) & TIL & & -26.75 & & 46.27 & & 13.47 & & 10.10 & & 0.70 & & 312.58 & \\
\hline 61_TIL_4_8 & $\mathrm{MI}(\mathrm{Ol})$ & TIL & & 20.87 & & 96.68 & & 7.36 & & 41.79 & & 0.93 & & 289.21 & \\
\hline 71_TIL_7_4 & MI (Ol) & TIL & & 5.16 & & 54.35 & & 9.33 & & 39.16 & & 1.26 & & 278.83 & \\
\hline 54_TIL_4_5 & MI (Ol) & TIL & & 14.68 & & 51.42 & & 11.07 & & 37.24 & & 1.05 & & 379.37 & \\
\hline 73_TIL_2_10 & MI (Ol) & TIL & & 9.77 & & 43.47 & & 14.61 & & 35.21 & & 0.65 & & 380.94 & \\
\hline 79-TIL-2-4 & MI (Ol) & TIL & & 13.80 & & 55.17 & & 9.93 & & 39.71 & & 1.00 & & 410.98 & \\
\hline 80-TIL-7-5 & MI (Ol) & TIL & & 12.61 & & 50.29 & & 9.61 & & 41.25 & & 1.01 & & 439.01 & \\
\hline 70_TIL_1_8 & MI (Cpx) & TIL & & 10.58 & & 48.43 & & 8.06 & & 31.97 & & 1.40 & & 404.85 & \\
\hline TIL-MG & Glass & TIL & $\mathrm{n}=6$ & 8.80 & 1.53 & 41.96 & 2.74 & 7.05 & 0.14 & 28.43 & 1.45 & 0.92 & 0.08 & 256.89 & 22.96 \\
\hline
\end{tabular}

Continued 
Table S3. Continued. Trace element composition of Masaya melt inclusions and glasses obtained by LA-ICP-MS. Includes raw data and PEC correction coefficient derived from Petrolog3 (Danyushevsy and Plechov, 2011). Data given in ppm unless noted otherwise.

\begin{tabular}{|c|c|c|c|c|c|c|c|c|c|c|c|c|c|c|c|}
\hline Sample & $\begin{array}{c}\text { Sample } \\
\text { Type } \\
\end{array}$ & Eruption & $\mathrm{n}$ & $\mathrm{Cr}$ & $1 \sigma$ & Co & $1 \sigma$ & $\mathrm{Ni}$ & $1 \sigma$ & $\mathrm{Cu}$ & $1 \sigma$ & $\mathrm{Zn}$ & $1 \sigma$ & $\mathrm{Rb}$ & $1 \sigma$ \\
\hline 15_MTL_8_4 & MI (Plag) & MTL & & 8.90 & & 33.39 & & -46.24 & & 547.69 & & 124.00 & & 22.19 & \\
\hline 7_MTL_3_10 & MI (Plag) & MTL & & 1.18 & & 32.92 & & -5.52 & & 293.93 & & 133.69 & & 22.08 & \\
\hline 8_MTL_5_10 & MI (Plag) & MTL & & 5.86 & & 28.57 & & -16.90 & & 288.40 & & 117.71 & & 24.81 & \\
\hline 19_MTL_3_8 & MI (Plag) & MTL & & 8.12 & & 28.15 & & -0.36 & & 347.02 & & 122.15 & & 18.71 & \\
\hline 20_MTL_3_9 & MI (Plag) & MTL & & 5.06 & & 22.28 & & -4.73 & & 204.52 & & 91.25 & & 17.53 & \\
\hline 6_MTL_5_7_A & MI (Plag) & MTL & & 3.22 & & 35.27 & & -41.84 & & 311.17 & & 128.18 & & 25.63 & \\
\hline 13_MTL_4_4 & MI (Plag) & MTL & & 2.95 & & 35.86 & & -64.75 & & 361.36 & & 132.34 & & 28.20 & \\
\hline 11_- $\mathrm{MTL} \_5 \_\overline{2} \_\mathrm{A}$ & MI (Plag) & MTL & & 19.06 & & 39.26 & & -10.64 & & 364.93 & & 145.45 & & 28.06 & \\
\hline 11_MTL 52 - B & MI (Plag) & MTL & & 14.85 & & 36.88 & & -30.28 & & 395.01 & & 155.91 & & 26.57 & \\
\hline 9_MTL_2_6_A & MI (Plag) & MTL & & 6.80 & & 28.66 & & 5.06 & & 272.27 & & 113.76 & & 22.47 & \\
\hline 21_MTL_3_1 & MI (Ol) & MTL & & 7.36 & & 37.92 & & 0.91 & & 340.80 & & 135.68 & & 26.74 & \\
\hline 22_MTL_7_6 & MI (Ol) & MTL & & 7.22 & & 38.33 & & 15.25 & & 343.15 & & 132.72 & & 26.22 & \\
\hline 12_MTL_7_2 & MI (Ol) & MTL & & 178.46 & & 44.46 & & 7.59 & & 390.36 & & 162.68 & & 19.84 & \\
\hline$\overline{\mathrm{M} T L}-\overline{\mathrm{M}} \overline{\mathrm{C}}$ & Glass & MTL & $\mathrm{n}=4$ & 11.08 & 8.67 & 34.72 & 1.70 & 12.53 & 13.30 & 336.69 & 59.21 & 129.28 & 22.15 & 24.89 & 1.55 \\
\hline 65_TIL_9_9 & MI (Plag) & TIL & & 9.95 & & 27.68 & & -23.75 & & 285.65 & & 119.91 & & 30.74 & \\
\hline 55_TIL_2_8 & MI (Ol) & TIL & & 13.73 & & 29.97 & & -0.81 & & 256.72 & & 101.89 & & 25.03 & \\
\hline 58_TIL_4_4 & MI (Ol) & TIL & & 22.45 & & 16.23 & & -148.92 & & 181.89 & & 85.38 & & 9.45 & \\
\hline 61_TIL_4_8 & MI (Ol) & TIL & & 26.78 & & 431.78 & & 241.36 & & 293.00 & & 457.13 & & 15.38 & \\
\hline 71_TIL_7_4 & MI (Ol) & TIL & & -36.31 & & 27.07 & & -30.57 & & 290.33 & & 114.63 & & 27.86 & \\
\hline 54_TIL_4_5 & MI (Ol) & TIL & & 12.51 & & 35.59 & & -37.60 & & 266.29 & & 123.97 & & 21.92 & \\
\hline 73_TIL_2_10 & MI (Ol) & TIL & & 42.18 & & 22.08 & & -71.53 & & 162.78 & & 82.70 & & 9.78 & \\
\hline 79-TIL-2-4 & MI (Ol) & TIL & & 2.19 & & 53.45 & & 37.88 & & 354.75 & & 152.28 & & 21.99 & \\
\hline 80-TIL-7-5 & MI (Ol) & TIL & & 2.89 & & 34.45 & & 15.35 & & 386.65 & & 141.50 & & 22.18 & \\
\hline 70_TIL_1_8 & MI (Cpx) & TIL & & 3.27 & & 32.94 & & 23.81 & & 291.09 & & 136.91 & & 29.97 & \\
\hline TIL-MG & Glass & TIL & $\mathrm{n}=6$ & 8.44 & 2.04 & 23.32 & 1.74 & 14.24 & 6.75 & 252.74 & 39.81 & 100.64 & 18.56 & 22.32 & 2.18 \\
\hline
\end{tabular}

Continued 
Table S3. Continued. Trace element composition of Masaya melt inclusions and glasses obtained by LA-ICP-MS. Includes raw data and PEC correction coefficient derived from Petrolog3 (Danyushevsy and Plechov, 2011). Data given in ppm unless noted otherwise.

\begin{tabular}{|c|c|c|c|c|c|c|c|c|c|c|c|c|c|c|c|}
\hline Sample & $\begin{array}{c}\text { Sample } \\
\text { Type }\end{array}$ & Eruption & $\mathrm{n}$ & $\mathrm{Sr}(\mathrm{Kr})$ & $1 \sigma$ & $\mathrm{Y}$ & $1 \sigma$ & $\mathrm{Zr}$ & $1 \sigma$ & $\mathrm{Nb}$ & $1 \sigma$ & $\mathrm{Ba}$ & $1 \sigma$ & $\mathrm{La}$ & $1 \sigma$ \\
\hline 15_MTL_8_4 & MI (Plag) & MTL & & 363.75 & & 28.61 & & 100.80 & & 2.78 & & 705.12 & & 10.62 & \\
\hline 7_MTL_3_10 & MI (Plag) & MTL & & 399.97 & & 27.82 & & 107.45 & & 4.20 & & 795.13 & & 12.48 & \\
\hline 8_MTL_5_10 & MI (Plag) & MTL & & 332.70 & & 22.37 & & 81.64 & & 3.29 & & 941.09 & & 10.17 & \\
\hline 19_MTL_3_8 & MI (Plag) & MTL & & 366.78 & & 18.33 & & 60.49 & & 1.56 & & 880.95 & & 8.35 & \\
\hline 20_MTL_3_9 & MI (Plag) & MTL & & 355.24 & & 15.04 & & 51.49 & & 1.86 & & 715.24 & & 6.99 & \\
\hline 6_MTL_5_7_A & MI (Plag) & MTL & & 346.33 & & 34.24 & & 129.65 & & 4.66 & & 929.77 & & 12.99 & \\
\hline 13_MTL_4_4 & MI (Plag) & MTL & & 317.92 & & 33.37 & & 124.81 & & 4.45 & & 839.74 & & 13.76 & \\
\hline 11_MTL_5_2_A & MI (Plag) & MTL & & 345.19 & & 32.77 & & 124.69 & & 4.48 & & 874.80 & & 12.53 & \\
\hline 11_MTL_5_2_B & MI (Plag) & MTL & & 323.58 & & 22.86 & & 80.23 & & 2.61 & & 607.52 & & 8.26 & \\
\hline 9_MTL_2_6_A & MI (Plag) & MTL & & 355.00 & & 24.82 & & 93.58 & & 3.65 & & 872.68 & & 10.81 & \\
\hline 21_MTL_3_1 & MI (Ol) & MTL & & 401.59 & & 35.06 & & 134.69 & & 4.64 & & 1027.20 & & 14.37 & \\
\hline 22_MTL_7_6 & MI (Ol) & MTL & & 383.24 & & 37.26 & & 135.46 & & 4.31 & & 990.88 & & 13.79 & \\
\hline 12_MTL_7_2 & MI (Ol) & MTL & & 541.96 & & 35.05 & & 82.59 & & 2.52 & & 800.48 & & 9.97 & \\
\hline MTL-MG & Glass & MTL & $\mathrm{n}=4$ & 386.70 & 11.16 & 32.51 & 2.28 & 125.78 & 7.09 & 4.15 & 0.15 & 883.35 & 88.27 & 12.38 & 0.46 \\
\hline 65_TIL_9_9 & MI (Plag) & TIL & & 367.21 & & 34.96 & & 132.25 & & 4.11 & & 792.67 & & 13.46 & \\
\hline 55_TIL_2_8 & $\mathrm{MI}(\mathrm{Ol})$ & TIL & & 430.32 & & 25.50 & & 105.42 & & 3.57 & & 926.79 & & 11.65 & \\
\hline 58_TIL_4_4 & MI (Ol) & TIL & & 282.27 & & 10.78 & & 40.80 & & 2.71 & & 418.88 & & 6.26 & \\
\hline 61_TIL_4_8 & $\mathrm{MI}(\mathrm{Ol})$ & TIL & & 227.54 & & 24.29 & & 96.27 & & 2.88 & & 701.46 & & 8.95 & \\
\hline 71_TIL_7_4 & MI (Ol) & TIL & & -162.53 & & 31.74 & & 112.91 & & 2.81 & & 1017.70 & & 15.24 & \\
\hline 54_TIL_4_5 & MI (Ol) & TIL & & 438.39 & & 23.66 & & 83.83 & & 3.46 & & 645.37 & & 10.11 & \\
\hline 73_TIL_2_10 & $\mathrm{MI}(\mathrm{Ol})$ & TIL & & 396.30 & & 13.64 & & 37.25 & & 2.02 & & 353.72 & & 4.52 & \\
\hline 79-TIL-2-4 & $\mathrm{MI}(\mathrm{Ol})$ & TIL & & 442.87 & & 26.82 & & 97.83 & & 2.96 & & 833.20 & & 10.41 & \\
\hline 80-TIL-7-5 & $\mathrm{MI}(\mathrm{Ol})$ & TIL & & 415.49 & & 29.18 & & 98.67 & & 2.89 & & 807.19 & & 10.17 & \\
\hline 70_TIL_1_8 & MI (Cpx) & TIL & & 419.07 & & 30.84 & & 121.50 & & 4.17 & & 1032.80 & & 13.53 & \\
\hline TIL-MG & Glass & TIL & $\mathrm{n}=6$ & 345.62 & 7.77 & 26.75 & 2.23 & 102.98 & 8.34 & 3.23 & 0.29 & 809.28 & 56.15 & 10.62 & 0.86 \\
\hline
\end{tabular}


Table S3. Continued. Trace element composition of Masaya melt inclusions and glasses obtained by LA-ICP-MS. Includes raw data and PEC correction coefficient derived from Petrolog3 (Danyushevsy and Plechov, 2011). Data given in ppm unless noted otherwise.

\begin{tabular}{|c|c|c|c|c|c|c|c|c|c|c|c|c|c|c|c|}
\hline Sample & $\begin{array}{c}\text { Sample } \\
\text { Type }\end{array}$ & Eruption & $\mathrm{n}$ & $\mathrm{Ce}$ & $1 \sigma$ & $\operatorname{Pr}$ & $1 \sigma$ & $\mathrm{Nd}$ & $1 \sigma$ & $\mathrm{Sm}$ & $1 \sigma$ & $\mathrm{Eu}$ & $1 \sigma$ & Gd(Dy) & $1 \sigma$ \\
\hline 15_MTL_8_4 & MI (Plag) & MTL & & 21.69 & & 3.27 & & 17.61 & & 4.86 & & 1.36 & & 4.78 & \\
\hline 7_MTL_3_10 & MI (Plag) & MTL & & 27.39 & & 4.00 & & 14.16 & & 6.21 & & 1.83 & & 5.69 & \\
\hline 8_MTL_5_10 & MI (Plag) & MTL & & 21.16 & & 3.15 & & 15.34 & & 3.68 & & 1.38 & & 4.38 & \\
\hline 19_MTL_3_8 & MI (Plag) & MTL & & 17.02 & & 2.59 & & 12.98 & & 2.93 & & 1.01 & & 3.53 & \\
\hline 20_MTL_3_9 & MI (Plag) & MTL & & 14.28 & & 2.20 & & 11.78 & & 2.42 & & 0.71 & & 3.36 & \\
\hline 6_MTL_5_7_A & MI (Plag) & MTL & & 26.62 & & 3.99 & & 20.54 & & 4.88 & & 1.68 & & 7.88 & \\
\hline 13_MTL_4_4 & MI (Plag) & MTL & & 27.95 & & 4.20 & & 20.68 & & 5.83 & & 1.50 & & 7.00 & \\
\hline 11_MTL_5_2_A & MI (Plag) & MTL & & 26.33 & & 4.13 & & 20.05 & & 5.54 & & 1.35 & & 5.94 & \\
\hline 11_MTL_5_2_B & MI (Plag) & MTL & & 18.09 & & 2.70 & & 11.86 & & 2.94 & & 1.52 & & 4.24 & \\
\hline 9_MTL_2_6_A & MI (Plag) & MTL & & 23.49 & & 3.66 & & 16.91 & & 4.33 & & 1.40 & & 5.02 & \\
\hline 21_MTL_3_1 & MI (Ol) & MTL & & 29.39 & & 4.49 & & 22.67 & & 5.74 & & 1.89 & & 6.56 & \\
\hline 22_MTL_7_6 & MI (Ol) & MTL & & 27.57 & & 4.36 & & 22.11 & & 5.57 & & 1.60 & & 6.63 & \\
\hline 12_MTL_7_2 & MI (Ol) & MTL & & 20.54 & & 3.27 & & 15.73 & & 4.72 & & 1.60 & & 5.99 & \\
\hline MTL-MG & Glass & MTL & $\mathrm{n}=4$ & 26.09 & 0.99 & 3.91 & 0.15 & 18.87 & 0.84 & 4.90 & 0.49 & 1.50 & 0.16 & 5.56 & 0.27 \\
\hline 65_TIL_9_9 & MI (Plag) & TIL & & 26.29 & & 4.16 & & 20.78 & & 5.96 & & 1.55 & & 5.54 & \\
\hline 55_TIL_2_8 & $\mathrm{MI}(\mathrm{Ol})$ & TIL & & 23.97 & & 3.66 & & 16.54 & & 4.52 & & 1.30 & & 4.65 & \\
\hline 58_TIL_4_4 & MI (Ol) & TIL & & 13.49 & & 1.09 & & 3.71 & & 1.27 & & 0.88 & & 1.65 & \\
\hline 61_TIL_4_8 & MI (Ol) & TIL & & 20.34 & & 3.80 & & 13.83 & & 3.08 & & 0.42 & & 4.79 & \\
\hline 71_TIL_7_4 & MI (Ol) & TIL & & 36.02 & & 4.53 & & 27.19 & & 10.72 & & 0.84 & & 6.22 & \\
\hline 54_TIL_4_5 & MI (Ol) & TIL & & 21.20 & & 3.26 & & 16.71 & & 4.15 & & 1.12 & & 4.36 & \\
\hline 73_TIL_2_10 & $\mathrm{MI}(\mathrm{Ol})$ & TIL & & 11.09 & & 1.71 & & 7.36 & & 2.39 & & 0.77 & & 2.14 & \\
\hline 79-TIL-2-4 & MI (Ol) & TIL & & 21.09 & & 3.32 & & 17.20 & & 3.87 & & 1.27 & & 4.23 & \\
\hline 80-TIL-7-5 & $\mathrm{MI}(\mathrm{Ol})$ & TIL & & 20.27 & & 3.20 & & 15.69 & & 3.93 & & 1.22 & & 4.37 & \\
\hline 70_TIL_1_8 & MI (Cpx) & TIL & & 28.67 & & 4.30 & & 20.41 & & 5.43 & & 1.58 & & 5.30 & \\
\hline TIL-MG & Glass & TIL & $n=6$ & 21.77 & 2.07 & 3.33 & 0.27 & 16.04 & 1.50 & 4.17 & 0.32 & 1.25 & 0.10 & 4.52 & 0.56 \\
\hline
\end{tabular}


Table S3. Continued. Trace element composition of Masaya melt inclusions and glasses obtained by LA-ICP-MS. Includes raw data and PEC correction coefficient derived from Petrolog3 (Danyushevsy and Plechov, 2011). Data given in ppm unless noted otherwise.

\begin{tabular}{|c|c|c|c|c|c|c|c|c|c|c|c|c|c|c|c|}
\hline Sample & $\begin{array}{c}\text { Sample } \\
\text { Type }\end{array}$ & Eruption & $\mathrm{n}$ & $\mathrm{Tb}$ & $1 \sigma$ & Dy & $1 \sigma$ & Ho & $1 \sigma$ & $\mathrm{Er}$ & $1 \sigma$ & $\mathrm{Tm}$ & $1 \sigma$ & $\mathrm{Yb}$ & $1 \sigma$ \\
\hline 15_MTL_8_4 & MI (Plag) & MTL & & 0.83 & & 5.03 & & 1.00 & & 3.59 & & 0.36 & & 2.75 & \\
\hline 7_MTL_3_10 & MI (Plag) & MTL & & 0.92 & & 5.78 & & 1.18 & & 3.21 & & 0.43 & & 3.29 & \\
\hline 8_MTL_5_10 & MI (Plag) & MTL & & 0.62 & & 4.53 & & 0.84 & & 2.65 & & 0.36 & & 2.29 & \\
\hline 19_MTL_3_8 & MI (Plag) & MTL & & 0.56 & & 3.32 & & 0.69 & & 1.76 & & 0.21 & & 1.82 & \\
\hline 20_MTL_3_9 & MI (Plag) & MTL & & 0.39 & & 3.25 & & 0.58 & & 1.57 & & 0.23 & & 1.56 & \\
\hline 6_MTL_5_7_A & MI (Plag) & MTL & & 0.85 & & 6.37 & & 1.29 & & 4.49 & & 0.63 & & 4.64 & \\
\hline 13_MTL_4_4 & MI (Plag) & MTL & & 0.98 & & 6.35 & & 1.43 & & 4.21 & & 0.53 & & 3.65 & \\
\hline 11_MTL_5_2_A & MI (Plag) & MTL & & 0.97 & & 6.24 & & 1.32 & & 3.92 & & 0.51 & & 3.51 & \\
\hline 11_MTL_5_2_B & MI (Plag) & MTL & & 0.70 & & 3.86 & & 0.93 & & 2.91 & & 0.35 & & 3.17 & \\
\hline 9_MTL_2_6_A & MI (Plag) & MTL & & 0.75 & & 4.75 & & 1.03 & & 2.78 & & 0.44 & & 2.90 & \\
\hline 21_MTL_3_1 & MI (Ol) & MTL & & 1.05 & & 6.66 & & 1.36 & & 4.23 & & 0.53 & & 3.74 & \\
\hline 22_MTL_7_6 & MI (Ol) & MTL & & 1.01 & & 6.78 & & 1.44 & & 4.18 & & 0.57 & & 4.00 & \\
\hline 12_MTL_7_2 & MI (Ol) & MTL & & 0.97 & & 6.52 & & 1.38 & & 3.85 & & 0.62 & & 3.66 & \\
\hline MTL-MG & Glass & MTL & $\mathrm{n}=4$ & 0.78 & 0.12 & 5.52 & 0.43 & 1.16 & 0.10 & 3.28 & 0.40 & 0.46 & 0.04 & 3.08 & 0.14 \\
\hline 65_TIL_9_9 & MI (Plag) & TIL & & 0.80 & & 5.11 & & 1.14 & & 3.82 & & 0.51 & & 3.12 & \\
\hline 55_TIL_2_8 & $\mathrm{MI}(\mathrm{Ol})$ & TIL & & 0.75 & & 4.43 & & 0.91 & & 2.45 & & 0.34 & & 2.18 & \\
\hline 58_TIL_4_4 & MI (Ol) & TIL & & 0.14 & & 1.51 & & 0.35 & & 1.40 & & 0.43 & & -0.36 & \\
\hline 61_TIL_4_8 & MI (Ol) & TIL & & 0.68 & & 4.37 & & 0.75 & & 2.02 & & 0.16 & & 0.47 & \\
\hline 71_TIL_7_4 & MI (Ol) & TIL & & 0.57 & & 6.93 & & 0.39 & & 7.77 & & 0.30 & & -0.46 & \\
\hline 54_TIL_4_5 & MI (Ol) & TIL & & 0.55 & & 3.62 & & 0.88 & & 2.17 & & 0.41 & & 2.38 & \\
\hline 73_TIL_2_10 & $\mathrm{MI}(\mathrm{Ol})$ & TIL & & 0.39 & & 2.26 & & 0.31 & & 0.95 & & 0.23 & & 1.51 & \\
\hline 79-TIL-2-4 & MI (Ol) & TIL & & 0.75 & & 4.65 & & 0.97 & & 2.63 & & 0.49 & & 3.03 & \\
\hline 80-TIL-7-5 & $\mathrm{MI}(\mathrm{Ol})$ & TIL & & 0.75 & & 4.52 & & 0.96 & & 2.90 & & 0.47 & & 2.68 & \\
\hline 70_TIL_1_8 & MI (Cpx) & TIL & & 0.82 & & 5.05 & & 1.09 & & 3.10 & & 0.44 & & 3.14 & \\
\hline TIL-MG & Glass & TIL & $n=6$ & 0.70 & 0.07 & 4.51 & 0.41 & 0.94 & 0.09 & 2.77 & 0.27 & 0.38 & 0.03 & 2.62 & 0.20 \\
\hline
\end{tabular}


Table S3. Continued. Trace element composition of Masaya melt inclusions and glasses obtained by LA-ICP-MS. Includes raw data and PEC correction coefficient derived from Petrolog3 (Danyushevsy and Plechov, 2011). Data given in ppm unless noted otherwise.

\begin{tabular}{|c|c|c|c|c|c|c|c|c|c|c|c|c|}
\hline Sample & $\begin{array}{c}\text { Sample } \\
\text { Type }\end{array}$ & Eruption & $\mathrm{n}$ & $\mathrm{Lu}$ & $1 \sigma$ & $\mathrm{Pb}$ & $1 \sigma$ & $\mathrm{Th}$ & $1 \sigma$ & $\mathrm{U}$ & $1 \sigma$ & $\begin{array}{l}\text { Corr } \\
\text { Coef }\end{array}$ \\
\hline 15_MTL_8_4 & MI (Plag) & MTL & & 0.51 & & 4.16 & & 1.81 & & 1.30 & & \\
\hline 7_MTL_3_10 & MI (Plag) & MTL & & 0.35 & & 6.08 & & 2.12 & & 1.65 & & \\
\hline 8_MTL_5_10 & MI (Plag) & MTL & & 0.33 & & 4.35 & & 1.48 & & 1.23 & & \\
\hline 19_MTL_3_8 & MI (Plag) & MTL & & 0.30 & & 3.55 & & 1.21 & & 0.88 & & \\
\hline 20 MTL 399 & MI (Plag) & MTL & & 0.23 & & 3.34 & & 0.85 & & 0.81 & & \\
\hline 6_MTL_5_7_A & MI (Plag) & MTL & & 0.63 & & 5.04 & & 2.28 & & 1.69 & & \\
\hline 13_MTL_4_4 & MI (Plag) & MTL & & 0.56 & & 5.50 & & 2.45 & & 1.76 & & \\
\hline 11_MTL_5_2_A & MI (Plag) & MTL & & 0.57 & & 4.86 & & 2.22 & & 1.75 & & \\
\hline 11_MTL_5_2_B & MI (Plag) & MTL & & 0.49 & & 4.86 & & 1.29 & & 1.28 & & \\
\hline 9_MTL_2_6_A & MI (Plag) & MTL & & 0.50 & & 4.27 & & 2.01 & & 1.55 & & \\
\hline 21_MTL_3_1 & MI (Ol) & MTL & & 0.64 & & 5.02 & & 2.46 & & 1.83 & & 0.987 \\
\hline 22_MTL_7_6 & MI (Ol) & MTL & & 0.62 & & 4.79 & & 2.47 & & 1.62 & & 1.003 \\
\hline 12_MTL_7_2 & MI (Ol) & MTL & & 0.51 & & 3.69 & & 1.63 & & 1.18 & & 1.015 \\
\hline$\overline{\mathrm{MTL}}-\overline{\mathrm{M}} \overline{\mathrm{C}}$ & Glass & MTL & $\mathrm{n}=4$ & 0.47 & 0.03 & 4.48 & 0.81 & 1.89 & 0.12 & 1.47 & 0.05 & \\
\hline 65_TIL_9_9 & MI (Plag) & TIL & & 0.53 & & 4.79 & & 2.07 & & 1.37 & & \\
\hline 55_TIL_2_8 & $\mathrm{MI}(\mathrm{Ol})$ & TIL & & 0.37 & & 3.95 & & 1.75 & & 1.35 & & 0.942 \\
\hline 58_TIL_4_4 & MI (Ol) & TIL & & 0.39 & & 1.19 & & 0.31 & & 1.33 & & 0.770 \\
\hline 61_TIL_4_8 & MI (Ol) & TIL & & -0.13 & & 1.01 & & 1.75 & & 1.02 & & 1.007 \\
\hline 71_TIL_7_4 & MI (Ol) & TIL & & 0.97 & & 5.49 & & 1.68 & & 1.49 & & 0.903 \\
\hline 54_TIL_4_5 & MI (Ol) & TIL & & 0.29 & & 3.84 & & 1.14 & & 1.07 & & 0.915 \\
\hline 73 TIL 2 - 10 & MI (Ol) & TIL & & 0.17 & & 1.96 & & 0.74 & & 0.46 & & 0.773 \\
\hline 79-TIL-2-4 & MI (Ol) & TIL & & 0.39 & & 3.55 & & 1.51 & & 1.19 & & 0.973 \\
\hline 80-TIL-7-5 & MI (Ol) & TIL & & 0.40 & & 3.81 & & 1.60 & & 1.14 & & 0.992 \\
\hline 70_TIL_1_8 & MI (Cpx) & TIL & & 0.47 & & 4.94 & & 2.09 & & 1.67 & & \\
\hline TIL-MG & Glass & TIL & $\mathrm{n}=6$ & 0.41 & 0.04 & 3.94 & 0.49 & 1.72 & 0.16 & 1.27 & 0.15 & \\
\hline
\end{tabular}


Table S4. Major- and minor-element composition of Masaya host minerals obtained by EPMA. Includes raw data for points located on the host mineral adjacent to the melt inclusion (MI), near the mineral core, and near the mineral rim. Data given in wt.\%. All Fe is reported as $\mathrm{FeO}$.

\begin{tabular}{|c|c|c|c|c|c|c|c|c|c|c|c|c|c|}
\hline Sample & Min Type & Eruption & $\mathrm{Na}_{2} \mathrm{O}$ & $\mathrm{Al}_{2} \mathrm{O}_{3}$ & $\mathrm{MgO}$ & $\mathrm{SiO}_{2}$ & $\mathrm{~K}_{2} \mathrm{O}$ & $\mathrm{P}_{2} \mathrm{O}_{5}$ & $\mathrm{CaO}$ & $\mathrm{TiO}_{2}$ & $\mathrm{MnO}$ & $\mathrm{FeO}$ & Total \\
\hline 23_LL_3A_hostmin_MI & Plag & LL & 2.52 & 32.47 & 0.10 & 49.02 & 0.13 & 0.00 & 15.45 & 0.07 & 0.04 & 1.09 & 100.90 \\
\hline 23 LL $3 \mathrm{~A}$ hostmin core & Plag & LL & 3.47 & 30.89 & 0.08 & 51.22 & 0.21 & 0.00 & 13.56 & 0.01 & 0.00 & 1.07 & 100.50 \\
\hline 23_LL_3A_hostmin_rim & Plag & LL & 2.46 & 32.67 & 0.17 & 48.80 & 0.14 & 0.03 & 15.86 & 0.00 & 0.00 & 1.09 & 101.23 \\
\hline 39_LL_39_hostmin_MI_A & Plag & LL & 2.34 & 32.89 & 0.14 & 48.00 & 0.13 & 0.00 & 15.61 & 0.10 & 0.04 & 1.08 & 100.32 \\
\hline 39_LL_39_hostmin_MI_B & Plag & LL & 2.45 & 32.48 & 0.13 & 48.51 & 0.13 & 0.01 & 15.84 & 0.00 & 0.00 & 1.10 & 100.65 \\
\hline 39_LL_39 hostmin_core & Plag & LL & 2.09 & 33.16 & 0.15 & 47.53 & 0.10 & 0.02 & 16.57 & 0.04 & 0.00 & 1.00 & 100.66 \\
\hline 39_LL_39_hostmin_rim & Plag & LL & 3.57 & 30.57 & 0.07 & 51.15 & 0.20 & 0.00 & 13.82 & 0.07 & 0.03 & 1.11 & 100.59 \\
\hline 38_LL_10_hostmin_MI_A & Plag & LL & 2.68 & 32.17 & 0.13 & 48.64 & 0.16 & 0.02 & 14.83 & 0.00 & 0.07 & 1.10 & 99.80 \\
\hline 38_LL_10_hostmin_MI_B & Plag & LL & 2.64 & 31.87 & 0.13 & 49.09 & 0.16 & 0.00 & 15.09 & 0.01 & 0.00 & 1.09 & 100.09 \\
\hline 38_LL_10_hostmin_core & Plag & LL & 2.95 & 31.59 & 0.13 & 49.58 & 0.19 & 0.00 & 14.53 & 0.03 & 0.00 & 0.98 & 100.00 \\
\hline 38_LL_10_hostmin_rim 1 & Plag & LL & 2.32 & 32.58 & 0.16 & 48.11 & 0.11 & 0.00 & 15.96 & 0.04 & 0.00 & 1.09 & 100.36 \\
\hline 38_LL_10_hostmin_rim2 & Plag & LL & 2.46 & 32.84 & 0.35 & 48.29 & 0.13 & 0.00 & 15.79 & 0.04 & 0.01 & 1.10 & 101.01 \\
\hline 37_LL_50_hostmin_MI_A & Plag & LL & 2.94 & 31.57 & 0.20 & 49.80 & 0.17 & 0.04 & 14.79 & 0.05 & 0.03 & 1.19 & 100.80 \\
\hline 37_LL_50_hostmin_MI_B & Plag & LL & 2.59 & 32.22 & 0.15 & 48.81 & 0.13 & 0.02 & 15.66 & 0.01 & 0.00 & 1.04 & 100.63 \\
\hline 37_LL_50_hostmin_core & Plag & LL & 2.70 & 31.83 & 0.17 & 49.34 & 0.15 & 0.01 & 15.12 & 0.00 & 0.00 & 1.04 & 100.36 \\
\hline 32_LL_27_hostmin_MI & Plag & LL & 2.59 & 32.24 & 0.17 & 48.93 & 0.12 & 0.01 & 15.48 & 0.00 & 0.00 & 1.02 & 100.56 \\
\hline 32_LL_27_hostmin_core & Plag & LL & 2.35 & 32.50 & 0.15 & 48.62 & 0.15 & 0.02 & 15.57 & 0.05 & 0.00 & 1.05 & 100.47 \\
\hline 32_LL_27_hostmin_rim & Plag & LL & 2.23 & 32.52 & 0.07 & 47.97 & 0.11 & 0.00 & 15.86 & 0.02 & 0.01 & 1.06 & 99.86 \\
\hline 31_LL_40_hostmin_MI & Plag & LL & 3.34 & 31.05 & 0.00 & 50.77 & 0.18 & 0.00 & 14.04 & 0.04 & 0.00 & 1.05 & 100.48 \\
\hline 31_LL_40_hostmin_core & Plag & LL & 2.91 & 31.56 & 0.00 & 49.76 & 0.17 & 0.00 & 14.89 & 0.04 & 0.00 & 0.98 & 100.31 \\
\hline 31_LL_40_hostmin_rim & Plag & LL & 3.65 & 30.38 & 0.16 & 51.25 & 0.22 & 0.00 & 13.60 & 0.00 & 0.00 & 1.12 & 100.38 \\
\hline 27_LL_19_hostmin_MI & Plag & LL & 2.87 & 31.67 & 0.17 & 49.28 & 0.16 & 0.00 & 14.70 & 0.05 & 0.00 & 0.94 & 99.84 \\
\hline 27_LL_19_hostmin_core & Plag & LL & 2.74 & 31.82 & 0.00 & 49.04 & 0.17 & 0.02 & 14.88 & 0.02 & 0.00 & 1.06 & 99.75 \\
\hline 27_LL_19_hostmin_rim & Plag & LL & 2.67 & 31.49 & 0.18 & 49.12 & 0.15 & 0.02 & 14.73 & 0.03 & 0.02 & 1.07 & 99.46 \\
\hline 25_LL_9_hostmin_MI_A & Plag & LL & 1.98 & 33.17 & 0.13 & 47.35 & 0.10 & 0.00 & 16.51 & 0.03 & 0.00 & 1.03 & 100.31 \\
\hline 25_LL 9 hostmin MI B & Plag & LL & 2.38 & 32.51 & 0.15 & 48.33 & 0.12 & 0.04 & 15.89 & 0.03 & 0.00 & 1.08 & 100.53 \\
\hline 25_LL_9_hostmin_core & Plag & LL & 1.91 & 33.03 & 0.12 & 47.08 & 0.09 & 0.04 & 16.49 & 0.05 & 0.01 & 1.00 & 99.81 \\
\hline $25^{-} \mathrm{LL}^{-} 9$ hostmin rim & Plag & LL & 2.48 & 32.38 & 0.14 & 48.80 & 0.13 & 0.01 & 15.52 & 0.05 & 0.00 & 1.14 & 100.67 \\
\hline
\end{tabular}

Continued 
Table S4. Continued. Major- and minor-element composition of Masaya host minerals obtained by EPMA. Includes raw data for points located on the host mineral adjacent to the melt inclusion (MI), near the mineral core, and near the mineral rim. Data given in wt.\%. All Fe is reported as FeO.

\begin{tabular}{|c|c|c|c|c|c|c|c|c|c|c|c|c|c|}
\hline Sample & Min Type & Eruption & $\mathrm{Na}_{2} \mathrm{O}$ & $\mathrm{Al}_{2} \mathrm{O}_{3}$ & $\mathrm{MgO}$ & $\mathrm{SiO}_{2}$ & $\mathrm{~K}_{2} \mathrm{O}$ & $\mathrm{P}_{2} \mathrm{O}_{5}$ & $\mathrm{CaO}$ & $\mathrm{TiO}_{2}$ & $\mathrm{MnO}$ & $\mathrm{FeO}$ & Total \\
\hline 24_LL_8_hostmin_MI & Plag & LL & 2.79 & 31.83 & 0.14 & 49.31 & 0.14 & 0.02 & 15.09 & 0.04 & 0.00 & 1.08 & 100.44 \\
\hline 24_LL_8_hostmin_core & Plag & LL & 2.93 & 31.83 & 0.13 & 49.32 & 0.18 & 0.02 & 15.07 & 0.09 & 0.04 & 1.15 & 100.75 \\
\hline 24_LL_8_hostmin_rim & Plag & LL & 2.87 & 31.72 & 0.16 & 49.67 & 0.18 & 0.00 & 14.96 & 0.08 & 0.04 & 1.08 & 100.77 \\
\hline 42_LL_20_hostmin_MI_A & Plag & LL & 3.03 & 31.07 & 0.16 & 50.19 & 0.17 & 0.01 & 14.46 & 0.12 & 0.03 & 1.04 & 100.29 \\
\hline 42_LL_20_hostmin_MI_B & Plag & LL & 2.52 & 32.46 & 0.17 & 48.99 & 0.13 & 0.00 & 15.45 & 0.03 & 0.03 & 1.18 & 100.98 \\
\hline 42_LL_20_hostmin_core & Plag & LL & 2.70 & 31.99 & 0.06 & 48.99 & 0.16 & 0.01 & 15.01 & 0.00 & 0.08 & 1.10 & 100.11 \\
\hline 42_LL_20_hostmin_rim & Plag & LL & 2.40 & 32.74 & 0.14 & 48.34 & 0.14 & 0.00 & 15.97 & 0.05 & 0.00 & 1.02 & 100.81 \\
\hline 41_LL_17_hostmin_MI_A & Plag & LL & 2.65 & 32.38 & 0.17 & 48.91 & 0.14 & 0.05 & 15.56 & 0.00 & 0.01 & 1.01 & 100.88 \\
\hline 41_LL_17_hostmin_MI & Plag & LL & 2.43 & 32.80 & 0.15 & 48.39 & 0.11 & 0.05 & 15.63 & 0.08 & 0.05 & 1.13 & 100.82 \\
\hline 41_LL_17_hostmin_core & Plag & LL & 1.98 & 32.87 & 0.13 & 47.83 & 0.09 & 0.01 & 16.30 & 0.05 & 0.02 & 1.08 & 100.35 \\
\hline 41_LL_17_hostmin_rim & Plag & LL & 2.64 & 32.19 & 0.00 & 49.14 & 0.13 & 0.02 & 15.16 & 0.01 & 0.03 & 1.05 & 100.37 \\
\hline 33_LL_42_hostmin_MI & Plag & LL & 2.09 & 33.26 & 0.00 & 47.84 & 0.10 & 0.02 & 16.33 & 0.03 & 0.02 & 0.96 & 100.65 \\
\hline 33_LL_42_hostmin_core & Plag & LL & 2.25 & 32.43 & 0.24 & 48.19 & 0.12 & 0.03 & 15.97 & 0.05 & 0.00 & 1.24 & 100.52 \\
\hline 33_LL_42_hostmin_rim & Plag & LL & 2.09 & 32.98 & 0.03 & 47.74 & 0.10 & 0.00 & 16.25 & 0.04 & 0.00 & 0.98 & 100.22 \\
\hline 26_LL_11_hostmin_MI_A & $\mathrm{Ol}$ & LL & 0.00 & 0.04 & 37.99 & 38.05 & 0.02 & 0.02 & 0.34 & 0.00 & 0.37 & 24.36 & 101.18 \\
\hline 26_LL_11_hostmin_MI_B & $\mathrm{Ol}$ & LL & 0.01 & 0.00 & 38.11 & 37.68 & 0.00 & 0.03 & 0.27 & 0.02 & 0.49 & 24.62 & 101.25 \\
\hline 26_LL_11_hostmin_MI_C & $\mathrm{Ol}$ & LL & 0.00 & 0.07 & 38.14 & 37.79 & 0.00 & 0.01 & 0.32 & 0.00 & 0.34 & 24.56 & 101.24 \\
\hline 26_LL_11_hostmin_core & $\mathrm{Ol}$ & LL & 0.01 & 0.03 & 38.22 & 37.52 & 0.00 & 0.01 & 0.28 & 0.00 & 0.48 & 24.83 & 101.37 \\
\hline 26_LL_11_hostmin_rim & $\mathrm{Ol}$ & LL & 0.02 & 0.03 & 37.75 & 37.37 & 0.01 & 0.03 & 0.25 & 0.06 & 0.42 & 24.45 & 100.40 \\
\hline 26_LL_11A_hostmin_MI & $\mathrm{Ol}$ & LL & 0.00 & 0.03 & 37.84 & 38.27 & 0.00 & 0.00 & 0.31 & 0.00 & 0.35 & 24.06 & 100.85 \\
\hline 26_LL_11A_hostmin_core & $\mathrm{Ol}$ & LL & 0.00 & 0.01 & 37.73 & 38.31 & 0.01 & 0.02 & 0.24 & 0.05 & 0.44 & 24.20 & 101.01 \\
\hline 26_LL_11A_hostmin_rim & $\mathrm{Ol}$ & LL & 2.82 & 13.98 & 4.72 & 50.98 & 1.49 & 0.33 & 8.86 & 1.49 & 0.26 & 13.04 & 97.98 \\
\hline 34_LL2_5_hostmin_MI & $\mathrm{Ol}$ & LL & 0.00 & 0.00 & 38.29 & 37.59 & 0.00 & 0.04 & 0.33 & 0.04 & 0.43 & 23.97 & 100.69 \\
\hline 34_LL2_5_hostmin_core & $\mathrm{Ol}$ & LL & 0.00 & 0.03 & 38.25 & 38.01 & 0.01 & 0.03 & 0.30 & 0.02 & 0.48 & 24.02 & 101.15 \\
\hline 34_LL2_5_hostmin_rim & $\mathrm{Ol}$ & LL & 0.00 & 0.04 & 38.32 & 37.76 & 0.00 & 0.05 & 0.29 & 0.03 & 0.45 & 24.16 & 101.11 \\
\hline LL2_33_hostmin_MI & $\mathrm{Ol}$ & LL & 3.15 & 13.87 & 4.61 & 51.45 & 1.54 & 0.41 & 8.67 & 1.37 & 0.27 & 13.71 & 99.04 \\
\hline LL2_33_hostmin_core & $\mathrm{Ol}$ & LL & 0.00 & 0.01 & 38.16 & 38.19 & 0.02 & 0.02 & 0.24 & 0.02 & 0.43 & 24.59 & 101.69 \\
\hline LL2_33_hostmin_rim1 & $\mathrm{Ol}$ & LL & 0.03 & 0.00 & 38.31 & 38.06 & 0.00 & 0.03 & 0.32 & 0.02 & 0.38 & 24.74 & 101.89 \\
\hline LL2 33 hostmin rim2 & $\mathrm{Ol}$ & $\mathrm{LL}$ & 3.06 & 13.82 & 4.72 & 51.65 & 1.44 & 0.34 & 8.76 & 1.47 & 0.30 & 13.91 & 99.47 \\
\hline
\end{tabular}

Continued 
Table S4. Continued. Major- and minor-element composition of Masaya host minerals obtained by EPMA. Includes raw data for points located on the host mineral adjacent to the melt inclusion (MI), near the mineral core, and near the mineral rim. Data given in wt.\%. All Fe is reported as FeO.

\begin{tabular}{|c|c|c|c|c|c|c|c|c|c|c|c|c|c|}
\hline Sample & Min Type & Eruption & $\mathrm{Na}_{2} \mathrm{O}$ & $\mathrm{Al}_{2} \mathrm{O}_{3}$ & $\mathrm{MgO}$ & $\mathrm{SiO}_{2}$ & $\mathrm{~K}_{2} \mathrm{O}$ & $\mathrm{P}_{2} \mathrm{O}_{5}$ & $\mathrm{CaO}$ & $\mathrm{TiO}_{2}$ & $\mathrm{MnO}$ & $\mathrm{FeO}$ & Total \\
\hline 46_LL2_37_hostmin_MI & $\mathrm{Cpx}$ & LL & 0.31 & 3.30 & 15.28 & 50.69 & 0.00 & 0.00 & 20.76 & 0.51 & 0.24 & 9.11 & 100.21 \\
\hline 46_LL2_37_hostmin_core & $\mathrm{Cpx}$ & LL & 0.33 & 3.44 & 15.41 & 49.83 & 0.00 & 0.00 & 20.27 & 0.50 & 0.26 & 9.26 & 99.30 \\
\hline 46_LL2_37_hostmin_rim & $\mathrm{Cpx}$ & LL & 0.31 & 3.15 & 15.41 & 50.67 & 0.01 & 0.01 & 20.28 & 0.48 & 0.25 & 9.11 & 99.67 \\
\hline 15_MTL_8_4_hostmin_MI & Plag & MTL & 2.27 & 32.46 & 0.06 & 48.13 & 0.11 & 0.04 & 15.92 & 0.00 & 0.04 & 0.96 & 99.99 \\
\hline 15_MTL_8_4_hostmin_core & Plag & MTL & 1.67 & 33.56 & 0.08 & 46.72 & 0.07 & 0.02 & 17.29 & 0.01 & 0.01 & 0.94 & 100.37 \\
\hline 15_MTL_8_4_hostmin_rim & Plag & MTL & 1.66 & 33.63 & 0.00 & 46.59 & 0.06 & 0.00 & 17.24 & 0.03 & 0.00 & 0.92 & 100.13 \\
\hline 7_MTL_3_10_hostmin_MI & Plag & MTL & 2.31 & 32.91 & 0.14 & 48.34 & 0.12 & 0.01 & 16.28 & 0.07 & 0.02 & 1.03 & 101.26 \\
\hline 7_MTL_3_10_hostmin_core & Plag & MTL & 2.31 & 32.76 & 0.00 & 48.30 & 0.12 & 0.02 & 16.00 & 0.04 & 0.01 & 0.99 & 100.56 \\
\hline 7_MTL_3_10_hostmin_rim & Plag & MTL & 2.19 & 32.62 & 0.11 & 48.04 & 0.12 & 0.01 & 16.07 & 0.01 & 0.04 & 0.94 & 100.15 \\
\hline 8_MTL_5_10_hostmin_MI & Plag & MTL & 2.56 & 32.34 & 0.13 & 48.86 & 0.11 & 0.02 & 15.84 & 0.03 & 0.00 & 0.94 & 100.84 \\
\hline 8_MTL_5_10_hostmin_core & Plag & MTL & 2.41 & 32.54 & 0.12 & 48.53 & 0.13 & 0.02 & 15.91 & 0.06 & 0.02 & 1.03 & 100.77 \\
\hline 8_MTL_5_10_hostmin_rim & Plag & MTL & 1.97 & 33.38 & 0.07 & 47.40 & 0.08 & 0.01 & 16.65 & 0.05 & 0.00 & 0.97 & 100.58 \\
\hline 19_MTL_3_8_hostmin_MI & Plag & MTL & 1.60 & 34.15 & 0.09 & 46.62 & 0.05 & 0.00 & 17.24 & 0.02 & 0.01 & 0.83 & 100.61 \\
\hline 19_MTL_3_8_hostmin_core & Plag & MTL & 1.44 & 34.53 & 0.08 & 45.93 & 0.05 & 0.00 & 17.58 & 0.02 & 0.07 & 0.96 & 100.67 \\
\hline 19_MTL_3_8_hostmin_rim & Plag & MTL & 1.85 & 33.58 & 0.10 & 47.15 & 0.06 & 0.01 & 16.80 & 0.05 & 0.01 & 0.88 & 100.50 \\
\hline 20_MTL_3_9_hostmin_MI & Plag & MTL & 2.26 & 33.07 & 0.11 & 48.27 & 0.11 & 0.04 & 16.28 & 0.05 & 0.00 & 1.04 & 101.23 \\
\hline 20_MTL_3_9_hostmin_core & Plag & MTL & 2.14 & 32.89 & 0.12 & 48.09 & 0.13 & 0.00 & 16.30 & 0.00 & 0.03 & 1.02 & 100.71 \\
\hline 20_MTL_3_9_hostmin_rim & Plag & MTL & 2.03 & 32.90 & 0.10 & 47.33 & 0.09 & 0.00 & 16.21 & 0.02 & 0.02 & 0.98 & 99.68 \\
\hline 6_MTL_5_7_hostmin_MI_A & Plag & MTL & 1.86 & 33.53 & 0.13 & 47.08 & 0.09 & 0.04 & 17.00 & 0.05 & 0.00 & 1.07 & 100.86 \\
\hline 6_MTL_5_7_hostmin_MI_B & Plag & MTL & 1.78 & 33.93 & 0.11 & 46.92 & 0.06 & 0.01 & 17.01 & 0.01 & 0.00 & 1.01 & 100.85 \\
\hline 6_MTL_5_7_hostmin_core & Plag & MTL & 1.59 & 34.07 & 0.14 & 46.66 & 0.07 & 0.00 & 17.39 & 0.02 & 0.03 & 1.03 & 101.00 \\
\hline 6_MTL_5_7_hostmin_rim & Plag & MTL & 1.69 & 33.89 & 0.10 & 46.17 & 0.08 & 0.00 & 17.27 & 0.01 & 0.01 & 1.02 & 100.24 \\
\hline 13_MTL_4_4_hostmin_MI & Plag & MTL & 1.66 & 33.56 & 0.08 & 46.99 & 0.09 & 0.00 & 16.81 & 0.08 & 0.00 & 1.02 & 100.28 \\
\hline 13_MTL_4_4_hostmin_core & Plag & MTL & 2.14 & 33.14 & 0.12 & 47.93 & 0.13 & 0.06 & 16.37 & 0.00 & 0.02 & 1.00 & 100.91 \\
\hline 13_MTL_4_4_hostmin_rim & Plag & MTL & 1.76 & 33.77 & 0.10 & 47.07 & 0.07 & 0.02 & 17.10 & 0.00 & 0.00 & 0.88 & 100.76 \\
\hline 11_MTL_5_2_hostmin_MI & Plag & MTL & 1.38 & 34.36 & 0.07 & 45.93 & 0.08 & 0.00 & 17.61 & 0.00 & 0.01 & 0.83 & 100.26 \\
\hline 11_MTL_5_2_hostmin_core & Plag & MTL & 1.26 & 34.57 & 0.10 & 45.67 & 0.02 & 0.02 & 17.99 & 0.00 & 0.04 & 0.95 & 100.63 \\
\hline 11_MTL_5_2_hostmin_rim & Plag & MTL & 2.13 & 33.28 & 0.00 & 47.91 & 0.12 & 0.00 & 16.06 & 0.08 & 0.00 & 0.97 & 100.54 \\
\hline
\end{tabular}

Continued 
Table S4. Continued. Major- and minor-element composition of Masaya host minerals obtained by EPMA. Includes raw data for points located on the host mineral adjacent to the melt inclusion (MI), near the mineral core, and near the mineral rim. Data given in wt.\%. All Fe is reported as FeO.

\begin{tabular}{|c|c|c|c|c|c|c|c|c|c|c|c|c|c|}
\hline Sample & Min Type & Eruption & $\mathrm{Na}_{2} \mathrm{O}$ & $\mathrm{Al}_{2} \mathrm{O}_{3}$ & $\mathrm{MgO}$ & $\mathrm{SiO}_{2}$ & $\mathrm{~K}_{2} \mathrm{O}$ & $\mathrm{P}_{2} \mathrm{O}_{5}$ & $\mathrm{CaO}$ & $\mathrm{TiO}_{2}$ & $\mathrm{MnO}$ & $\mathrm{FeO}$ & Total \\
\hline 9_MTL_2_6_hostmin_MI & Plag & MTL & 2.11 & 33.26 & 0.14 & 47.74 & 0.10 & 0.04 & 16.26 & 0.08 & 0.01 & 1.00 & 100.74 \\
\hline 9_MTL_2_6_hostmin_core & Plag & MTL & 2.17 & 33.07 & 0.00 & 47.51 & 0.11 & 0.01 & 16.54 & 0.02 & 0.04 & 1.08 & 100.56 \\
\hline 9_MTL_2_6_hostmin_rim & Plag & MTL & 2.26 & 33.07 & 0.00 & 48.01 & 0.11 & 0.01 & 16.18 & 0.03 & 0.03 & 0.93 & 100.63 \\
\hline 21_MTL_3_1_hostmin_MI & $\mathrm{Ol}$ & MTL & 0.02 & 0.06 & 36.67 & 37.76 & 0.01 & 0.01 & 0.26 & 0.00 & 0.51 & 25.99 & 101.29 \\
\hline 21_MTL_3_1_hostmin_core & $\mathrm{Ol}$ & MTL & 0.00 & 0.02 & 36.49 & 37.77 & 0.01 & 0.02 & 0.31 & 0.05 & 0.47 & 26.34 & 101.48 \\
\hline 21_MTL_3_1_hostmin_rim & $\mathrm{Ol}$ & MTL & 0.00 & 0.02 & 36.35 & 37.76 & 0.00 & 0.02 & 0.24 & 0.00 & 0.52 & 26.13 & 101.06 \\
\hline 22_MTL_7_6_hostmin_MI & $\mathrm{Ol}$ & MTL & 0.02 & 0.00 & 36.98 & 37.74 & 0.01 & 0.00 & 0.28 & 0.04 & 0.44 & 26.13 & 101.63 \\
\hline 22_MTL_7_6_hostmin_core & $\mathrm{Ol}$ & MTL & 0.03 & 0.02 & 36.56 & 38.06 & 0.01 & 0.14 & 0.23 & 0.03 & 0.50 & 26.07 & 101.65 \\
\hline 22_MTL_7_6_hostmin_rim & $\mathrm{Ol}$ & MTL & 0.00 & 0.00 & 36.54 & 38.02 & 0.00 & 0.01 & 0.30 & 0.02 & 0.43 & 25.97 & 101.30 \\
\hline 12_MTL_7_2_hostmin_MI & $\mathrm{O} 1$ & MTL & 0.01 & 0.05 & 36.23 & 38.00 & 0.00 & 0.00 & 0.23 & 0.00 & 0.46 & 26.46 & 101.44 \\
\hline 12_MTL_7_2_hostmin_core & $\mathrm{Ol}$ & MTL & 0.00 & 0.00 & 36.56 & 37.81 & 0.02 & 0.02 & 0.25 & 0.04 & 0.45 & 26.55 & 101.71 \\
\hline 12_MTL_7_2_hostmin_rim & $\mathrm{Ol}$ & MTL & 0.02 & 0.00 & 36.49 & 37.99 & 0.03 & 0.00 & 0.30 & 0.00 & 0.50 & 26.35 & 101.67 \\
\hline 65_TIL_9_9_hostmin_MI & Plag & TIL & 1.32 & 34.47 & 0.03 & 44.91 & 0.04 & 0.00 & 17.87 & 0.03 & 0.00 & 0.86 & 99.53 \\
\hline 65_TIL_9_9_hostmin_core & Plag & TIL & 1.53 & 34.10 & 0.00 & 45.83 & 0.07 & 0.01 & 17.60 & 0.02 & 0.01 & 0.83 & 99.98 \\
\hline 65_TIL_9_9_hostmin_rim & Plag & TIL & 1.12 & 35.13 & 0.00 & 44.98 & 0.03 & 0.00 & 18.49 & 0.00 & 0.05 & 0.80 & 100.60 \\
\hline 55_TIL_2_8_hostmin_MI & $\mathrm{Ol}$ & TIL & 0.00 & 0.02 & 38.98 & 38.24 & 0.01 & 0.02 & 0.25 & 0.02 & 0.37 & 23.23 & 101.15 \\
\hline 55_TIL_2_8_hostmin_core & Ol & TIL & 0.00 & 0.06 & 38.95 & 37.70 & 0.00 & 0.01 & 0.26 & 0.03 & 0.41 & 23.04 & 100.46 \\
\hline 55 TIL_2_8 hostmin rim & $\mathrm{Ol}$ & TIL & 0.02 & 0.01 & 39.11 & 37.66 & 0.00 & 0.02 & 0.26 & 0.02 & 0.38 & 23.27 & 100.75 \\
\hline 58_TIL_4_4_hostmin_MI & $\mathrm{Ol}$ & TIL & 0.00 & 0.06 & 43.15 & 39.34 & 0.00 & 0.00 & 0.23 & 0.01 & 0.32 & 18.54 & 101.66 \\
\hline 58_TIL_4_4_hostmin_core & $\mathrm{Ol}$ & TIL & 0.02 & 0.04 & 45.26 & 39.50 & 0.00 & 0.01 & 0.19 & 0.04 & 0.27 & 15.98 & 101.32 \\
\hline 58_TIL_4_4_hostmin_rim & $\mathrm{Ol}$ & TIL & 0.01 & 0.01 & 39.56 & 38.27 & 0.00 & 0.00 & 0.24 & 0.03 & 0.38 & 22.45 & 100.96 \\
\hline 61_TIL_4_8_hostmin_MI & $\mathrm{Ol}$ & TIL & 0.01 & 0.02 & 38.70 & 38.05 & 0.00 & 0.01 & 0.25 & 0.02 & 0.45 & 23.50 & 101.00 \\
\hline 61_TIL_4_8_hostmin_core & $\mathrm{Ol}$ & TIL & 0.01 & 0.00 & 39.23 & 37.91 & 0.00 & 0.00 & 0.27 & 0.00 & 0.45 & 23.70 & 101.57 \\
\hline 61_TIL_4_8_hostmin_rim & $\mathrm{Ol}$ & TIL & 0.03 & 0.04 & 38.71 & 38.00 & 0.00 & 0.02 & 0.29 & 0.04 & 0.46 & 23.32 & 100.91 \\
\hline 71_TIL_7_4_hostmin_MI & $\mathrm{Ol}$ & TIL & 0.00 & 0.02 & 38.87 & 38.12 & 0.02 & 0.07 & 0.23 & 0.02 & 0.42 & 23.01 & 100.79 \\
\hline 71_TIL_7_4_hostmin_core & $\mathrm{Ol}$ & TIL & 0.02 & 0.03 & 38.78 & 37.98 & 0.01 & 0.00 & 0.24 & 0.02 & 0.42 & 23.18 & 100.68 \\
\hline 71_TIL_7_4_hostmin_rim & $\mathrm{Ol}$ & TIL & 0.04 & 0.02 & 38.95 & 38.57 & 0.02 & 0.03 & 0.23 & 0.08 & 0.37 & 23.34 & 101.66 \\
\hline
\end{tabular}

Continued 
Table S4. Continued. Major- and minor-element composition of Masaya host minerals obtained by EPMA. Includes raw data for points located on the host mineral adjacent to the melt inclusion (MI), near the mineral core, and near the mineral rim. Data given in wt.\%. All Fe is reported as FeO.

\begin{tabular}{|c|c|c|c|c|c|c|c|c|c|c|c|c|c|}
\hline Sample & Min Type & Eruption & $\mathrm{Na}_{2} \mathrm{O}$ & $\mathrm{Al}_{2} \mathrm{O}_{3}$ & $\mathrm{MgO}$ & $\mathrm{SiO}_{2}$ & $\mathrm{~K}_{2} \mathrm{O}$ & $\mathrm{P}_{2} \mathrm{O}_{5}$ & $\mathrm{CaO}$ & $\mathrm{TiO}_{2}$ & $\mathrm{MnO}$ & $\mathrm{FeO}$ & Total \\
\hline 54_TIL_4_5_hostmin_MI & $\mathrm{O} 1$ & TIL & 0.02 & 0.04 & 39.15 & 38.51 & 0.01 & 0.00 & 0.24 & 0.00 & 0.36 & 23.02 & 101.35 \\
\hline 54_TIL_4_5_hostmin_core & $\mathrm{O} 1$ & TIL & 0.03 & 0.02 & 39.32 & 38.41 & 0.00 & 0.03 & 0.22 & 0.00 & 0.41 & 23.05 & 101.49 \\
\hline 54_TIL_4_5_hostmin_rim & $\mathrm{Ol}$ & TIL & 0.01 & 0.02 & 38.61 & 38.06 & 0.03 & 0.01 & 0.26 & 0.00 & 0.43 & 23.67 & 101.09 \\
\hline 73_TIL_2_10_hostmin_MI & $\mathrm{Ol}$ & TIL & 0.02 & 0.05 & 44.94 & 39.36 & 0.00 & 0.00 & 0.26 & 0.00 & 0.27 & 16.50 & 101.41 \\
\hline 73_TIL_2_10_hostmin_core & $\mathrm{O} 1$ & TIL & 0.02 & 0.02 & 45.16 & 39.48 & 0.00 & 0.01 & 0.26 & 0.00 & 0.26 & 16.26 & 101.47 \\
\hline 73_TIL_2_10_hostmin_rim & $\mathrm{O} 1$ & TIL & 0.00 & 0.00 & 43.61 & 39.78 & 0.00 & 0.00 & 0.21 & 0.01 & 0.30 & 17.21 & 101.12 \\
\hline 64_TIL_4_6_hostmin_MI & $\mathrm{O} 1$ & TIL & 0.01 & 0.00 & 38.97 & 38.60 & 0.00 & 0.03 & 0.25 & 0.04 & 0.43 & 23.50 & 101.82 \\
\hline 64_TIL_4_6_hostmin_core & $\mathrm{Ol}$ & TIL & 0.00 & 0.00 & 38.83 & 38.52 & 0.01 & 0.00 & 0.18 & 0.00 & 0.44 & 23.27 & 101.24 \\
\hline 64_TIL_4_6_hostmin_rim & $\mathrm{O} 1$ & TIL & 0.01 & 0.04 & 39.06 & 38.04 & 0.00 & 0.00 & 0.19 & 0.02 & 0.43 & 23.56 & 101.34 \\
\hline 79_TIL_2_4_hostmin_MI & $\mathrm{Ol}$ & TIL & 0.00 & 0.03 & 36.96 & 37.93 & 0.00 & 0.04 & 0.27 & 0.04 & 0.53 & 25.74 & 101.54 \\
\hline 79_TIL_2_4_hostmin_core & $\mathrm{Ol}$ & TIL & 0.00 & 0.03 & 37.02 & 37.64 & 0.00 & 0.02 & 0.22 & 0.01 & 0.47 & 25.85 & 101.26 \\
\hline 79_TIL_2_4_hostmin_rim & $\mathrm{O} 1$ & TIL & 0.00 & 0.01 & 36.91 & 37.88 & 0.00 & 0.00 & 0.25 & 0.00 & 0.42 & 25.58 & 101.05 \\
\hline 80_TIL_7_5_hostmin_MI & $\mathrm{Ol}$ & TIL & 0.02 & 0.02 & 36.15 & 37.19 & 0.01 & 0.05 & 0.29 & 0.06 & 0.47 & 26.72 & 100.97 \\
\hline 80_TIL_7_5_hostmin_core & $\mathrm{Ol}$ & TIL & 0.00 & 0.00 & 35.99 & 37.22 & 0.00 & 0.05 & 0.21 & 0.04 & 0.50 & 26.90 & 100.90 \\
\hline 80_TIL_7_5_hostmin_rim & $\mathrm{Ol}$ & TIL & 0.00 & 0.01 & 36.20 & 37.43 & 0.01 & 0.00 & 0.25 & 0.02 & 0.42 & 26.36 & 100.70 \\
\hline 70_TIL_1_8_hostmin_MI & Cpx & TIL & 0.36 & 3.55 & 14.99 & 50.67 & 0.01 & 0.03 & 20.27 & 0.53 & 0.25 & 9.63 & 100.29 \\
\hline 70_TIL_1_8_hostmin_core & Cpx & TIL & 0.32 & 3.43 & 14.58 & 50.46 & 0.00 & 0.02 & 20.42 & 0.56 & 0.25 & 9.89 & 99.91 \\
\hline 70_TIL_1_8_hostmin_rim & Cpx & TIL & 0.33 & 3.58 & 14.98 & 50.53 & 0.00 & 0.02 & 20.94 & 0.62 & 0.23 & 9.61 & 100.85 \\
\hline
\end{tabular}


Table S5. Data on in-run standards for SIMS analysis used in this study.

\begin{tabular}{c|ccc}
\hline Standard & \multicolumn{3}{|c}{$519-4-1$} \\
- & accepted & \multicolumn{2}{c}{ measured } \\
& & 16 & $1 \sigma$ \\
\hline $\mathrm{CO}_{2}$ ppm & 160.00 & 162.03 & 3.64 \\
$\mathrm{H}_{2} \mathrm{O}$ wt.\% & 0.17 & 0.15 & 0.01 \\
$\mathrm{~F} \mathrm{ppm}$ & 94.00 & 104.91 & 2.40 \\
$\mathrm{~S} \mathrm{ppm}$ & 889.00 & 861.78 & 14.21 \\
$\mathrm{Cl} \mathrm{ppm}$ & 46.00 & 42.61 & 1.29 \\
\hline
\end{tabular}

Accepted values for 519-4-1 are from Colman et al. (2015) 
Table S6. Data on in-run standards for EPMA analysis used in this study. All Fe is reported as FeO.

\begin{tabular}{|c|c|c|c|c|c|c|c|c|c|}
\hline \multirow{3}{*}{$\begin{array}{c}\text { Standard } \\
-\end{array}$} & \multicolumn{3}{|c|}{ AGV-1 } & \multicolumn{3}{|c|}{ VG-2 } & \multicolumn{3}{|c|}{ P1326-2 } \\
\hline & \multirow[t]{2}{*}{ accepted } & \multicolumn{2}{|c|}{ measured } & \multirow[t]{2}{*}{ accepted } & \multicolumn{2}{|c|}{$\underline{\text { measured }}$} & \multirow[t]{2}{*}{ accepted } & \multicolumn{2}{|c|}{$\underline{\text { measured }}$} \\
\hline & & $\mathrm{n}=27$ & $1 \sigma$ & & $\mathrm{n}=38$ & $1 \sigma$ & & $\mathrm{n}=42$ & $1 \sigma$ \\
\hline $\mathrm{Na}_{2} \mathrm{O}$ & 4.25 & 4.07 & 0.50 & 2.63 & 2.68 & 0.26 & 2.76 & 2.81 & 0.09 \\
\hline $\mathrm{Al}_{2} \mathrm{O}_{3}$ & 17.11 & 17.49 & 0.12 & 14.00 & 13.97 & 0.26 & 14.48 & 14.75 & 0.08 \\
\hline $\mathrm{MgO}$ & 1.51 & 1.49 & 0.15 & 6.70 & 6.84 & 0.19 & 7.30 & 7.52 & 0.13 \\
\hline $\mathrm{SiO}_{2}$ & 59.38 & 59.68 & 0.44 & 50.60 & 49.90 & 0.28 & 50.00 & 49.29 & 0.23 \\
\hline $\mathrm{K}_{2} \mathrm{O}$ & 2.94 & 2.94 & 0.05 & 0.22 & 0.21 & 0.02 & 0.17 & 0.17 & 0.01 \\
\hline $\mathrm{P}_{2} \mathrm{O}_{5}$ & 0.49 & 0.51 & 0.03 & 0.22 & 0.21 & 0.03 & 0.12 & 0.13 & 0.03 \\
\hline $\mathrm{CaO}$ & 4.89 & 4.89 & 0.07 & 11.10 & 10.87 & 0.14 & 12.18 & 12.10 & 0.12 \\
\hline $\mathrm{TiO}_{2}$ & 1.05 & 1.09 & 0.04 & 1.79 & 1.88 & 0.04 & 1.53 & 1.54 & 0.06 \\
\hline $\mathrm{MnO}$ & 0.10 & 0.11 & 0.03 & 0.20 & 0.21 & 0.05 & 0.16 & 0.19 & 0.03 \\
\hline $\mathrm{FeO}^{*}$ & 6.08 & 6.23 & 0.10 & 11.80 & 11.70 & 0.10 & 10.82 & 10.84 & 0.13 \\
\hline Total & 97.79 & 98.64 & 0.40 & 99.83 & 98.49 & 0.37 & 99.52 & 99.33 & 0.40 \\
\hline
\end{tabular}

Accepted values for AGV-1 are USGS values from Jochum et al. (2016)

Accepted values for VG-2 are from Coumans et al. (2015)

Accepted values for P1326-2 are from Stix et al. (1995)

Continued 
Table S6. Continued. Data on in-run standards for EPMA analysis used in this study. All Fe is reported as FeO.

\begin{tabular}{|c|c|c|c|c|c|c|c|c|c|c|c|c|}
\hline \multirow{3}{*}{$\begin{array}{c}\text { Standard } \\
-\end{array}$} & \multicolumn{3}{|c|}{ San Carlos Olivine } & \multicolumn{3}{|c|}{ Lake County Plagioclase } & \multicolumn{3}{|c|}{ Biotite- 3} & \multicolumn{3}{|c|}{ Hornblende-Kakanui } \\
\hline & \multirow{2}{*}{ accepted } & \multicolumn{2}{|c|}{$\underline{\text { measured }}$} & \multirow{2}{*}{$\underline{\text { accepted }}$} & \multicolumn{2}{|c|}{$\underline{\text { measured }}$} & \multirow{2}{*}{$\underline{\text { accepted }}$} & \multicolumn{2}{|c|}{ measured } & \multirow[t]{2}{*}{$\underline{\text { accepted }}$} & \multicolumn{2}{|c|}{ measured } \\
\hline & & $\mathrm{n}=20$ & $1 \sigma$ & & $\mathrm{n}=22$ & $1 \sigma$ & & $\mathrm{n}=18$ & $1 \sigma$ & & $\mathrm{n}=18$ & $1 \sigma$ \\
\hline $\mathrm{Na}_{2} \mathrm{O}$ & & 0.02 & 0.02 & 3.45 & 3.67 & 0.11 & 0.69 & 0.62 & 0.05 & 2.60 & 2.59 & 0.09 \\
\hline $\mathrm{Al}_{2} \mathrm{O}_{3}$ & & 0.02 & 0.01 & 30.91 & 31.14 & 0.15 & 10.72 & 11.17 & 0.20 & 14.90 & 14.33 & 0.17 \\
\hline $\mathrm{MgO}$ & 49.42 & 49.50 & 0.19 & 0.14 & 0.15 & 0.16 & 14.01 & 13.63 & 0.19 & 12.80 & 12.41 & 0.26 \\
\hline $\mathrm{SiO}_{2}$ & 40.81 & 40.75 & 0.25 & 51.25 & 51.21 & 0.32 & 38.62 & 37.95 & 0.65 & 40.37 & 40.02 & 0.44 \\
\hline $\mathrm{K}_{2} \mathrm{O}$ & & 0.00 & 0.02 & 0.18 & 0.12 & 0.02 & 9.21 & 8.82 & 0.15 & 2.05 & 2.01 & 0.04 \\
\hline $\mathrm{P}_{2} \mathrm{O}_{5}$ & & 0.01 & 0.01 & & 0.02 & 0.02 & & 0.02 & 0.01 & & 0.03 & 0.02 \\
\hline $\mathrm{CaO}$ & 0.03 & 0.10 & 0.02 & 13.64 & 13.55 & 0.12 & 0.02 & 0.01 & 0.01 & 10.30 & 10.01 & 0.09 \\
\hline $\mathrm{TiO}_{2}$ & & 0.01 & 0.02 & 0.05 & 0.04 & 0.03 & 2.26 & 2.23 & 0.05 & 4.72 & 4.82 & 0.10 \\
\hline $\mathrm{MnO}$ & 0.14 & 0.14 & 0.03 & 0.01 & 0.01 & 0.02 & 0.95 & 0.95 & 0.05 & 0.09 & 0.08 & 0.04 \\
\hline $\mathrm{FeO}^{*}$ & 9.55 & 9.85 & 0.14 & 0.46 & 0.43 & 0.04 & 18.13 & 18.03 & 0.22 & 10.92 & 10.76 & 0.24 \\
\hline Total & 99.95 & 100.41 & 0.26 & 100.09 & 100.34 & 0.44 & 94.61 & 93.43 & 1.16 & 98.75 & 97.05 & 0.84 \\
\hline
\end{tabular}

Accepted values for San Carlos Olivine from Smithsonian Jarosewich

Accepted values for Lake County Plagioclase are from Jarosewich et al. (1980)

Accepted values for Biotite-3 are determined by electron microprobe from AMNH

Accepted values for Hornblende-Kakanui are from Jarosewich Geostandards Newsletter, 4, 43-47 